\title{
Functional Analysis of MAP Kinase Pathways in Plant Defense Responses in Solanum lycopersicum
}

A thesis Submitted to the Faculty of Graduate Studies and Research of Carleton University in partial fulfillment of the requirement for the degree of Master of Science in Biology.

\footnotetext{
Carleton University

Canada

(C) 2014, Nesreen Abdukhi
} 


\section{ACKNOWLEDGEMENTS}

First, I gratefully acknowledge my supervisor, Dr. Tim Xing, for giving me the opportunity to receive training in Carleton University and agreeing to bring me on as a member of his lab team. Thank you Dr. Xing, I truly appreciate your patience, enthusiasm, and encouragement.

I would like to sincerely thank my committee members, Dr. Owen Rowland and Dr. Thérèse Ouellet, for their insightful discussions and the helpful comments and suggestions. Their advice was extremely helpful in establishing, designing, and developing an integral project and keeping it on track.

I would like to thank Dr. Myron Smith and his graduate students for providing support and research facilities as well as the Saudi Arabian Cultural Bureau (SACB) for providing the financial support for this project. Also, I would like to express my heartfelt thanks to my friends Fatme Lezzeik and Yasamin Al-Rewashdy for training me in the lab and correcting my committee reports. I learned a great deal from them, and I certainly enjoyed working with them.

Before I finish, I owe my husband for sacrificing his job and his study to take care of my two little daughters while I am studying. Finally, I am truly grateful to my mom and my seven sisters for always believing in me, encouraging me, and reminding me that "Life is a daring adventure or nothing at all". 


\begin{abstract}
Mitogen-activated protein kinase (MAPK) modules are implicated in plant responses to biotic and abiotic stresses. Solanum lycopersicon MAP kinase LeMPK3 plays a vital role in tomato defense responses. TAB2 (a nucleoside diphosphate protein kinase, NDPK) was shown to interact with LeMPK3. In this project, the function of the genes in defense pathways that involve salicylic acid (SA) and Fumonisin B1 (FB1) have been studied. While LeMPK3 was up-regulated, TAB2 was not, suggesting that TAB2 is probably not involved in LeMPK3 pathway. LeMPK3 is an ERK-type MAP kinase. The increased expression of LeMPK3 and SA or FB1 responsive genes was not significantly altered by an ERK inhibitor, suggesting that LeMPK3 may not be involved in SAtriggered PR1 and FB1-triggered PDF1.2 expression. The effect of FB1, SA and the ERK inhibitor treatment on the cell death of tomato leaves was also studied. ERK inhibitor reversed the cell death induced by SA and FB1, suggesting that ERK-type MAPKs could be involved in SA- and FB1-induced cell death process. The phosphorylation TXY site of LeMPK3 was mutated. The full length of the LeMPK3 $3^{M U T}$ was generated and the mutation will be confirmed by sequencing. The findings may help in developing strategies for disease resistance.
\end{abstract}




\section{TABLE OF CONTENTS}

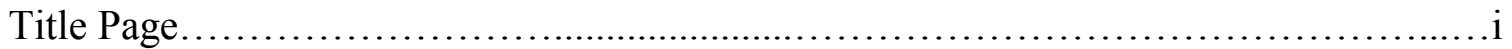

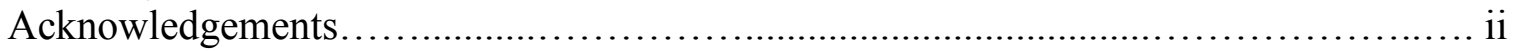

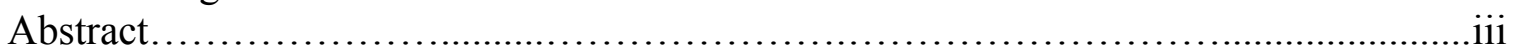

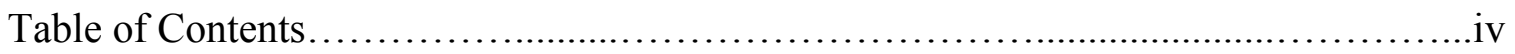

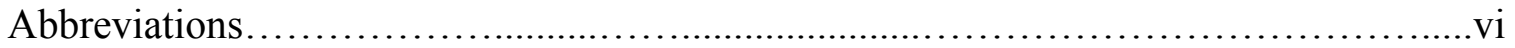

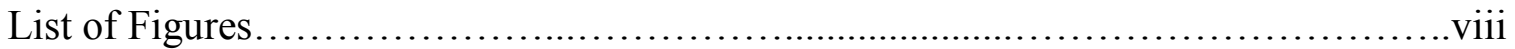

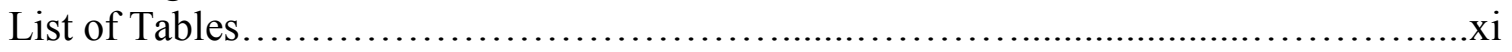

Chapter I

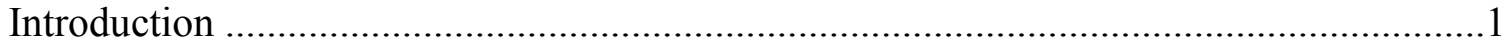

1.1. Protein phosphorylation and plant defense.................................................... 1

1.2. MAP Kinase cascade and defense response in plants....................................

1.3. Solanum lycopersicum and the study of plant defense mechanisms......................4

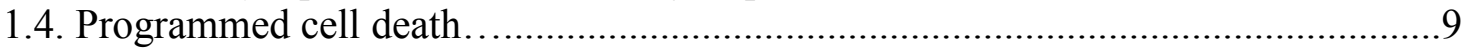

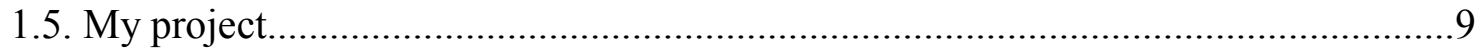

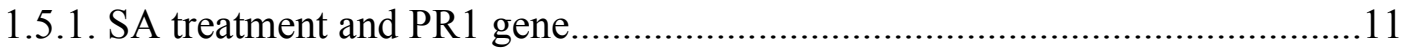

1.5.2. FB1 treatment and PDF1.2 gene............................................................ 12

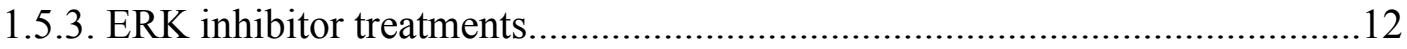

Chapter II

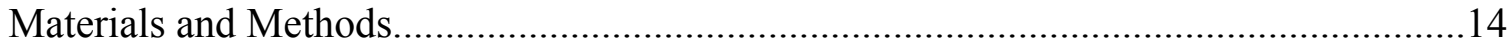

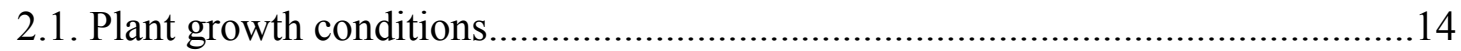

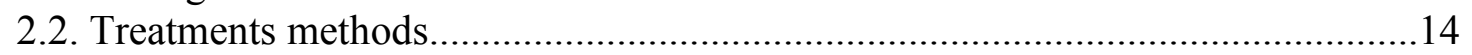

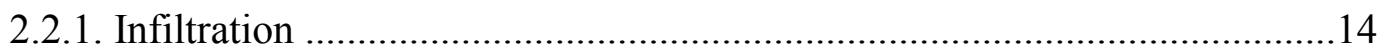

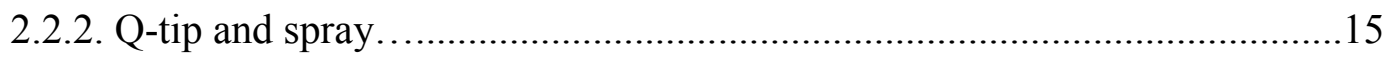

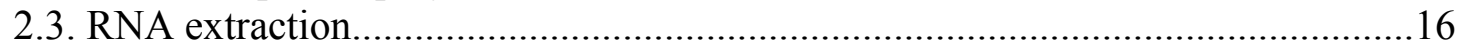

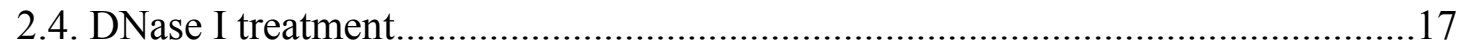

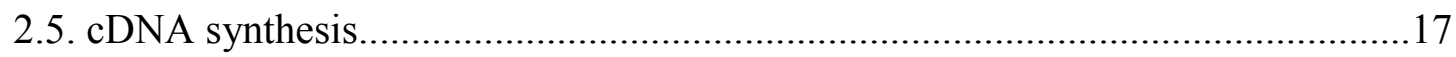

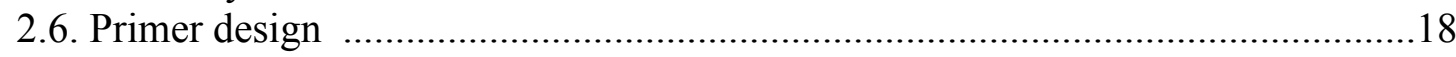

2.7. RT-PCR (reverse transcriptase polymerase chain reaction) ...............................19

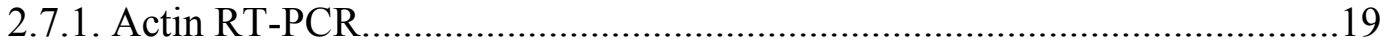

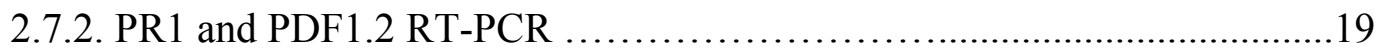

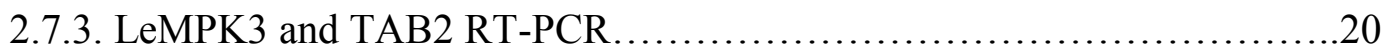

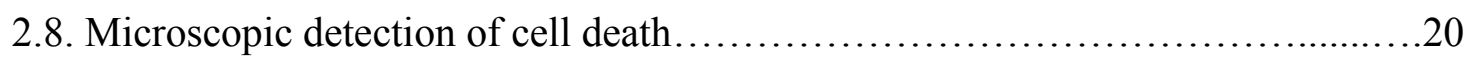

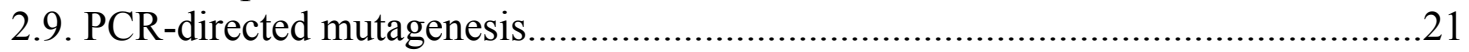

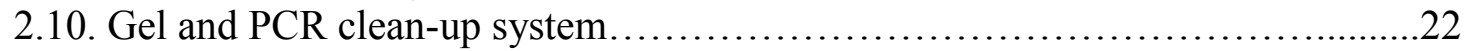

Chapter III

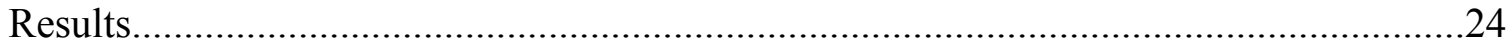

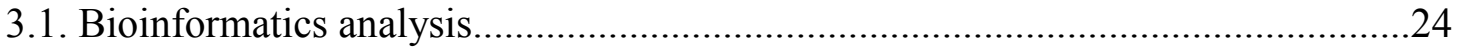

3.1.1. Phylogenetic trees of Solanum lycopersicum LeMPK3 and Arabidopsis

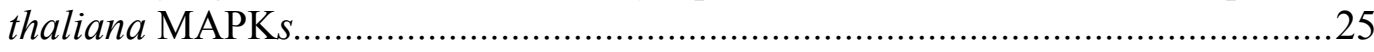

3.1.2. Nucleotide sequence alignment and amino acid sequences alignment of Solanum lycopersicum leMPK3 with Arabidopsis thaliana 


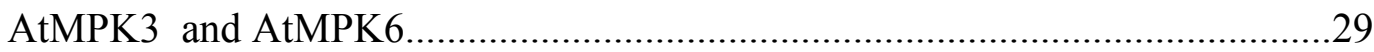

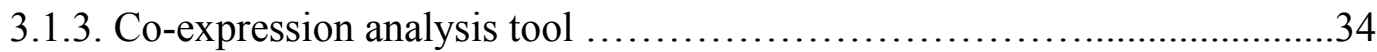

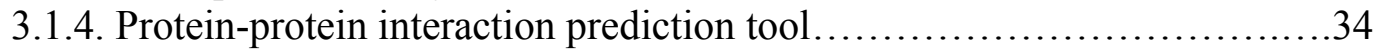

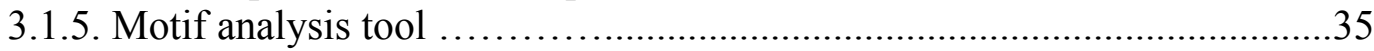

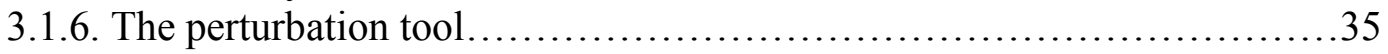

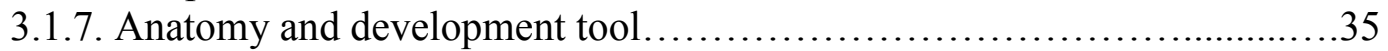

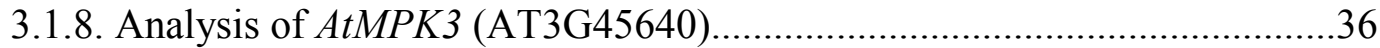

3.1.9. Analysis of AtMPK6 (NM 129941).....................................44

3.1.10. Analysis of AtNDPK (At5g63310) ..................................52

3.1.11. Motif analysis of Solanum lycopersicumLeMPK3 ......................60

3.2. Finding the appropriate annealing temperature for LeMPK3, TAB2, PR1

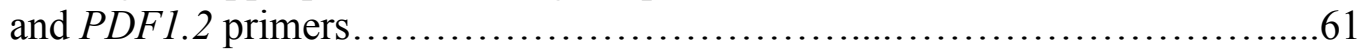

3.3.Effect of SA and FB1 on LeMPK3 and TAB2 transcription.........................62

3.4.Effect of ERK inhibitor with SA and ERK inhibitor with FB1 on LeMPK3

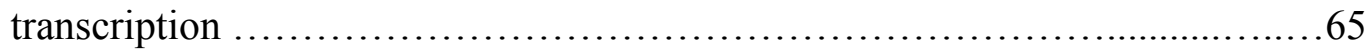

3.5. Microscopic analysis of the effect of SA, FB1, and ERK inhibitor on

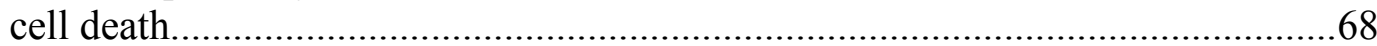

3.6. PCR-directed mutagenesis of LeMPK3 ...........................................73

Chapter IV

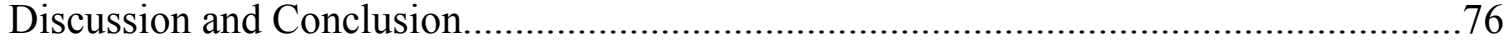

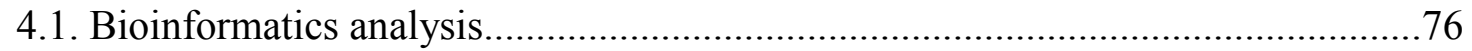

4.2. Analysis of Arabidopsis AtMPK3, AtMPK6, and AtNDPK.....................77

4.3. LeMPK3 protein and TEY motif............................................. 80

4.4. Effect of SA and FB1 on LeMPK3 and TAB2 expression......................8 80

4.5. Effect of ERK inhibitor with SA or ERK inhibitor with FB1 on LeMPK3

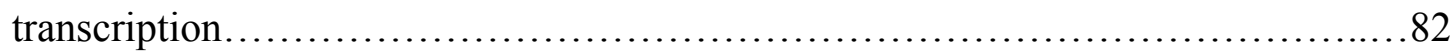

4.6. Microscopic analysis of the effect of SA, FB1, and ERK inhibitor on cell

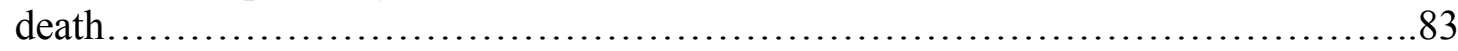

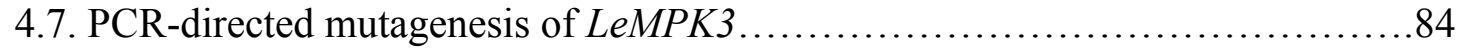

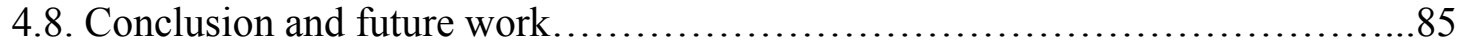

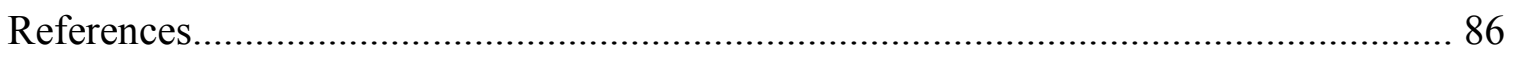

Appendix I. ScanSite Database Analysis of Arabidopsis AtMPK3 Protein ......................92

Appendix II. ScanSite Database Analysis of Arabidopsis AtMPK6 Protein .....................93

Appendix III. ScanSite Database Analysis of Arabidopsis AtNDPK Protein ...................94

Appendix IV. Analysis of Solanum lycopersicum PR1....................................................95

Appendix V. Analysis of Solanum lycopersicum PDF1.2..............................................103 


\author{
ABBREVIATIONS \\ AtMPK3: Arabidopsis thaliana MPK3 \\ AtMPK6: Arabidopsis thaliana MPK6 \\ AtNDPK: Arabidopsis thaliana nucleoside diphosphate protein kinase \\ AtMKP2: Arabidopsis thaliana MAPK phosphatase \\ BLAST: Basic local alignment search tool \\ cDNA: Complementary DNA \\ DEPC: Diethylpyrocarbonate \\ ERK: Extracellular signal-regulated kinases \\ E2/UBC: Ubiquitin conjugating enzyme \\ FB1: Fumonisin B1 \\ HR: Hypersensitive response
}

JA: Jasmonic acid

JNKs: c-Jun N-terminal kinase/stress-activated protein kinases

LeMPK3: Lycopersicon esculentum mitogen-activated protein kinase 3

MAPK: Mitogen-activated protein kinase.

MAPKK: MAPK kinase

MAPKKK: MAPKK kinase

MAPKKKK: MAPKKK kinase

NCBI: National Center for Biotechnology Information

NDPK: Nucleoside diphosphate protein kinase

NO: Nitric oxide 
NR: Nitrate reductase

PCD: Programmed cell death

PCR: polymerase chain reaction

PDF1.2: Defensin, gamma-thionin

PR1: Pathogenesis-related protein 1

ROS: Reactive oxygen species

RT-PCR: Reverse transcription polymerase chain reaction

SA: Salicylic acid

SAR: Systemic acquired resistance

TF: Transcription factor 


\section{LIST OF FIGURES}

\section{Chapter I}

Figure 1.1: Protein phosphorylation is a pivotal process during plant-pathogen interactions.

Figure 1.2: Dynamic regulatory mechanisms contribute to the final effectiveness of MAPK pathways in plant defense.

\section{Chapter III}

Figure 3.1: The similarity of the nucleotide sequences between Solanum lycopersicum LeMPK3 (AY261514) and Arabidopsis thaliana AtMPK3 (NM_114433.2/AT3G45640) gene.

Figure 3.2: The phylogenetic tree of Solanum lycopersicum LeMPK3 with Arabidopsis thaliana MAPKs based on nucleotide sequences.

Figure 3.3: The phylogenetic tree of Solanum lycopersicum LeMPK3 with Arabidopsis thaliana MAPKs based on amino acid sequences.

Figure 3.4: Nucleotide sequence alignment of Solanum lycopersicum leMPK3 and Arabidopsis thaliana AtMPK3.

Figure 3.5: Nucleotide sequence alignment of Solanum lycopersicum leMPK3 and Arabidopsis thaliana AtMPK6.

Figure 3.6: Amino acid sequence alignment of Solanum lycopersicum leMPK3 and Arabidopsis thaliana AtMPK3.

Figure 3.7: Amino acid sequence alignment of Solanum lycopersicum leMPK3 and Arabidopsis thaliana AtMPK6.

Figure 3.8: A. The co-expression analysis of $A t M P K 3$ gene; B. Description of the most correlated genes to AtMPK3 (top 25).

Figure 3.9: Proteins that are predicted to co-occur with AtMPK3.

Figure 3.10: High stringency ScanSite Motif Scan output for AtMPK3 protein sequence indicating multiple protein phosphorylation sites.

Figure 3.11: Effect of FB1/MetOH on AtMPK3 expression in Arabidopsis thaliana root culture.

Figure 3.12: Effect of SA on AtMPK3 expression in Arabidopsis thaliana leaves.

Figure 3.13: Expression levels of AtMPK3 in rosette leaves of Arabidopsis thaliana at different stages of their development. 
Figure 3.14: Overall expression of AtMPK3 across different stages of development.

Figure 3.15: A. The co-expression analysis of AtMPK6 gene; B. Description of the most correlated genes to AtMPK6 (top 25).

Figure 3.16: Proteins that are predicted to co-occur with AtMPK6.

Figure 3.17: High stringency ScanSite Motif Scan output for AtMPK6 protein sequence indicating potential protein phosphorylation sites and a SH3 binding site.

Figure 3.18: Effect of FB1/MetOH on AtMPK6 expression in Arabidopsis thaliana protoplast.

Figure 3.19: Effect of SA on AtMPK6 expression in Arabidopsis thaliana leaves.

Figure 3.20: Expression levels of AtMPK6 in rosette leaves of Arabidopsis thaliana at different stages of their development.

Figure 3.21: Overall expression of AtMPK6 across different stages of development.

Figure 3.22: A. The co-expression analysis of AtNDPK gene; B. Description of the most correlated genes to AtNDPK (top 25).

Figure 3.23: Proteins that are predicted to co-occur with AtNDPK.

Figure 3.24: High stringency ScanSite Motif Scan output for AtNDPK protein sequence.

Figure 3.25: Effect of FB1/MetOH on AtNDPK expression in Arabidopsis thaliana protoplast samples.

Figure 3.26: Effect of SA on AtNDPK expression in Arabidopsis thaliana leaves.

Figure 3.27: Expression levels of AtNDPK in rosette leaves of Arabidopsis thaliana at different stages of their development.

Figure 3.28: Overall expression level of AtMPK3 across different stages of development.

Figure 3.29: Amino acid sequence alignment of Solanum lycopersicum leMPK3, Arabidopsis thaliana AtMPK1, and human ERK Kinase MPK1 (GenBank accession numbers NP_001234360, AEE28553.1 and NP_002736.3, respectively).

Figure 3.30: Results of gradient PCR with temperatures ranging from $55.0^{\circ} \mathrm{C}$ to $75.0^{\circ} \mathrm{C}$ for LeMPK3, TAB2, PR1 and PDF1.2 amplification.

Figure 3.31: RT-PCR determination of Solanum lycopersicum LeMPK3 and TAB2 expression.

Figure 3.32: RT-PCR determination of Solanum lycopersicum LeMPK3 expression. 
Figure 3.33: The effect of SA, FB1 and ERK inhibitor on cell death examined microscopically using infiltration method.

Figure 3.34: The effect of SA, FB1 and ERK inhibitor on cell death examined microscopically using spray and Q-tip methods.

Figure 3.35: The first round of PCR using LeMPK3 end Rev plus LeMPK3 mid mut For and LeMPK3 head For plus LeMPK3 mid mut Rev.

Figure 3.36: The recovery of $L e M P K 3$ PCR products after gen clean by Wizard ${ }^{\circledR} S V$ Gel and PCR Clean-Up System.

Figure 3.37: Second round of PCR using the two PCR products from the first round of PCR as primers. 


\section{Chapter I}

\section{LIST OF TABLES}

Table 1.1: Tomato MAPKs.

Table 1.2: A list of tomato MAPKs, MAPKKs or MAPKKKs in various biological processes.

\section{Chapter II}

Table 2.1: The different treatments used and their corresponding concentrations.

Table 2.2: List of primers used for RT-PCR.

Table 2.3: Primers used for LeMPK3 mutagenesis.

\section{Chapter III}

Table 3.1: Summary of prediction and function of proteins that co-occur with AtMPK3.

Table 3.2: Summary of prediction and function of proteins that co-occur with AtMPK6.

Table 3.3: Summary of prediction and function of proteins that co-occur with AtNDPK. 


\section{CHAPTER I}

\section{INTRODUCTION}

\subsection{Protein phosphorylation and plant defense}

Plant diseases are regarded as a huge problem in agricultural practice. Pathogens may attack the leaves, stems, flowers, fruits or roots, via wounded tissue, stomata, lenticels or the surface layer. The first defense line is the external structure, such as the thick cell walls and epidermal wax layer. The defense can also involve various biochemical and molecular mechanisms, such as the production of phytoalexins and the regulation of protein phosphorylation (Xing et al., 2007).

The regulatory mechanisms of any plant-pathogen interaction are complex and dynamic. One of the basic methods of post-translational modifications that occur in eukaryotes and prokaryotes is protein phosphorylation, and it controls subcellular location of proteins, their biological activity, stability, half-life time, and their interaction with DNA and other proteins. Together, all of these will contribute to the final effectiveness of a defense signal transduction pathway (Xing et al., 2002; Xing and Laroche, 2011). Phosphorylation on serine, threonine, tyrosine and histidine residues may affect protein-protein interactions, particularly protein complex and protein docking formation (Cvetkovska et al., 2005). 


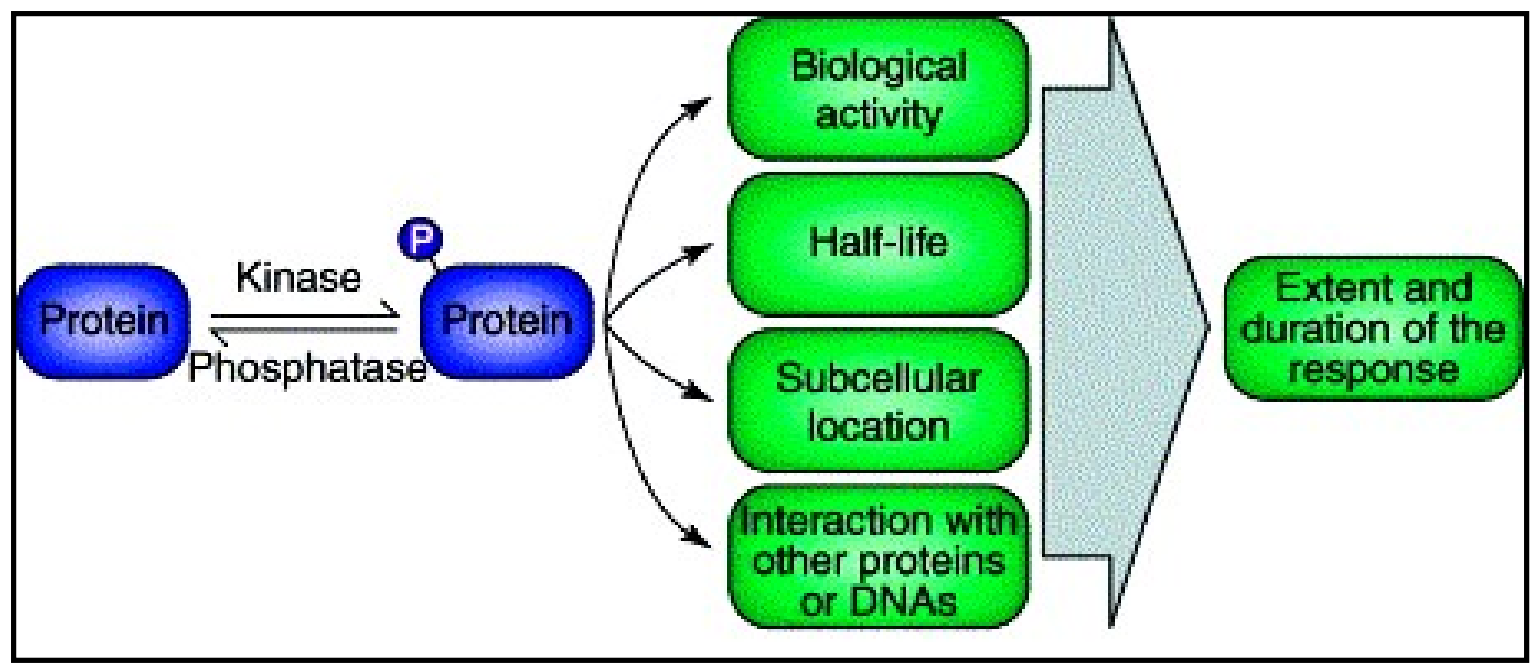

Figure 1.1: Protein phosphorylation is a pivotal process during plant-pathogen interactions. Phosphorylation of a protein changes its behaviour, including its intrinsic biological activity, subcellular location, half-life time, and interaction with other proteins. The final efficiency of a defense mechanism that engages phosphorylation will be determined by the collective effect of the complex phosphorylation machinery (Xing et al., 2002).

\subsection{MAP kinase cascade and defense response in plants}

Normally, all eukaryotes have four classes of functionally related kinases that appear as gene families, and these proteins are organized in hierarchical shape to work as signal transmission cascades. The generally accepted pathway has the following components:

Stimulus

MAPK
Receptor

MAPKKKK

MAPKKK
MAPKK 
MAPK cascades could be regulated by diverse stimuli such as pathogen attacks, wounding, high or cold temperatures, high salinity, UV, ozone, reactive oxygen species (ROS), drought, and high osmolarity (Cvetkovska et al., 2005). When an upstream MAPKKKK or MAPKKK is activated by external stimuli, it activates downstream MAPKKs through phosphorylation on serine and threonine residues in a conserved $\mathrm{S} / \mathrm{T}-$ X3-5-S/T motif, and then the MAPKKs activate downstream MAPKs through phosphorylation on threonine and tyrosine residues in the TXY motif (Stulemeijer et al., 2007). The activated MAPK will phosphorylate a variety of substrates including transcription factors (TFs), other protein kinases, enzymes, and cytoskeleton-associated proteins. It is believed that MAPK cascades are critical to plant growth and development and to plant response to environmental stimuli (Nakagami et al., 2005; Qi and Elion, 2005; Stulemeijer et al., 2007; Xing and Jordan, 2000).

Defense response to pathogen infections may include regulation of redox chain, hypersensitive response (HR) cell death, production of reactive oxygen species, systemic acquired resistance (SAR), activation of pathogenesis-related $(P R)$ genes and protective genes (Cvetkovska et al., 2005). 


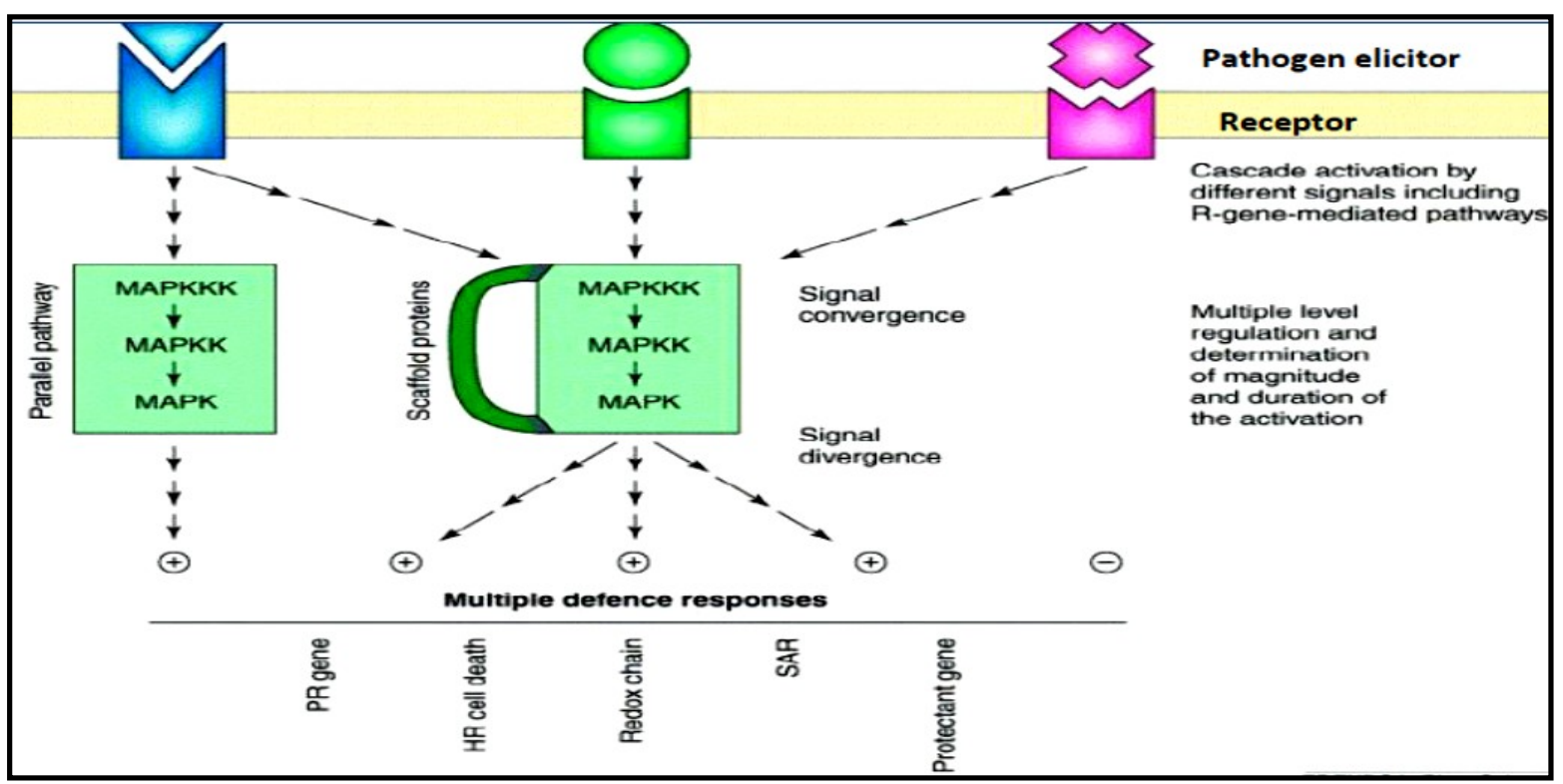

Figure 1.2: Dynamic regulatory mechanisms contribute to the final effectiveness of MAPK pathways in plant defense. An extracellular signal is perceived by a receptor system followed by the activation of MAPK cascades. The active mitogen-activated protein kinase may activate other protein kinases, phosphorylate cytoskeletal components, or translocate to the nucleus and activate transcription factors, thus altering the expression of specific genes (Xing et al., 2002).

\subsection{Solanum lycopersicum and the study of plant defense mechanisms}

Tomato (Lycopersicon esculentum) is a popular model system for both biochemical and molecular genetics studies (Rick and Yoder, 1988; The Tomato Genome Consortium, 2012). In addition to the study of fruit development, tomato has been well studied for disease resistance mechanisms. One of the better studied systems follows 'gene-for-gene' interaction, where a tomato $C f$ resistance gene product interacts with an Avr gene product from fungal pathogen Cladosporium fulvum (Xing, 2007). The interaction triggers complex defense reactions in tomato plants (Xing and Jordan, 2000). 
Another well studied resistance gene in tomato is Pto, which confers 'gene-forgene' type of resistance to the bacterial pathogen Pseudomonas syringae pv. tomato carrying the pathogen effector avrPto gene (Xing, 2007). In addition, this gene induces tomato resistance to Xanthomonas campestris pv. vesicatoria and Cladosporium fulvum, when over expressed (Xing et al., 2001; Ekengren et al., 2003). Pto-mediated resistance triggers numerous signal transduction pathways to induce defense resistance, including rapid changes in the expression of over 400 genes, oxidative burst and localized cell death (Ekengren et al., 2003). Key genes involved in Pto-mediated resistance pathway include two MAPKKs (MEK1 and MEK2), two MAPKs (NTF6 and WIPK, i.e. woundinduced protein kinase), NPR1 (a key regulator of systemic acquired resistance), and two transcription factors (TGA1a and TGA2.2) (Ekengren et al., 2003).

MAPK pathways play a central role in plant defense against pathogen attacks in other model plants and crop species (e.g. Arabidopsis, tobacco, parsley, rice and wheat) (Xing et al., 2002; Xing and Laroche, 2011). More recent studies have shown that tomato MAPKs LeMPK1, LeMPK2, and LeMPK3 are specifically activated in Cf-4/Avr4induced defense signaling in response to stress caused by the wound signaling peptide systemin, oligosaccharide elicitors, UV-B radiation, and the fungal toxin fusicoccin (Stulemeijer et al., 2007). In some cases, LeMPK1 as well as LeMPK2 are triggered in a Pto-specific manner upon expression of AvrPto. Also, they are triggered by the expression of LeMAPKKK $\alpha$. LeMPK3 is triggered by UV-B, fungal and bacterial elicitors, mechanical stress and wounding (Stulemeijer et al., 2007; Hamel et al., 2006; Kandoth et al., 2007; Nakagami et al., 2005). LeMKK2 and LeMKK4 serve a critical 
role in the phosphorylation of LeMPK1 and LeMPK2 in vivo and they also phosphorylate LeMPK3 weakly (Kandoth et al., 2007).

tMEK2, currently named LeMKK2, has been studied by the Xing lab. Previous work with tMEK2 ${ }^{\mathrm{WT}}$ (wild-type) and tMEK2 ${ }^{\mathrm{MUT}}$ (constitutively activated) in a tomato protoplast system and in transgenic plants indicated that tMEK2 ${ }^{\mathrm{MUT}}$ overexpression enhanced the expression of TAB2 (a nucleoside diphosphate protein kinase, NDPK), ER5 (a wound-inducible gene), PR1b1, PR2, PR3, and Twi1 (a pathogenesis-related genes) (Xing et al., 2001, 2008). Recent phospho-proteomics analysis has revealed that when tMEK2 pathway was activated, a group of proteins were more phosphorylated including a superoxide dismutase, peptidyl-prolyl isomerase, nucleoside diphosphate kinase, acylCoA-binding protein, GrpE protein, phosphoglycerate mutase, calreticulin (CRT), ribonucleoprotein, glutathione peroxidase, plastocyanin, and ubiquitin conjugating enzyme (E2/UBC) (Thurston et al., 2005; Xing and Laroche, 2011). tMEK2 $2^{\mathrm{MUT}}$ overexpression enhanced tomato resistance again bacterial pathogen Pseudomonas syringae pv. tomato (Xing et al., 2001; Xing et al., 2008).

Despite the huge number of known tomato MAP kinases (Table 1.1) encoded in the plant genome, only a very small number have an assigned function (Kandoth et al., 2007; Melech-Bonfil and Sessa, 2010; Nakagami et al., 2005). In tomato leaves, MAPKKK $\alpha$ overexpression activates MAPKs and MAPKKs, causing pathogenindependent cell death; for this reason, MAPKKK $\alpha$ is regarded as a positive regulator of cell death in tomato (Solanum lycopersicum) (Oh and Martin, 2011). Tomato MAPKKKe is also a positive regulator of cell death (Melech-Bonfil and Sessa, 2010). 


\begin{tabular}{|c|c|c|c|}
\hline Name & Unigene Identifier & TXY & Residues \\
\hline LeMPK1 & SGN-U316697 & TEY & 397 \\
\hline LeMPK2 & SGN-U316695 & TEY & 395 \\
\hline LeMPK3 & SGN-U313928 & TEY & 374 \\
\hline LeMPK4 & SGN-U323634 & TEY & 373 \\
\hline LeMPK5 & SGN-U313996 & TEY & 281 \\
\hline LeMPK6 & SGN-U313995 & MEY & 377 \\
\hline LeMPK7 & SGN-U323219 & TEY & 380 \\
\hline LeMPK8 & SGN-U318773 & TEY & 371 \\
\hline LeMPK9 & SGN-U316113 & TEY & 373 \\
\hline LeMPK10 & SGN-U317229 & TDY & 576 \\
\hline LeMPK11 & SGN-U322516 and TC168576 & - & 395 \\
\hline LeMPK12 & SGN-U318438 & TDY & 622 \\
\hline LeMPK13 & SGN-U316366 and SGN-316367 & TDY & 596 \\
\hline LeMPK14 & SGN-U318361 & TDY & 496 \\
\hline LeMPK15 & SGN-U332259 & - & 207 \\
\hline LeMPK16 & SGN-U318101 & TDY & 576 \\
\hline
\end{tabular}

Table1.1: Tomato MAPKs (from Stulemeijer et al., 2007). 


\begin{tabular}{|l|l|}
\hline Gene & Biological functions \\
\hline LeMPK1 & Elicitor signaling, UV-B \\
\hline LeMPK2 & Elicitor signaling, UV-B \\
\hline LeMPK3 & $\begin{array}{l}\text { UV-B, fungal and bacterial elicitor signaling, mechanical stress, } \\
\text { wounding }\end{array}$ \\
\hline LeMKK2 & Bacterial elicitor signaling, cell death \\
\hline LeMKK4 & Bacterial elicitor signaling, cell death \\
\hline LeMAPKKK $\alpha$ & Bacterial elicitor signaling, cell death \\
& \\
\hline
\end{tabular}

Table 1.2: A list of tomato MAPKs, MAPKKs or MAPKKKs in various biological processes (summarized from Nakagami et al., 2005; Kandoth et al., 2007). 


\subsection{Programmed cell death}

Programmed cell death (PCD) has been observed in all multicellular organisms, and it means death of a cell in any form, mediated by an intracellular program. This strategy is essential for the organisms to free themselves of unwanted, damaged, or infected cells. This cellular process is also regulated by plants during tissue growth, development, reproduction, and in response to pathogen attacks (Greenberg, 1996; Plett et al., 2009; Xing et al., 2005).

\subsection{My project}

Pathogens infect plants and cause yield loss. The regulation mechanisms of any plant-pathogen interactions are complex and dynamic. One of the defense mechanisms is mediated by MAPK pathways. In our previous work, tMEK $2^{\mathrm{MUT}}$, a constitutively activated mutant of tomato MAPKK tMEK2 was created by replacing S-221 and T-226 between sub-domains VII and VIII with D (Xing et al., 2001, 2008). Its overexpression enhanced resistance to bacterial pathogen $P$. syringae in tomato (Xing et al., 2008), and enhanced resistance to leaf rust in wheat (Xing, 2007).

The recognition of the molecules and the docking interaction is achieved through the docking groove and scaffold proteins. The Kinase Interaction Motif $\left(\mathrm{KIM},[\mathrm{K} / \mathrm{R}]_{(3-4)^{-}}\right.$ $\left.\mathrm{X}_{(1-6)^{-}}[\mathrm{L} / \mathrm{I}]-\mathrm{X}-[\mathrm{L} / \mathrm{I}]\right)$ sequence mediates interaction with many MAPKs, predominantly ERK1 and ERK2 members (see Xing et al., 2008 for details). TAB2, a nucleoside diphosphate protein kinase (NDPK), is a tMEK2 downstream component and it contains a KIM motif (KKGFSLKGLKLI). We created TAB2 ${ }^{\mathrm{DM}}$, a mutated TAB2 at its KIM (replacing the positively charged K-21 and K-22 with negatively charged D) (Xing et al., 
2008). When $T A B 2^{D M}$ and $t M E K 2^{M U T}$ were co-transfected in tomato protoplasts, we found that this mutation at KIM significantly reduced $t M E K 2^{M U T}$-induced up-regulation of PR1b1, $\beta$-1,3-glucanase and endochitinase genes, suggesting that TAB2 interacts with a downstream MAPK (Xing et al., 2008). Further protein-protein interaction analysis has indicated that TAB2 is downstream of LeMPK3 in tMEK2 disease resistance pathway (Xing et al., 2008). Overexpression of TAB2 in tomato enhanced resistance to virulent Pseudomonas syringae pv. Tomato (Xing et al., 2008). So far, we have a linear pathway consisting of tMEK2, LeMPK3 and TAB2.

\section{My research hypothesis:}

In my work, I will mainly test two hypothesis. (1) There are correlations between the expression of these tMEK 2 pathway components and the expression of other genes, and the correlation may or may not be reflected at protein interaction level. (2) LeMPK3 mediates SA-induced defense response and FB1-induced cell death process.

\section{My main objectives:}

(1) analyze gene expression level of leMPK3 under biotic stresses by RT-PCR;

(2) study LeMPK3 downstream components (e.g. TAB2);

(3) analyze cellular responses when MAPK pathways are interrupted;

(4) study interactive proteins of this tMEK2 pathway. 


\subsubsection{SA treatment and PR1 gene}

Salicylic acid (SA) plays a critical role in plant life but was only confirmed as an endogenous plant signaling molecules within the last few decades. The best understood function of SA in plants is as a mediator of defense responses both locally and systemically. Many of these effects are mediated by NPR1, which has emerged as the key activating component of the plant response to biotrophic and hemibiotrophic pathogens (those that do not immediately kill the host cell as part of the infection process). SA has other effects on plant growth, development, and abiotic stress responses, but these are not as well defined at the molecular level (Chen et al., 2009). The study of SA is immensely important because SA is a cornerstone of plants' ability to defend against microbial pathogens; without it, they would be seriously compromised. Exogenous application of SA on healthy tomato seedlings increases plant resistance against purple top phytoplasma infection (Wu et al., 2012). Treatment of leaves with SA may lead to transcriptional reprogramming of tomato $L e M P K 3$ and cause $L e M P K 3$ up-regulation in early stages $(\mathrm{Wu}$ et al., 2012). Furthermore, the signaling pathways of both SA and LeMPK3 are involved in tomato resistance against bacterial wilt caused by the soil-borne bacterium Ralstonia solanacearum (Chen et al., 2009).

In general, the pathogenesis-related (PR) protein family has been used as markers of plant defense response. One of the most commonly used is PR1, which encodes a basic protein; its expression is triggered by the SA-dependent pathway (Mitsuhara et al., 2008). Activation of the SA pathway induces basal and $R$ gene-mediated biotrophic pathogen defense in Arabidopsis (Zarate et al., 2007). PR1 will be used as an SA responsive gene and serve as a positive control of SA effect in my project. 


\subsubsection{FB1 treatment and PDF1.2 gene}

Fungal toxin fumonisin B1 (FB1) is a cell death-eliciting toxin produced by the necrotrophic fungal plant pathogen Fusarium moniliforme (Stone et al., 2000). It triggers PCD in animals and in Arabidopsis (Asai et al., 2000). In eukaryotes, FB1 inhibits ceramide synthase and disrupts sphingolipid metabolism (Desai et al., 2002). Ceramide synthase is an essential enzyme involved in the biosynthesis of sphingolipids, which play various roles in cellular functions (Young et al., 2012).

Defense-related proteins are another important antimicrobial family. These proteins are known for their ability to inhibit a variety of infections including oomycetes, fungi, bacteria, viruses, or insect attacks by affecting their growth and morphological development (Van Loon et al., 2006). PDF1.2 is a tomato defensin (also called gammathionin), and it will be used as a positive control of FB1 effect in my project.

\subsubsection{ERK inhibitor treatments}

There are three different groups of MAPKs: extracellular signal-regulated kinase (ERK-type MAPKs), c-Jun N-terminal kinase/stress-activated protein kinases (JNKs), and p38 kinases (Cvetkovska et al., 2005). The ERK family can regulate cell growth and differentiation via distinct signal transduction pathways in mammalian cells (Chuang et al., 2000). 3-(2-Aminoethyl)-5-((4-ethoxyphenyl) methylene)-2,4-thiazolidinedione hydrochloride (ERKI), which is also an ERK-docking domain inhibitor, was administered $24 \mathrm{~h}$ after stress-induced activation of ERK1/2 signaling pathway in rats (Yang et al., 2012). This ERKI effectively blocked the ERK1/2-mediated phosphorylation of Elk-1 (Yang et al., 2012). LeMPK3 belongs to the ERK family. ERK docking domain inhibitor 
will be applied in this study to determine whether SA- and FB1-induced response is mediated by an ERK-type MAP kinase.

This project was carried out on the LeMPK3 tomato gene $S G N-U 313928$ for its role in plant defense. It is hoped that this work will provide new insight into diverse aspects of MAPK pathways to aid in our comprehensive and molecular understanding of the complex defense system. 


\section{CHAPTER II \\ MATERIALS AND METHODS}

\subsection{Plant growth conditions}

Tomato (Lycopersicon esculentum cv. Bonny Best) seeds were obtained from Ritchie Feed \& Seed Inc. (Ottawa, Ontario). The seeds were sterilized in $70 \%$ ethanol for 2 minutes and then in a solution of $100 \%$ bleach with $10 \mu \mathrm{L}$ Triton-X 100 for 8 minutes. Then seeds were rinsed 10 times with autoclaved double distilled water. The seeds were planted in pots filled with the autoclaved Pro-mix BX soil (Ritchie Feed \& Seed Inc., Ottawa, Ontario) and placed in the long day growth chamber $\left(16\right.$ hours light at $22^{\circ} \mathrm{C}$ and 8 hours darkness at $18^{\circ} \mathrm{C}$, ENCONAIR Technologies Inc, Winnipeg, Manitoba) for four weeks with watering as needed.

\subsection{Treatment methods}

\subsubsection{Infiltration}

At the end of the fourth week, the tomato seedlings were removed from the soil, and three to four leaves were collected and vacuum infiltrated with the corresponding chemicals at indicated concentrations for 30 minutes. After 30 minutes of infiltration, the leaves were collected, placed into sterile RNase-free Falcon tubes, snap-frozen in liquid nitrogen and stored at $-80^{\circ} \mathrm{C}$. The rest of the leaves were placed on filter paper in Petri dishes containing the same chemicals at the same concentration, then transferred to the chamber and maintained for $30 \mathrm{~m}, 60 \mathrm{~m}, 2 \mathrm{~h}, 4 \mathrm{~h}, 24 \mathrm{~h}$, and $48 \mathrm{~h}$. Tissues were collected at different time points, as indicated in the experiments, placed into sterile RNase-free Falcon tubes, snap-frozen in liquid nitrogen, and stored at $-80^{\circ} \mathrm{C}$. 


\subsubsection{Q-tip and spray}

In the Q-tip and spray approaches, the tomato seedlings were selected based on the similarity in physical characteristics (similar green color, length, size, and health condition). The cotton Q-tip was used to apply FB1 solution to every single tomato leaf, and SA solution was sprayed onto each tomato leaf. Wiping FB1 and spraying SA on tomato leaves was repeated at least three times to ensure their entry through stomata.

The treated plants were transferred to the chamber and grown there to maintain the photosynthesis process. Tissues were harvested from treated leaves at different time points as indicated in experiments $(0 \mathrm{~m}, 30 \mathrm{~m}, 60 \mathrm{~m}, 2 \mathrm{~h}, 4 \mathrm{~h}, 24 \mathrm{~h}$, and $48 \mathrm{~h})$. Then, the samples were placed in sterile RNase-free Falcon tubes, snap-frozen in liquid nitrogen, and stored at $-80^{\circ} \mathrm{C}$.

The frozen samples were used for RNA extraction. Table 2.1 below shows the name of the treatments that have been used in my project and their concentrations. In some experiments, SA and FB1 were combined with other treatments (i.e. SA + ERKI, FB1 + ERKI)

\begin{tabular}{|c|c|}
\hline Treatment & Concentration \\
\hline FB1 & $5 \mu \mathrm{M}$ \\
\hline SA & $100 \mu \mathrm{M}$ \\
\hline ERKI & $250 \mu \mathrm{M}$ \\
\hline
\end{tabular}

Table 2.1: The different treatments used and their corresponding concentrations. 


\subsection{RNA extraction}

Before RNA extraction, mortars and pestles were sterilized by incubation in DEPC-treated distilled water overnight, followed by autoclaving to remove any contaminating RNase. Approximately $0.1 \mathrm{~g}$ of frozen leaf samples were ground in liquid nitrogen with sterilized mortars and pestles until the tomato tissues became fine powder. The fine powder was placed in RNase-free Eppendorf tubes.

The leaf tissues were homogenized in $1 \mathrm{~mL}$ of TRIzol Reagent Kit (Life Technologies, USA) and incubated at room temperature for 5 min to permit the complete dissociation of nucleoprotein complexes. About $200 \mu \mathrm{L}$ of chloroform was added, and the mixture was shaken vigorously for about $15 \mathrm{~s}$. The sample was then incubated for 3 min at room temperature. After incubation, the sample was centrifuged using 5804R Eppendorf centrifuge at $12,000 \mathrm{~g}$ for $15 \mathrm{~min}$ at $4^{\circ} \mathrm{C}$. Following centrifugation, three separate layers formed: a colorless upper aqueous phase, an interphase, and the phenolchloroform phase. The upper colorless layer that contained the RNA was transferred to a new tube and $500 \mu \mathrm{L}$ isopropyl alcohol was added. Then, the sample was incubated for $10 \mathrm{~min}$ at room temperature and centrifuged at $12,000 \mathrm{~g}$ for $10 \mathrm{~min}$ at $4^{\circ} \mathrm{C}$. The supernatant was carefully removed using a pipette, and the resulting pellet (RNA) was washed with $500 \mu \mathrm{L} \mathrm{75 \%}$ ethanol and vortexed for proper mixing. The sample was then centrifuged at 7,500g for $5 \mathrm{~min}$ at $4^{\circ} \mathrm{C}$. Ethanol was then removed, and the pellet was dried at room temperature for $10 \mathrm{~min}$. This pellet was then dissolved in $25 \mu \mathrm{L}$ RNasetreated water and broken up mechanically using a pipette tip. It was then incubated at $60^{\circ} \mathrm{C}$ for $10 \mathrm{~min}$ in a water bath. RNA concentration was measured using a 15 Nanodrop 
ND-1000 spectrophotometer (ThermoFisher Scientific, USA). The sample was stored at $20^{\circ} \mathrm{C}$.

\subsection{DNase treatment}

Following TRIzol extraction, $1 \mu \mathrm{g}$ of RNA sample was treated in an RNase-free $0.5 \mathrm{~mL}$ microcentrifuge tube with $1 \mu \mathrm{L}$ of $10 \mathrm{x}$ DNase I reaction buffer $(100 \mathrm{mM}$ Tris-HCL (pH7.5), $25 \mathrm{mM} \mathrm{MgCl}_{2}, 5 \mathrm{mM} \mathrm{CaCl}$ ), and $1 \mu \mathrm{L}$ of the DNase I (Amplification Grade1U/ $\mu \mathrm{L}$, Life Technologies, Burlington, Ontario) to remove genomic DNA contamination from RNA samples. DEPC-treated water was added to bring the sample volume to $10 \mu \mathrm{L}$. Then the samples were incubated at $15-30^{\circ} \mathrm{C}$ for $15 \mathrm{~min}$, then at $4^{\circ} \mathrm{C}$ for 2 min. One $\mu \mathrm{L}$ of $25 \mathrm{mM}$ EDTA ( $\mathrm{pH} 8.0$ ) was added into each tube, and then these tubes were heated at $65^{\circ} \mathrm{C}$ for $10 \mathrm{~min}$ in a thermal cycler and stored at $-20^{\circ} \mathrm{C}$. In the end, RNA concentration was measured using a NanoDrop ND-1000 spectrophotometer (ThermoFisher Scientific, USA).

\section{5. cDNA synthesis}

cDNA synthesis was carried out using Cloned AMV First-Strand cDNA Synthesis Kit (Life Technologies, Burlington, Ontario). One $\mu \mathrm{L}$ of oligo (dT) ${ }_{20}, 1 \mu \mathrm{g}-5 \mu \mathrm{g}$ of RNA, $2 \mu \mathrm{L}$ of $10 \mathrm{mM}$ dNTP mix were added in a 0.2 or $0.5 \mathrm{~mL}$ tube. The volume was brought up to $12 \mu \mathrm{L}$ with DEPC-treated water. The samples were heated at $65^{\circ} \mathrm{C}$ for 5 min in a thermal cycle and then placed on ice for 2 min. To synthesize the first strand of the cDNA $4 \mu \mathrm{L}$ of $5 \mathrm{x}$ cDNA synthesis buffer, $1 \mu \mathrm{L}$ of $0.1 \mathrm{M}$ DTT, $1 \mu \mathrm{L}$ of RNase OUT (40U/ $\mu \mathrm{l}), 1 \mu \mathrm{L}$ DEPC-treated water, and $0.5 \mu \mathrm{L}$ of Cloned AMV RT (15 units $/ \mu \mathrm{L})$ were added to the samples. The samples were heated at $48^{\circ} \mathrm{C}$ for $48 \mathrm{~min}$, followed by $85^{\circ} \mathrm{C}$ for 5 min in a thermal cycler. Finally, DNA concentrations in the samples were measured by 
NanoDrop ND-1000 spectrophotometer (ThermoFisher Scientific, USA) and then stored at $-20^{\circ} \mathrm{C}$

\subsection{Primer design}

Primer sequences were designed based on the sequence information from the NCBI database (GenBank) using Primer-Blast (http://www.ncbi.nlm.nih.gov/tools/ primer-blast/index.cgi?LINK_LOC=NcbiHomeAd). Table 2.2 lists the primers for RTPCR.

\begin{tabular}{|l|l|l|}
\hline Gene & Forward primer & Reverse primer \\
\hline Actin & $\begin{array}{l}\text { 5'-TGGCATCATACTTTCTACAA } \\
\text { TG-3' }\end{array}$ & 5'-CTAATATCCACGTCACATTTCAT-3' \\
\hline LeMPK3 & $\begin{array}{l}\text { 5'-GATCGGATCCATGGTTGA } \\
\text { TGC TAATATGGG -3' }\end{array}$ & $\begin{array}{l}\text { 5'-GATCCT CGAGTTAAGCATATTCAG } \\
\text { GATTCAACG-3' }\end{array}$ \\
\hline TAB2 & $\begin{array}{l}\text { 5'-AAGCTCATTACTGTGGACC } \\
\text { GTGCCT-3' }\end{array}$ & $\begin{array}{l}\text { 5'- TCCTTCAGGGAACCAAAG AGCGA- } \\
\text { 3' }\end{array}$ \\
\hline PR1 & $\begin{array}{l}\text { 5'-CCAAGACTATCTTGCGGT } \\
\text { TC -3' }\end{array}$ & 5'-GAACCTAAGCCACGATACCA -3' \\
\hline PDF1.2 & $\begin{array}{l}\text { 5'-GGCAAACTCCATGCGTTTA } \\
\text { T-3' }\end{array}$ & 5'-TCTCACATACCGAGGCACAA -3' \\
\hline
\end{tabular}

Table 2.2: List of primers used for RT-PCR. 


\subsection{RT-PCR (reverse transcription polymerase chain reaction)}

In the 0.2 or $0.5 \mathrm{~mL}$ tube, $2.5 \mu \mathrm{L}$ of $10 \mathrm{x}$ PCR Reaction Buffer, $2 \mu \mathrm{L}$ of $25 \mathrm{mM}$ $\mathrm{MgCl}_{2}, 0.75 \mu \mathrm{L}$ of $10 \mathrm{mM}$ dNTPs, $0.75 \mu \mathrm{L}$ of $\mathrm{FW}$ (forward) primer, $0.75 \mu \mathrm{L}$ of RV (reverse) primer, and $0.3 \mu \mathrm{L}$ Taq DNA polymerase (Life Technologies, Burlington, Ontario) were added gradually, and the amplification was performed in a PTC 200 thermal cycler (Life Technologies, Burlington, Ontario).

\subsubsection{Actin RT-PCR}

Actin gene was used as an internal standard for the adjustment of loading amount of different samples. RT-PCR protocol for tomato actin was as follows: Cycle 1 (1x) Step 1: $94^{\circ} \mathrm{C}$ for 3 minutes. Cycle 2 (28x): Step $1: 94^{\circ} \mathrm{C}$ for 45 seconds (DNA denaturing); Step 2: $60.2^{\circ} \mathrm{C}$ for 1 minute (primer annealing); Step 3: $72^{\circ} \mathrm{C}$ for 90 seconds (DNA fragment extension). Cycle 3 (1x): $72^{\circ} \mathrm{C}$ for 10 minutes (extension). Cycle $4: 4{ }^{\circ} \mathrm{C}$ forever. The size of the actin gene PCR product was around $600 \mathrm{bp}$.

\subsubsection{PR1 and PDF1.2 RT-PCR}

RT-PCR of tomato PRI and PDF1 was included in this work and the two genes served as positive control of $\mathrm{SA}$ and $\mathrm{FB} 1$ treatment (i.e. as marker genes). Tomato $P R I$ RT-PCR protocol was as follows: Cycle 1(1x) Step 1: $95^{\circ} \mathrm{C}$ for 1 minute. Cycle 2 (40x): Step 1: $95^{\circ} \mathrm{C}$ for 15 seconds; Step 2: $60^{\circ} \mathrm{C}$ for 15 seconds; Step 3: $72^{\circ} \mathrm{C}$ for 15 seconds. Cycle 3 (1x): $72^{\circ} \mathrm{C}$ for 10 minutes. Cycle $4: 4^{\circ} \mathrm{C}$ forever. The size of the PR1 RT-PCR product was $423 \mathrm{bp}$.

Amplification protocol for tomato PDF1.2 gene was as follows: Cycle 1(1x) Step 1: $95^{\circ} \mathrm{C}$ for 1 minute. Cycle $2(35 \mathrm{x})$ : Step $1: 95^{\circ} \mathrm{C}$ for 15 seconds; Step $2: 66.9^{\circ} \mathrm{C}$ for 30 
seconds; Step 3: $64^{\circ} \mathrm{C}$ for 30 seconds; Step 4: $72^{\circ} \mathrm{C}$ for 45 seconds. Cycle 3 (1x): $72^{\circ} \mathrm{C}$ for 7 minutes. Cycle $4: 4^{\circ} \mathrm{C}$ forever. The size of $P D F 1.2$ RT-PCR product was $469 \mathrm{bp}$.

\subsubsection{LeMPK3 and TAB2 RT-PCR}

Amplification protocol for tomato LeMPK3 gene was as follows: Cycle 1(1x) Step 1: $95^{\circ} \mathrm{C}$ for 1 minute. Cycle 2 (35x): Step 1: $95^{\circ} \mathrm{C}$ for 15 seconds. Step 2: $63.5^{\circ} \mathrm{C}$ for 30 seconds; Step $3: 72^{\circ} \mathrm{C}$ for 45 seconds. Cycle $3(1 \mathrm{x}): 72^{\circ} \mathrm{C}$ for 7 minutes. Cycle $4: 4{ }^{\circ} \mathrm{C}$ forever. The size of LeMPK3 RT-PCR product was $1122 \mathrm{bp}$. RT-PCR of TAB2 was carried out under the same conditions except that melting temperature for TAB2 was $64.8^{\circ} \mathrm{C}$. The size of $T A B 2 \mathrm{RT}-\mathrm{PCR}$ product was $500 \mathrm{bp}$.

RT-PCR products were fractionated in $1 \%$ agarose gels with $1 \mathrm{x}$ TAE buffer to check the size of the PCR products. Ethidium bromide was added to the agarose gel and PCR products were visualized under UV light.

\subsection{Microscopic detection of cell death}

Ten $\mathrm{mL}$ of ethanol-lactophenol-trypan blue were prepared by mixing 2 volumes of ethanol, 1 volume each of phenol, glycerol, lactic acid, and distilled water (1:1:1:1) followed by $0.05 \%$ of trypan blue. The leaves were placed in $15 \mathrm{~mL}$ Falcon tubes and covered with the ethanol-lactophenol-trypan blue. The samples were incubated at $95^{\circ} \mathrm{C}$ for $4 \mathrm{~min}$ and then kept at room temperature for $20 \mathrm{~min}$. The staining solution was removed, and $1.5 \mathrm{~mL}$ chloral hydrate destaining solution $\left(2.5 \mathrm{~g} / \mathrm{mL} \mathrm{H}_{2} \mathrm{O}\right)$ was added to each tube. The leaves were cleared for 2 days, with replacing the destaining solution twice. Destained leaves were suspended in 50\% glycerol and examined under Axioplan 2 microscope (Carl Zeiss, Germany) with white light. 


\subsection{PCR-directed mutagenesis}

The primers used in this experiment were designed to contain restriction enzyme cleavage sites, so the PCR product can be inserted into multiple cloning sites of vectors. Table 2.3 lists the pairs of primers used for LeMPK3 mutagenesis and the restriction enzyme cleavage sites they contained.

\begin{tabular}{|l|l|}
\hline $\begin{array}{l}\text { LeMPK3 Mid mut FOR } \\
\text {-BamHI and } N c o I\end{array}$ & 5-GGAAGAAGATGTAGTAACCAGATGG-3 \\
\hline $\begin{array}{l}\text { LeMPK3 end REV- } \\
\text { SalI and } \text { SmaI }\end{array}$ & $\begin{array}{l}\text { 5-ATCCCGGGGTCGACTTAAGCATATTCAGGAT } \\
\text { TCAACGCC-3 }\end{array}$ \\
\hline $\begin{array}{l}\text { LeMPK3 Mid mut } \\
\text { REV- } \\
\text { SalI and } \text { SmaI }\end{array}$ & 5-CCATCTGGTTACTACATCTTCTTCC-3 \\
\hline $\begin{array}{l}\text { LeMPK3 head FOR- } \\
\text { Bam HI and NcoI }\end{array}$ & $\begin{array}{l}\text { 5-CGGATCCATGGATGGTTGATGCTAATATGGG } \\
\text { TGCTGC-3 }\end{array}$ \\
\hline
\end{tabular}

Table 2.3: Primers used for LeMPK3 mutagenesis.

In PCR-directed mutagenesis, two pairs of primer, LeMPK3 Mid mut FOR plus LeMPK3 end REV and LeMPK3 head FOR plus LeMPK3 Mid mut REV, were run in the first round of PCR. The amplification protocol for these genes was as follows: Cycle 1(1x) Step 1: $95^{\circ} \mathrm{C}$ for 1 minute. Cycle 2 (35x): Step 1: $95^{\circ} \mathrm{C}$ for 15 seconds. Step 2: $60^{\circ} \mathrm{C}$ for 30 seconds; Step 3: $72^{\circ} \mathrm{C}$ for 45 seconds. Cycle $3(1 \mathrm{x}): 72^{\circ} \mathrm{C}$ for 7 minutes. Cycle 4: $4{ }^{\circ} \mathrm{C}$ forever. The size of PCR product was tested using agarose gel electrophoresis. To ensure the purity of these bands, they were cleaned using a gel and PCR clean-up system. 


\subsection{Gel and PCR clean-up system}

Following gel electrophoresis PCR product was visualized using a longwavelength UV lamp. DNA fragment of interest was excised using a clean razor blade. Wizard $^{\circledR}$ SV Gel and PCR Clean-Up System (Promega, USA) was used for PCR product extraction from the gel slides. Membrane Binding Solution was added at a ratio of $10 \mu \mathrm{L}$ of solution per $10 \mathrm{mg}$ of agarose gel slice. The mixture was vortexed and incubated at $50-$ $65^{\circ} \mathrm{C}$ for $10 \mathrm{~min}$ or until the gel slice is completely dissolved. After that, the tube was vortexed every few minutes to increase the rate of agarose gel melting. The tube was centrifuged briefly at room temperature to ensure the contents were at the bottom of the tube. The dissolved gel mixture was transferred to the SV Minicolumn assembly and incubated for $1 \mathrm{~min}$ at room temperature. The SV Minicolumn assembly was centrifuged in a microcentrifuge at $16,000 \mathrm{~g}$ for 1 minute. Then the SV Minicolumn was removed from the Spin Column assembly and the liquid in the Collection Tube was discarded. The SV Minicolumn was re-connected to the Collection Tube.

The column was washed by adding $700 \mu \mathrm{L}$ of Membrane Wash Solution to the SV Minicolumn. The SV Minicolumn assembly was centrifuged for $1 \mathrm{~min}$ at $16,000 \mathrm{~g}$. The Collection Tube was emptied as before and the SV Minicolumn was placed back in the Collection Tube. Next, the wash with $500 \mu \mathrm{l}$ of Membrane Wash Solution was repeated and the SV Minicolumn assembly was centrifuged for 5 minute at $16,000 \mathrm{~g}$. The Collection Tube was emptied and the column assembly was centrifuged again for $1 \mathrm{~min}$ with the microcentrifuge lid open (or off) to allow evaporation of any residual ethanol. The SV Minicolumn was transferred to a clean $1.5 \mathrm{~mL}$ microcentrifuge tube. Then, $50 \mu \mathrm{L}$ of Nuclease-free water was added, with the pipette tip, directly to the center of the 
column without touching the membrane. Following incubation at room temperature for 1 min, the column assembly was centrifuged for 1 minute at $16,000 g$. Finally, the microcentrifuge tube containing the eluted DNA was stored at $4^{\circ} \mathrm{C}$ or $-20^{\circ} \mathrm{C}$.

After obtaining the two bands, a second round of PCR was carried out. This time, the primers were the first and the second halves of the gene generated during the first round PCR. In both the first and second rounds, 35 cycles were run, as previously indicated. After the size of PCR product was checked by agarose gel electrophoresis it was cleaned up using Wizard SV Gel and PCR Clean-Up System (Promega, USA). 


\section{CHAPTER III}

\section{RESULTS}

The main interest of this research project is to study the relationship between LeMPK3, TAB2 and tMEK2 in plant defense response in tomato. In previous studies of MAPK pathways, tMEK2 (or called LeMEK1 or LeMKK1) has been used as a model system. Its overexpression in tomato, Arabidopsis or wheat has been shown to increase plant diseases resistance (Xing, 2007). Previous investigation has identified some downstream proteins that were phosphorylated and activated by tMEK2 in tomato (Thurston et al., 2005). Thus, in this report we will study some of these proteins. Specifically we will focus on studying LeMPK3 as it is a downstream component of tMEK2 (Xing et al., 2008).

LeMPK3 is upstream of TAB2, and it directly interacts with TAB2 at the protein level (Xing et al., 2008). Both LeMPK3 and TAB2 genes are activated when tomato leaves were challenged by the virulent strains of bacterial pathogen Pseudomonas syringae pv. tomato (Stulemeijer et al., 2007; Xing et al., 2008; Xing, unpublished). Previous work in our lab has indicated that the phosphorylation level of TAB2 was enhanced when tMEK2 was constitutively activated and TAB2 was involved in tMEK2mediated disease resistance (Xing et al., 2008).

\subsection{Bioinformatic analysis}

Genevestigator consists of collection of curated experiments that are analyzed individually, as well as integrates all experiments and their analysis across experiments in multiple laboratories without a universal growth and treatment conditions. Genevestigator thus use a few strategies to to normalize these data. Effort includes the consideration of 
experimental design, number of arrays, and diversity of tissue types. Genevestigator database hosts data from a variety of platforms as well.

In Genevestigator database, in which microarray data can be mined, data for Solanum lycopersicum LeMPK3 (AY261514), our gene of interest, were not available. In Arabidopsis thaliana, on the other hand, the genome has been sequenced, annotated, and extensively studied. Due to the advantages of Arabidopsis thaliana for basic research in cellular, genetics, and molecular biology, this plant is a model organism for the study of plant-pathogen interactions. Thus, LeMPK3 homolog in Arabidopsis thaliana was examined.

\subsubsection{Phylogenetic trees of Solanum lycopersicum LeMPK3 and Arabidopsis thaliana}

\section{MAPKs}

One homolog gene, AtMPK3 (AT3G45640), was found to have the highest nucleotide sequence similarity to the Solanum lycopersicum LeMPK3 gene when using the BLAST tool from NCBI (http://www.ncbi.nlm.nih.gov) (Figure 3.1). The phylogenetic trees of the Arabidopsis MAPKs and the Solanum lycopersicum LeMPK3 are represented below (Figure 3.2 and 3.3). This analysis seems to indicate that Arabidopsis AtMPK3 (AT3G45640) is most homologous to Solanum lycopersicum LeMPK3 at the DNA level, while AtMPK6 (AT2G43790.1) is most homologous to Solanum lycopersicum LeMPK3 at the amino acid level. The phylogenetic trees were generated using the Phylogeny.fr tool (http://www.phylogeny.fr/version2_cgi). 
AT3G45640.1 I Symbols: ATMPK3, MPK3, ATMAPK3 I mitogen-activated protein kinas 3 I chr3:16756770-16758698 FORWARD LENGTH=1483

Length $=1483$

Score $=172$ bits $(87)$, Expect $=6 e-42$

Identities $=177 / 207(858)$

strand = Plus / Plus

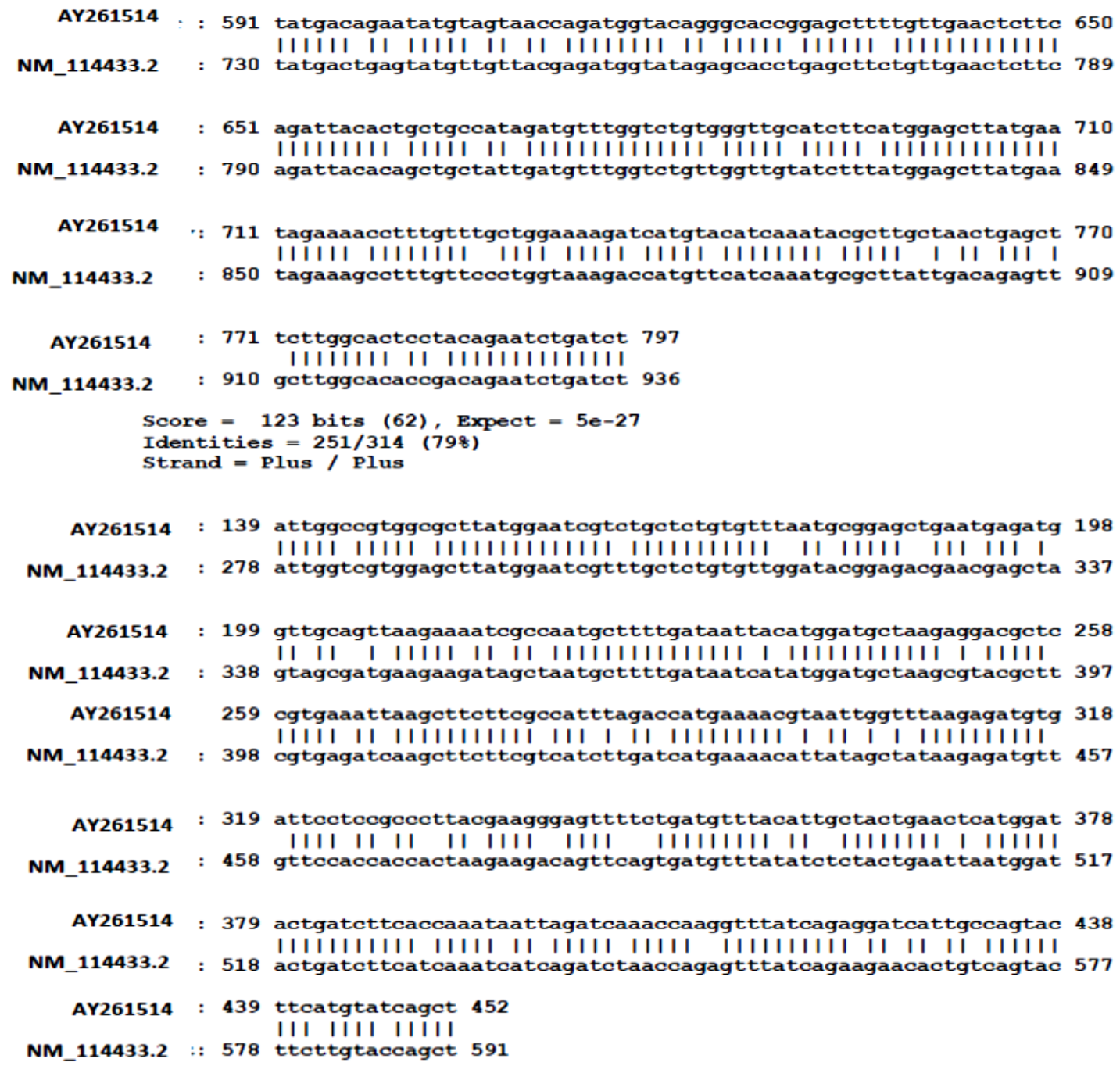

Figure 3.1: The similarity of the nucleotide sequences between Solanum lycopersicum

\section{LeMPK3 (AY261514) and Arabidopsis thaliana AtMPK3 (NM_114433.2/AT3G45640)}

gene. This figure was generated using the BLAST tool from NCBI (http://www.ncbi.

nlm.nih.gov). 


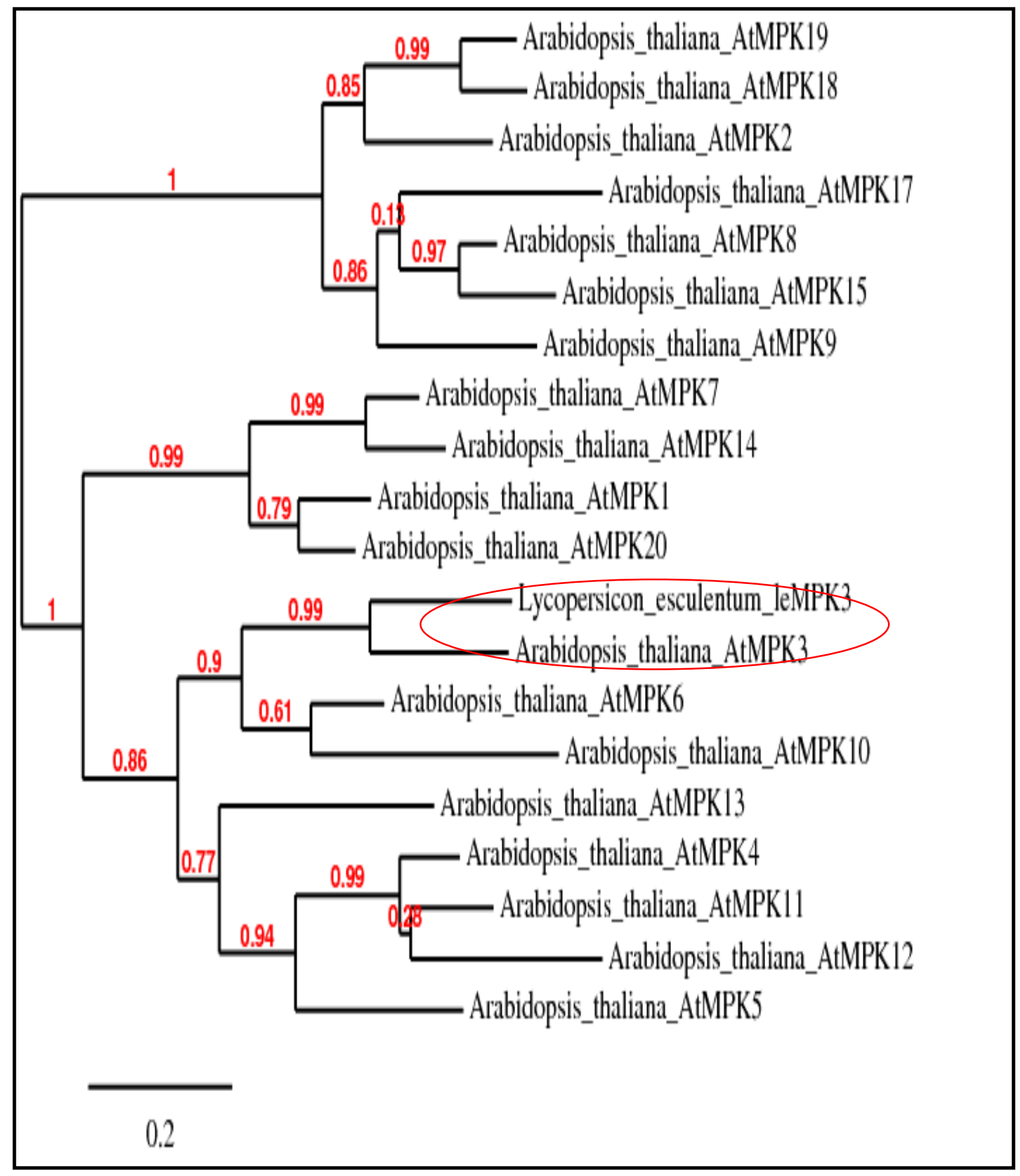

Figure 3.2: The phylogenetic tree of Solanum lycopersicum LeMPK3 with Arabidopsis thaliana MAPKs based on nucleotide sequences. Solanum lycopersicum LeMPK3 and Arabidopsis thaliana AtMPK3 are most homologous. The phylogenetic tree was generated using the Phylogeny.fr tool (http://www.phylogeny.fr/version2_cgi/simple _phylogeny.cgi). 


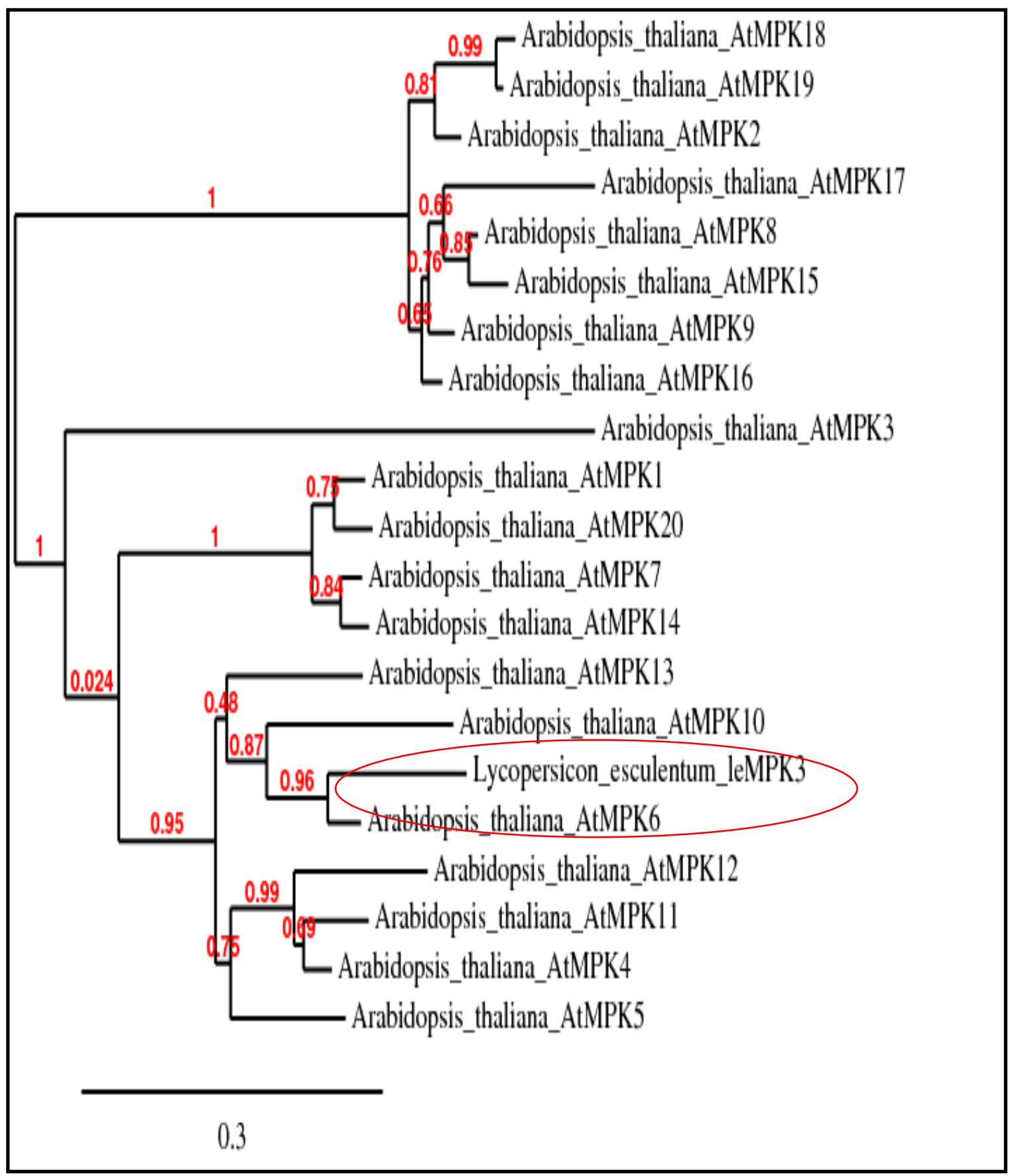

Figure 3.3: The phylogenetic tree of Solanum lycopersicum LeMPK3 with Arabidopsis thaliana MAPKs based on amino acid sequences. Solanum lycopersicum LeMPK3 and Arabidopsis thaliana AtMPK6 are homologous. The phylogenetic tree was generated using the Phylogeny.fr tool (http://www.phylogeny.fr/ version2_cgi/simple_phylogeny.cgi). 


\subsubsection{Nucleotide sequence alignment and amino acid sequences alignment}

of Solanum lycopersicum leMPK3 with Arabidopsis thaliana AtMPK3 and AtMPK6

Alignment analysis of Solanum lycopersicum leMPK3 and Arabidopsis thaliana AtMPK3 and AtMPK6 are presented below (Figure 3.4, 3.5, 3.6, and 3.7). At the DNA level, the alignment seems to agree to the phylogeny tree results. At the amino acid level, it seems that LeMPK3 are much more homologous to AtMPK6 than to AtMPK3. 
LEMPK 3

A. $T$ MPK 3

LeMPK 3 A $t$ MPK 3

LEMPK 3 A tMPK3

LeMPK 3 A $t$ MPK 3

LEMPK3 A. $T$ MPK 3

LEMPK3 A $t M P K 3$

LEMPK3 A $t$ MPK 3

LeMPK3 AtMPK 3

LEMPK 3 AtMPK3

LEMPK 3 A. $T$ MPK 3

LEMPK3 A $t M P K 3$

LEMPK3 AtMPK3

LeMPK 3 A $t$ MPK 3

LEMPK 3 A. $T$ MPK3

LEMPK3 A $T M P K 3$

LEMPK3 A $T$ MPK 3

LeMPK 3 A tMPK 3

LEMPK 3 AtMPK 3

LEMPK3 A $t M P K 3$

LeMPK3 A $T M P K 3$

LEMPK 3 A tMPK3

LEMPK 3 A tMPK3

LEMPK 3 A.MPK 3

LeMPK3 A $t$ MPK 3

LeMPK3 A tMPK 3

ACCGCGAAAACTCATCTCTGCTCAATCCTCAATCTCAGTCTCTCTGTTGACTCCGACTGT PATATAAAACCATACAAATACCTTCAGATTCACTACTTCAAACCTCAAAGCAACCACTGA

ATCTCGACTTTGATAATATGG--

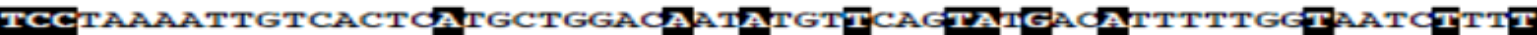
TCCGCGGAGGCGGGGGAAACTCACGGAGdACAGTTCATAAGTIACGATATCTTCGGTAGT TGAGATTACTAACAAGTATCAACCTCCIATCATGCCTATTGGCCGTGGCGCTTATGGAAT CGAGATCACATCTAAGTATCGTCCTCCAATIATACCAATTGGICGTGGAGCTTATGGAAT

CGTCTGCTCTGTGTTAATGCGGACCTGAATGAGATGGTTGCAGTTAAGAAAATCGCAA CGITIGCTCTGIGTIGGATAACGAACGAGCIAGTAGCGATGAAGAAGATAGCTAA-- - TGCTTTMATAAT PACATGATGCTAAGAGGACCTCCGTGA/ATTAAGCTTCTTCGCCA TGCTTTTGATAAT A AATGGATGCTAAGCGIACGCTICGTGAGATCAAGCTTCTTCGTCA

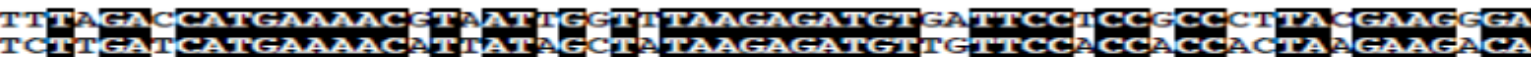
GTTTCTEATGTTPCATIGCTACTGAACTCATGEATACTGATCTTCACCAAATAATTAG GTTCAGTGATGTTATATCTCTACTGAAT AATGGATACTGATCTTCATCAAATCATCAG ATCAAACCAAG GTPATCAGAGGAICAITGCCAGPACTTCATGPATCAGCTICTCCETGG ATCTAACCAGA GTTPATCAGA GA ACATGICAGTACTTCTTGTACCAGCTACTTCEAGG GCTAAAGPACATACATTCGCGCATGTPATPCATAGAGATCTCAAACCAAGTAACCTCTT ACTGAAGTATATCCACTCAGCTAACATTATTCATAGGGATTTAAAGCCGAGCAATCTTCT GCTAAATGCAAATTETGATCTPAAGATATGCGATPTPGGTCTPGCAAGGCCAAACGTAGA GTIGAACGCGAATTGCGATITAAAGATITGIGATTTCGGTCTTGCTAGACCTACTTCAGA GAACGAGAATATGACAGA PATGPAGTAACAGATGGPACAGGGCACCGGAGCITITGPI GAATGATTTATGACTGA TATGTIGTIACGAGATGGTAIAGA GCACCTGAGCTTCTGTT

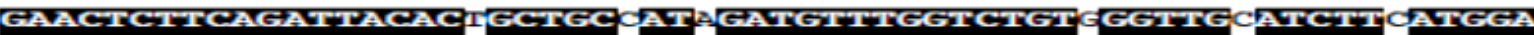
GAACTCTTCAGATTACACA GCTGCIATIGATGTTTGGTCTGTIGGTTGTATCTTIATGGA GCTPATGAATAGAAAACCTPTGPTIGCTGGAAAAGAICATGTACATCAAATACGCTTGCT GCTTATGAATAGAAAGCCTTTGTTCCCTGGIAAAGACCATGTICATCAAATGCGCTIATI AACTGAGCTCTTGGCACTCCTACAGAATCTEATCTTAGCTTCCTCCGTAATGAAGATGC GACAGAGTTGCTTGGCACACCAACAGAATCTGATCTCGGITTTACTCACAATGAGGATGC AAAAAGATAC FCAGGCAACTCCCACAACA TCCACGCCAGCAGTTAGCAACAGTGTTCCC AAAAGATAC TCCGGCAACT TCCCAACTTCCCACGICAGCCCTTAGCTA AАTTTTC PCATGTGAATCCAITAGCCATTGATCTTGTAGAIAAGATGTTGACGCTCGACCCTACTAG TCATGTTAACCCAATGGCCATTGATCTTGIIGACAGAATGTTGACGITIGACCCCAACAG AAGAATA ACAGTTGAGGAAGCATPACTCAICCCPACCTCGCAAAGCTCCATGATGCAGC AAGAATCACTGTTGAACAAGCICTGAATCACCAGTACCTIGCIAAATTGCACGACCCGAA

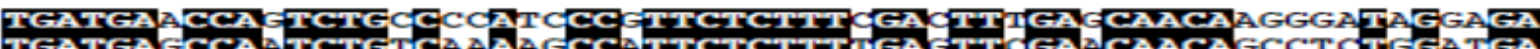
TGATGAGCCA ATCTGTCAAAAGCCATTCTCTTTIGAGTTCGAACAACAGCCTCTEGATGA AGAGCAGATPAAAGACATGATPTAPCAAGAAGCPTTGGCGTTGAATCCTGAATATGCTTA

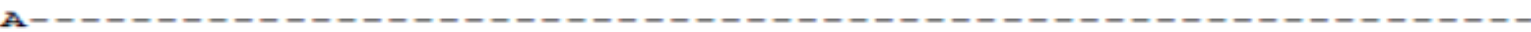
GAAGTGCAGCAGCCCCGTGAATGCCTGGTATTACCCAATAACCATCCGAATGGCTACTTA

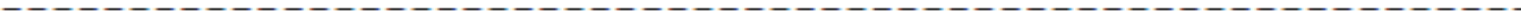

ATTTGTTTGTTCATGTTATTTACTGCTAGTGATTAAGTGTAGCTCCAATGTAAAGTACTC 1440

Figure 3.4: Nucleotide sequence alignment of Solanum lycopersicum leMPK3 and Arabidopsis thaliana AtMPK3. Nucleotide sequences that are shaded in black are shared by at least two sequences. 
I AMPK 3 AtMPK 6

I AMPKS AtMPK 6

IeMPK AtMPK 6

I AMPK3 AtMPK 6

IEMPK3 AtMPK 6

IEMPK AtMPK

IEMPK AtMPK 6

IEMPK AtMPK

INMPK3 AtMPK 6

I MMPK: AtMPK 6

IAMPK: AtMPK 6

IAMPK 3 AtMPK 6

IEMPK AtMPK

IEMPK: AtMPK 6

IeMPK3 AtMPK 6

I MPP AtMPK

IEMPK AtMPK 6

IeMPK3 A tMPRE

IEMPK A $t M P R^{\prime} 6$

IeMPK 3 AtMPK 6

INMPK 3 AtMPK 6

INMPK AtMPK 6

I AMPK 3 AtMPK 6

I MMPK AtMPK 6

IeMPKC: AtMPRK 6

IEMPK 3 AtMPK 6

IeMPK AtMPK 6
GTCTCTCAGATCTGTTTTCACCCCAAAACCAACGAATATCAATTTCTCCAATTTCATTCA

-

TAATTCACTCACCCCAAAATTACAAAAAAAAAAAAAAAAAAACATTTTCCATTTCCCTCT

TCTCGATCCACCACCACCACCAACCTCAAAACCTTTCATCTTTACCCGTCATCGACGCTC

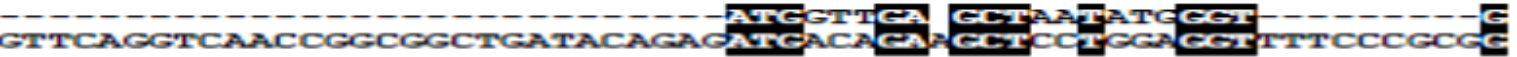
180

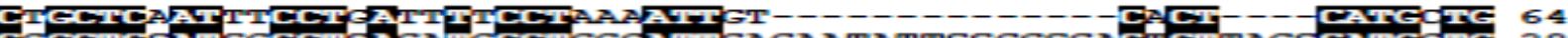

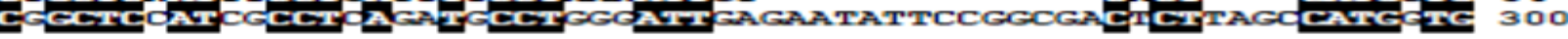

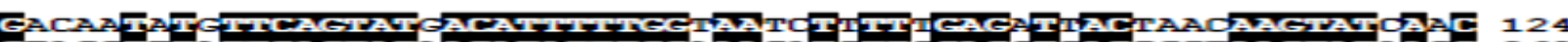

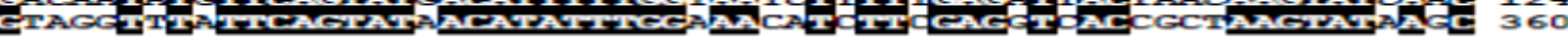

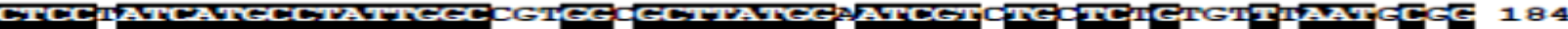

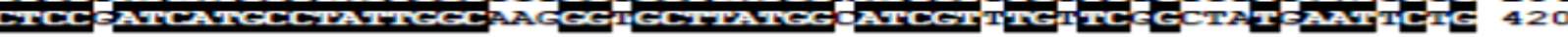

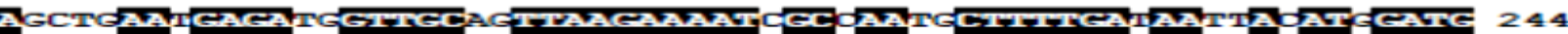

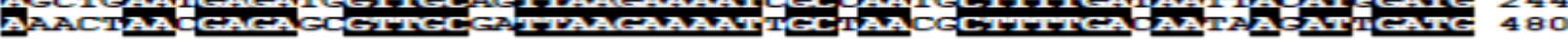

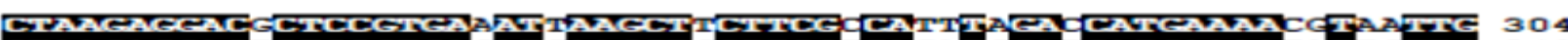

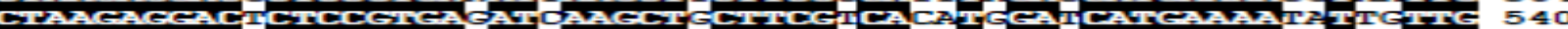

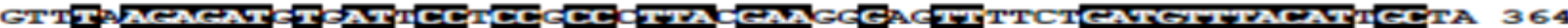

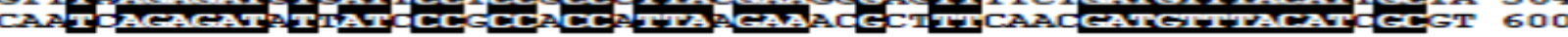

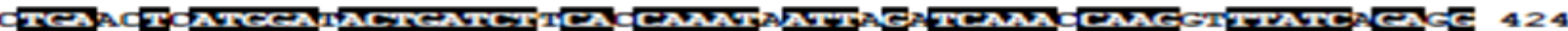

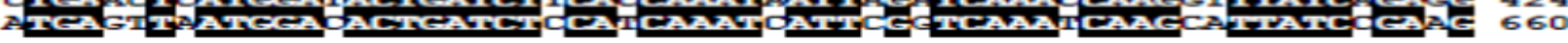

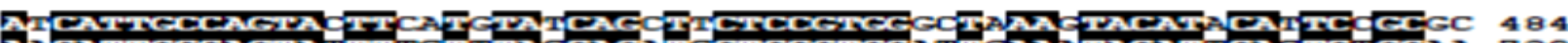

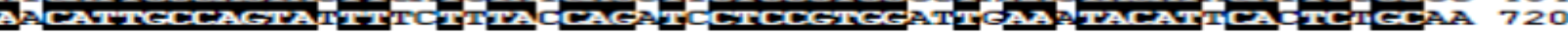

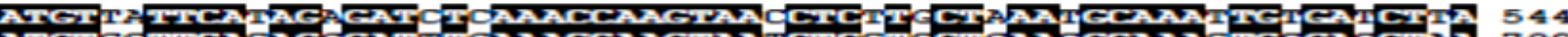

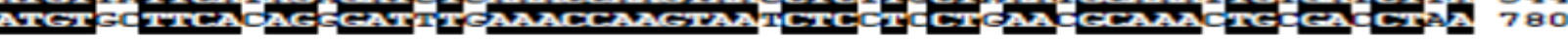

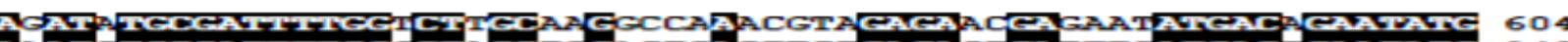

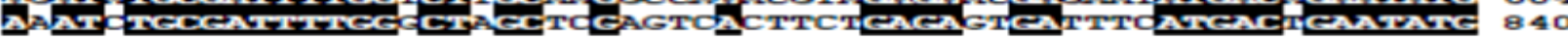

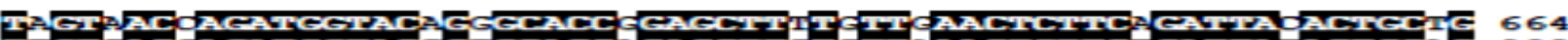

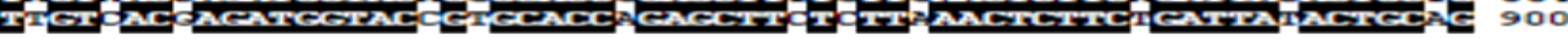

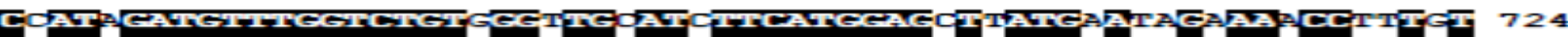

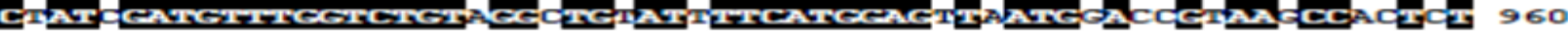

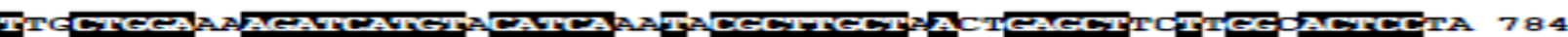

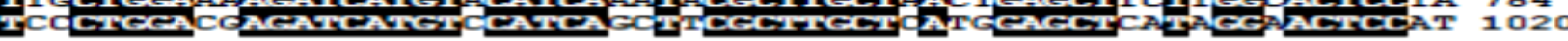

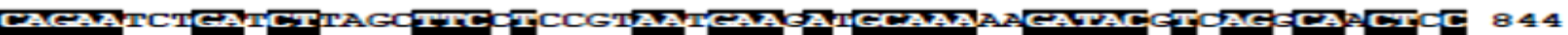

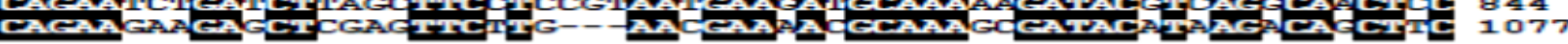

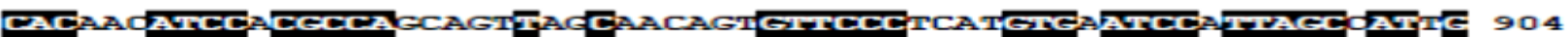

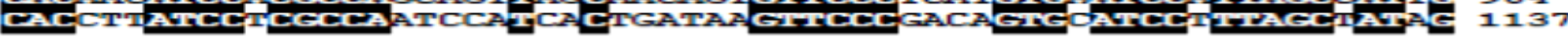

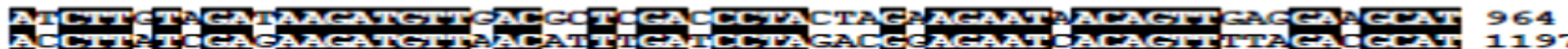

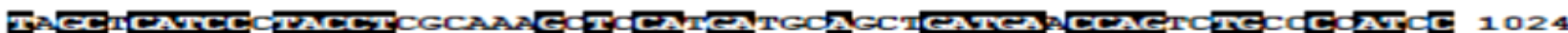

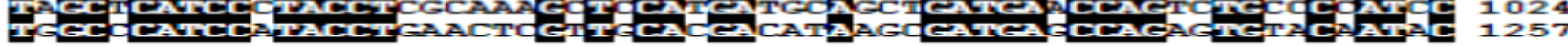

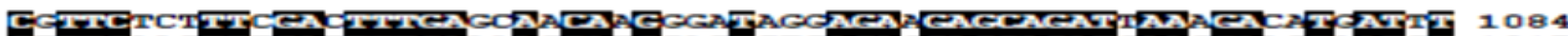

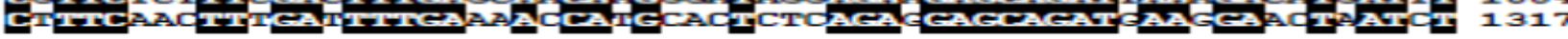

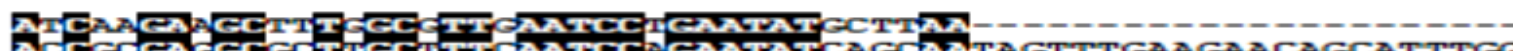

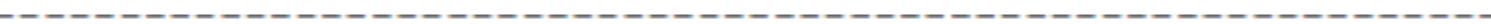
CACATGAAGATGAGATAAGGGTTTGGCGTTATTTGGTTTGGACAACATTCTTAAAAGCAC

CAAAGATCATTGTтTGTCTтTтGTGTATACTTGTGAGAGATGTTGAAGCGCATCGGTCTC

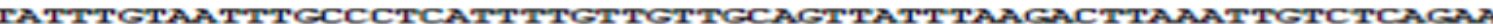

1617

Figure 3.5: Nucleotide sequence alignment of Solanum lycopersicum leMPK3 and

Arabidopsis thaliana AtMPK6. Nucleotide sequences that are shaded in black are shared

by at least two sequences. 
LeMPK3 A $T$ MPK 3

LeMPK3 A $t$ MPK 3

LeMPK 3 A. $T$ MPK3

LEMPK3 A $t$ MPK 3

LeMPK3 AtMPK3

LeMPK3 A $t$ MPK 3

LeMPK3 A $T$ MPK3

LeMPK3 AtMPK3

LEMPK3 AtMPK3

LeMPK3 A $t$ MPK 3

LeMPK3 AtMPK3

LEMPK3 A $T$ MPK 3

LeMPK3 AtMPK3

LeMPK3 A $t$ MPK 3

LeMPK3 AtMPK3

LeMPK3 A $t$ MPK3

LeMPK3 A $T$ MPK 3

LEMPK3 AtMPK3

LEMPK3 A $T$ MPK 3

LEMPK3 AtMPK 6

LeMPK3 A $T$ MPK3

LEMPK3 A $T$ MPK3

LeMPK3 AtMPK3
MVDANMGAAOFPDFPKIVTHAGOYVOYDIFGMIFEITNKYOPPIMPIGPGAYGIVCSVFN 6O ABLNEMVAVRKIANAFDNYMDAKRTIRBIMIERHIDAPNVIGLRDVIPPRIRREFSDVYI 120

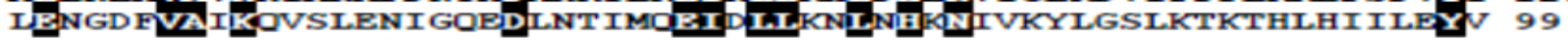

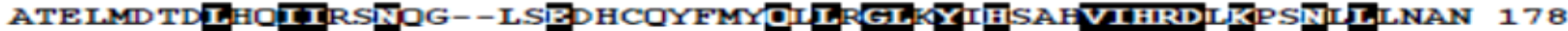

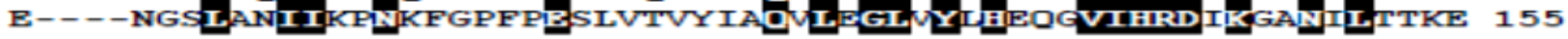

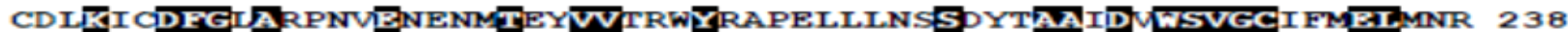

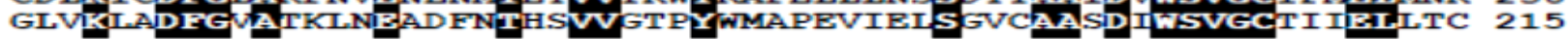

KPLFAGKDHVHOIRLLTELLGTPTESDISS- - - - - -FIRNEDAKRYVROIPGFP- - 285 VPPYYDLOPMPAIYRIVODDTPPIPDSISPDITDFLRICFKKDSRORPDAKTILSFPWIR 275

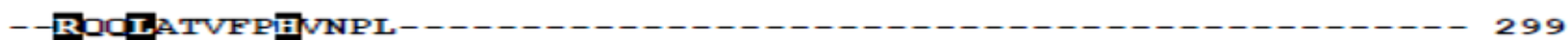
NSRRALRSSLRHSGTIRYMTETDSSSEKDAEGSOEVVESVSAEKVEVTKTNSKSKIPVIG 335

326 GASFRSEKDOSSPSDIGEEGTDSEDDINSDOGPTLSMHDKSSROSGTCSISSDAKGTSOD 395

LAKIEIDAADEPVCP - $\ldots \ldots \ldots$.

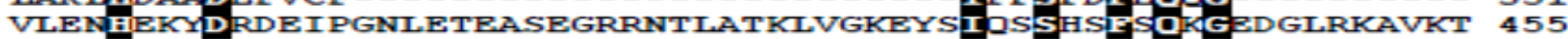
PSSFGGNELTRFSDPPGDASLHDIFHPLDKVPEGKTNEASTSTPTANVNOGDSPVADGGK 515 _. NDI.ATKLRARIAOKOMEGETGHSQDGGDLFRIMMGVI.KDDVINIDDIVEDEIKVPPENIFP 575 (1)-LOAVEFSRLVSSLRPDESEDAIVTSSLKLVAMFRORPGOKAVFVTONGFLPI.MDILDIPK SRVI CAVIOLINEIVIRDNTDFLENACLVGLI PLVMSFAGFERDRSREIRKEAAYFIOOLC OSSPLTLOMFISCRGI PVLVGFLFADYAKHRFMVHI.AIDGMWOVFKILKSTSRNDFCRIA

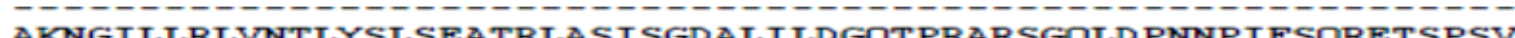
IDHPDGLKTRNGGGEEPSHATTSNSOSSDVHOPDAIHPDGDRPRISSVNADATEDVIOQH

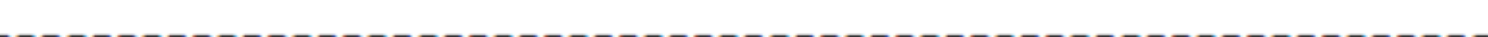
RISLSANRTSTDKLOKIAAGASNGFPVTOPDOVRPLLSLLEKEPPSRKISGOLDYVKHIA

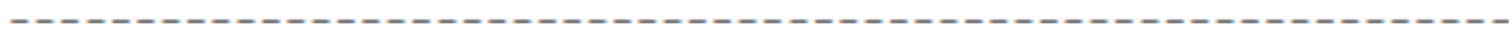
GIERHESRLPLLYASDEKKTNGDIEFIMAFFAEVSGRGKENGNLDTAPRYSSKTMTKIVM

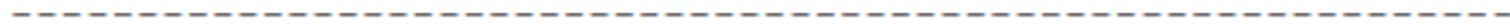
AIERVASTCGIASOTASGVLSGSGVLNARPGSTTSSGLI.AHALSADVSMIYLEKVADI.LI

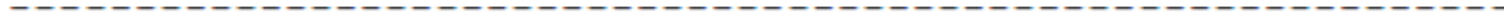
EFARAETTVKSYMCSOSLLSRIFOMFNRVEPPILLKILECTNHISTD PNCLENLORADAI

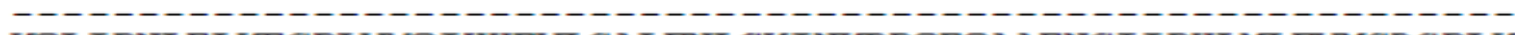
KOLI PNLELKEGPLVYOI HHEVLSALFNLCKINKRROEOAAENGI IPHIMIFVMSDSPLK

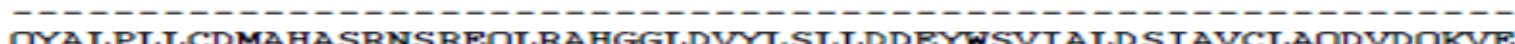
(1)

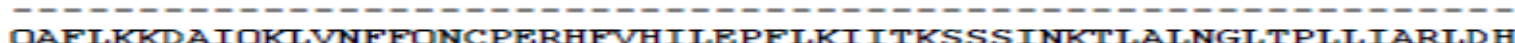

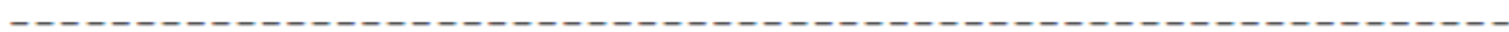
ODAIARI.NLIKLIKAVYEKHPKPKOLIVEND LPOKILONLI EERRDGORSGGOVLVKOMAT

Figure 3.6: Amino acid sequence alignment of Solanum lycopersicum leMPK3 and Arabidopsis thaliana AtMPK3. Amino acids that are shaded in black are shared by at least two sequences. 


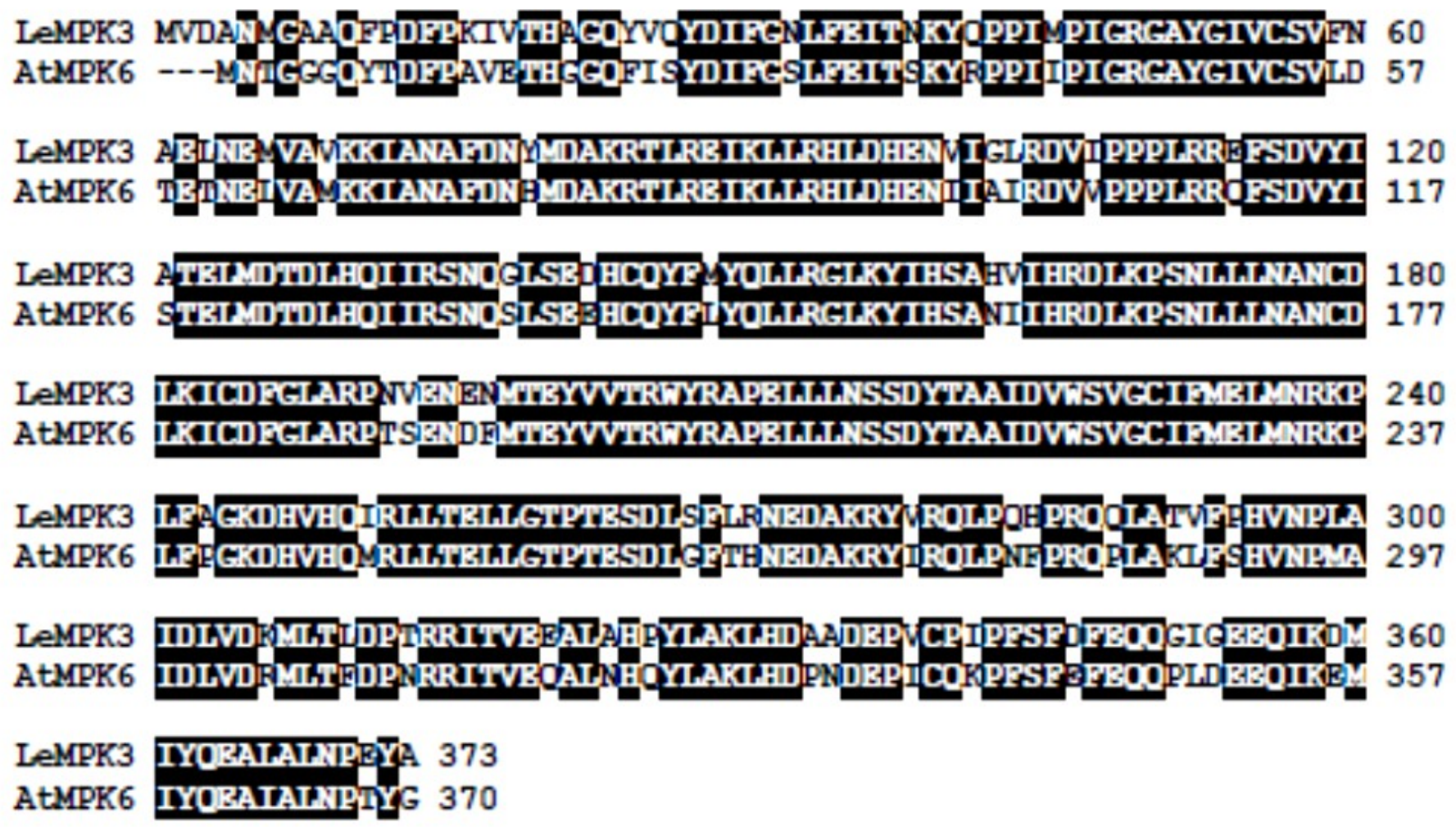

Figure 3.7: Amino acid sequence alignment of Solanum lycopersicum leMPK3 and Arabidopsis thaliana AtMPK6. Amino acids that are shaded in black are shared by at least two sequences.

To investigate possible functions of tomato LeMPK3, bioinformatic tools and resources were applied to the analysis of Arabidopsis two closest homologs in terms of co-expression, prediction of protein-protein interactions (PPI), and the mining of the expression profiles under different treatments. AtMPK3, AtMPK6 and AtNDPK were studied. The following approaches were taken. 


\subsubsection{Co-expression analysis tool}

The gene co-expression pattern was used to identify the expression level and the co-expressed genes, which might facilitate identifying the biological function of the genes.

\subsection{4. protein-protein interaction prediction tool}

STRING (http://string-db.org) database was applied to the prediction of proteinprotein interactions (PPI) and the identification of proteins that probably interact with the protein of interest.

Data mining with STRING is based on multiple themes. The prediction comes from previous knowledge (e.g. PubMed), transferring knowledge from other organisms, genomic context, high-throughput experiments, and conserved co-expression. The prediction uses information from 1133 organisms and covers 5,214,234 proteins. It claims to integrate interaction data quantitatively from these sources. Normally, we would expect that protein interaction is at the level of direct physical contact. However, STRING takes the view that proteins do not necessarily need to undergo a stable physical interaction to have a specific, functional interplay; they can catalyze subsequent reactions in a metabolic pathway, regulate each other transcriptionally or post-transcriptionally, or jointly contribute to larger, structural assemblies without ever making direct contact. Together with direct physical interactions, such indirect interactions constitute the larger superset of 'functional protein-protein associations' or 'functional protein linkages'. Thus, it is likely that the prediction is not only based on interactive domains but is also based at 'functional' levels. 


\subsubsection{Motif analysis tool}

The motif analysis using the ScanSite tool (http://scansite.mit.edu) assists the recognition of motifs in protein sequences, which may suggest possible functions and the regulatory mechanisms of the protein.

\subsubsection{The perturbation tool}

The perturbation tool in Genevestigator provides a summary of gene expression responses to a wide variety of perturbations, such as chemicals, pathogens, hormones, other stresses, and mutations. In this tool, the gene expression responses are calculated as $\log$ ratios between experimental and control samples, and the resulting values thus reflect up- or down-regulation of genes and are given as ratios (linear scale) or log ratios $\left(\log _{2}\right.$ scale).

In statistical significance testing, the p-value is the probability of obtaining a test statistic result at least as extreme as the one that was actually observed, assuming that the null hypothesis is true, and it is used in the context of null hypothesis testing in order to quantify the idea of statistical significance of evidence (http://en.wikipedia.org). In Genevestigator, $\mathrm{p}$-value is provided for the determination of significance of difference in gene expression levels. In the program, the p-value threshold is 0.05 .

\subsubsection{Anatomy and development tool}

The anatomy and development tool shows the expression profiles of the genes across different stages of development or in different tissues. 


\subsubsection{Analysis of AtMPK3 (AT3G45640)}

In Figure 3.8, the target gene was Arabidopsis AtMPK3, which was highly homologous to Solanum lycopersicum LeMPK3. According to the calculation of the Pearson's correlation coefficients for gene pairs, a total of 25 genes could co-expressed with AtMPK3. It is noticeable that NSL1(Necrotic Spotted Lesions1 AT1G28380), which is related to cell death, and leucine-rich repeat transmembrane protein kinase (AT2G31880), which is related to protein kinase family, are the most correlated genes to Arabidopsis AtMPK3 as they had higher correlation coefficients.

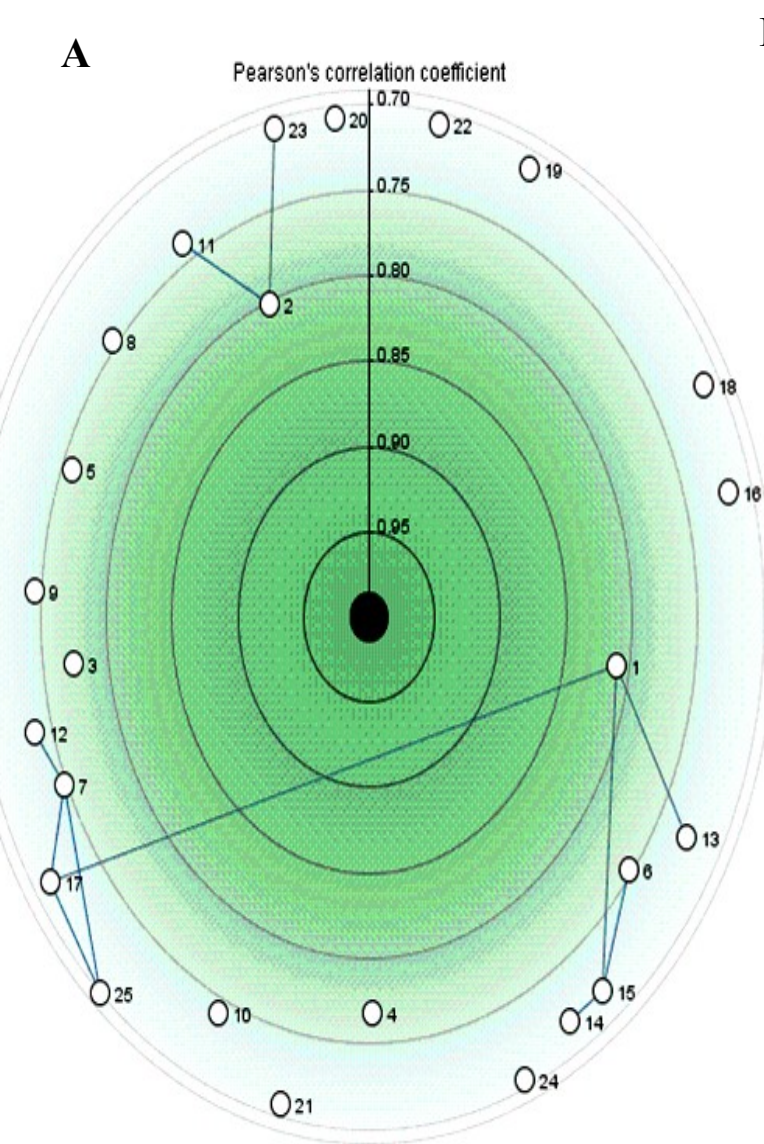

B

\begin{tabular}{|c|c|c|c|}
\hline & Gene & Score & Description \\
\hline O1 & AT1G28380 & 0.81 & NSL1 (NECROTIC SPOTTED LESIONS 1); similar t. \\
\hline $\mathrm{O}_{2}$ & AT2G31880 & 0.80 & leucine-rich repeat transmembrane protein kinase, .. \\
\hline $\mathrm{O}_{3}$ & AT2G41430 & 0.77 & Encodes hydrophilic protein lacking Cys residues t... \\
\hline $\mathrm{O}_{4}$ & AT4G12720 & 0.77 & Encodes a protein with ADP-ribose hydrolase activit. \\
\hline O5 & AT4G28400 & 0.76 & protein phosphatase $2 \mathrm{C}$, putative / PP $2 \mathrm{C}$, putative;... \\
\hline Ob & AT5G06320 & 0.75 & encodes a protein whose sequence is similar to to... \\
\hline $\mathrm{O}_{7}$ & AT5G42050 & 0.75 & similar to unknown protein [Arabidopsis thaliana] $(\mathrm{T}$. \\
\hline O8 & АТ 3 G11820 & 0.75 & Encodes plasma membrane syntaxin, which is a $\mathrm{m}$. \\
\hline Oو & AT3G56050 & 0.75 & protein kinase family protein; similar to protein kina... \\
\hline $\mathrm{O}_{10}$ & AT2G3044... & 0.74 & signal peptidase, putative; similar to chloroplast thy.. \\
\hline O11 & AT2G40270 & 0.74 & protein kinase family protein; similar to protein kina... \\
\hline & AT1G01550 & 0.74 & BYPASS1, required to prevent constitutive productio.. \\
\hline & AT5G 47220 & 0.73 & Encodes a member of the ERF (ethylene response \\
\hline 14 & AT1G16670 & 0.72 & protein kinase family protein; similar to protein kina... \\
\hline 10 & AT4G17230 & 0.72 & Encodes a scarecrow-like protein (SCL13). Membe.. \\
\hline & AT3G14090 & 0.72 & A member of EX070 gene family, putative exocyst s... \\
\hline 71 & AT1G07630 & 0.71 & Encodes a protein phosphatase $2 \mathrm{C}$ like gene, simi. \\
\hline 1 & AT3G12740 & 0.71 & LEM3 (ligand-effect modulator 3) family protein / CD. \\
\hline 18 & AT5G61210 & 0.71 & membrane localized t-SNARE SNAP25 homologue,.. \\
\hline 20 & AT4G08850 & 0.71 & leucine-rich repeat family protein / protein kinase fa... \\
\hline 121 & AT5G11670 & 0.71 & The malic enzyme (EC 1.1.1.40) encoded by AtNAD... \\
\hline 22 & AT4G38550 & 0.71 & similar to unknown protein [Arabidopsis thaliana] ( $\mathrm{T}$. \\
\hline 23 & AT5G02290 & 0.71 & Encodes a candidate protein kinase NAK that is si... \\
\hline & AT1G79380 & 0.71 & copine-related; similar to copine-related [Arabidops. \\
\hline 25 & AT4G2569... & 0.70 & similar to unknown protein [Arabidopsis thaliana] $(T$. \\
\hline
\end{tabular}

Figure 3.8: A. The co-expression analysis of AtMPK3 gene; B. Description of the most correlated genes to AtMPK3 (top 25). The image was generated using pre-existing transcriptome data obtained from Genevestigator database. 
AtMPK3 was analyzed using STRING. Figure 3.9 represents 10 potential AtMPK3-interactive proteins. Interactions may occur between AtMPK3 and transcription factors WRKY22, WRKY 33 and WRKY53. AtMPK3 are also predicted to interact with other proteins, such as NDPK (nucleoside diphosphate protein kinase), ATMPK1 (Arabidopsis thaliana MAPK1), PP2C5 (Arabidopsis thaliana phosphatase 2C5), MKP2 (Arabidopsis thaliana MAPK phosphatase 2), and MKK4 (Arabidopsis thaliana MAPKK4). Table 3.1 summarizes the prediction and the functions of co-occurred proteins.

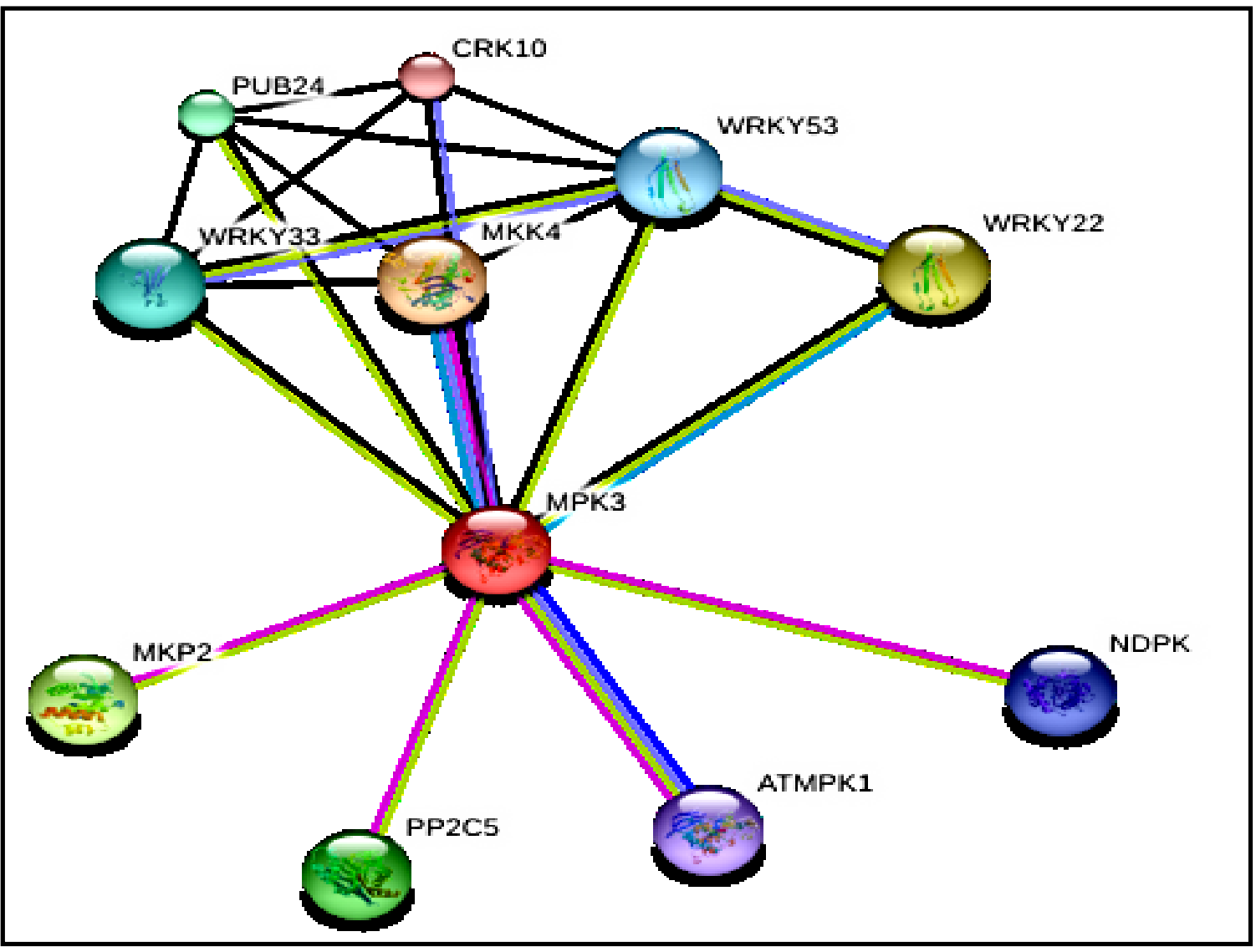

Figure 3.9: Proteins that are predicted to co-occur with AtMPK3. Purple lines indicate that the interactions are supported by experimental evidence. Data were obtained using STRING (http://string-db.org). 


\begin{tabular}{|c|c|c|c|c|}
\hline \multicolumn{2}{|r|}{ Protein ID } & Manner of Prediction & Main Function & References \\
\hline ATMKK4 & $\begin{array}{l}\text { Arabidopsis thaliana } \\
\text { Mitogen-Activated } \\
\text { Protein Kinase } \\
\text { Kinase } 4\end{array}$ & $\begin{array}{l}\text { Co-expression/ } \\
\text { Experiments/ } \\
\text { Databases/ } \\
\text { Homology }\end{array}$ & $\begin{array}{l}\text { Involved in innate } \\
\text { immunity }\end{array}$ & $\begin{array}{l}\text { (Braun et al., } \\
\text { 2011) }\end{array}$ \\
\hline WRKY22 & $\begin{array}{l}\text { Member of the plant } \\
\text { WRKY Transcription } \\
\text { Factor Group }\end{array}$ & $\begin{array}{l}\text { Co-expression/ } \\
\text { Databases / } \\
\text { Text mining }\end{array}$ & $\begin{array}{l}\text { Involved in the } \\
\text { expression of defense } \\
\text { genes in innate immune } \\
\text { response of plants }\end{array}$ & $\begin{array}{l}\text { (Asai et al., } \\
\text { 2002) }\end{array}$ \\
\hline MKP2 & $\begin{array}{l}\text { Mitogen-Activated } \\
\text { Protein Kinase } \\
\text { Phosphatase } 2\end{array}$ & $\begin{array}{l}\text { Experiments/ } \\
\text { Text mining }\end{array}$ & $\begin{array}{l}\text { Encodes a nuclear- } \\
\text { localized MAP kinase } \\
\text { phosphatase }\end{array}$ & $\begin{array}{l}\text { (Lumbreras et al., } \\
\text { 2010) }\end{array}$ \\
\hline PP2C5 & $\begin{array}{l}\text { Arabidopsis thaliana } \\
\text { Phosphatase } 2 \mathrm{C} 5\end{array}$ & $\begin{array}{l}\text { Experiments/ } \\
\text { Text mining }\end{array}$ & $\begin{array}{l}\text { Involved in protein } \\
\text { amino acid } \\
\text { dephosphorylation }\end{array}$ & $\begin{array}{l}\text { (Brock et al., } \\
\text { 2010) }\end{array}$ \\
\hline PUB24 & Plant U-Box 24 & $\begin{array}{l}\text { Co-expression/ } \\
\text { Text mining }\end{array}$ & $\begin{array}{l}\text { Functions as an E3 } \\
\text { ubiquitin ligase }\end{array}$ & $\begin{array}{l}\text { (Jensen et al., } \\
\text { 2009) }\end{array}$ \\
\hline WRKY33 & $\begin{array}{l}\text { Member of the plant } \\
\text { WRKY Transcription } \\
\text { Factor Group }\end{array}$ & $\begin{array}{l}\text { Co-expression/ } \\
\text { Text mining }\end{array}$ & $\begin{array}{l}\text { Involved in response to } \\
\text { various abiotic stresses }\end{array}$ & $\begin{array}{l}\text { (Mao et al., } \\
\text { 2011) }\end{array}$ \\
\hline WRKY53 & $\begin{array}{l}\text { Member of the plant } \\
\text { WRKY Transcription } \\
\text { Factor Group }\end{array}$ & $\begin{array}{l}\text { Co-expression/ } \\
\text { Text mining }\end{array}$ & $\begin{array}{l}\text { Regulates the early } \\
\text { events of leaf } \\
\text { senescence }\end{array}$ & $\begin{array}{l}\text { (Jensen } \text { et al., } \\
\text { 2009) }\end{array}$ \\
\hline NDPK & $\begin{array}{l}\text { Nucleoside } \\
\text { Diphosphate Protein } \\
\text { Kinase } 2\end{array}$ & $\begin{array}{l}\text { Experiments / } \\
\text { Text mining }\end{array}$ & $\begin{array}{l}\text { Involved in } \\
\text { phytochrome-mediated } \\
\text { light signaling }\end{array}$ & $\begin{array}{l}\text { (Moon et al., } \\
\text { 2003) }\end{array}$ \\
\hline ATMPK1 & $\begin{array}{l}\text { Arabidopsis thaliana } \\
\text { Mitogen-Activated } \\
\text { Protein Kinase1 }\end{array}$ & $\begin{array}{l}\text { Co-occurance/ } \\
\text { Experiments / } \\
\text { Text mining/ } \\
\text { Homology }\end{array}$ & Encodes ATMPK1 & $\begin{array}{l}\text { (Ulm et al., } \\
\text { 2002) }\end{array}$ \\
\hline CRK10 & $\begin{array}{l}\text { Arabidopsis thaliana } \\
\text { Cysteine -Rich Rlk10 }\end{array}$ & $\begin{array}{l}\text { Co-expression/ } \\
\text { Homology }\end{array}$ & $\begin{array}{l}\text { Encodes a receptor-like } \\
\text { protein kinase }\end{array}$ & $\begin{array}{l}\text { (Jensen et al., } \\
\text { 2009) }\end{array}$ \\
\hline
\end{tabular}

Table 3.1: Summary of prediction and function of proteins that co-occur with AtMPK3. 
Using the ScanSite tool (http://scansite.mit.edu), motif analysis of Arabidopsis AtMPK3 has indicated the presence of six possible protein phosphorylation sites (at T87, T180, T679, T795, T852, and T953) (Figure 3.10). The Baso_ST_kin is a basophilic serine/threonine kinase group, and the Acid_ST_kin is an acidophilic serine/threonine kinase group.

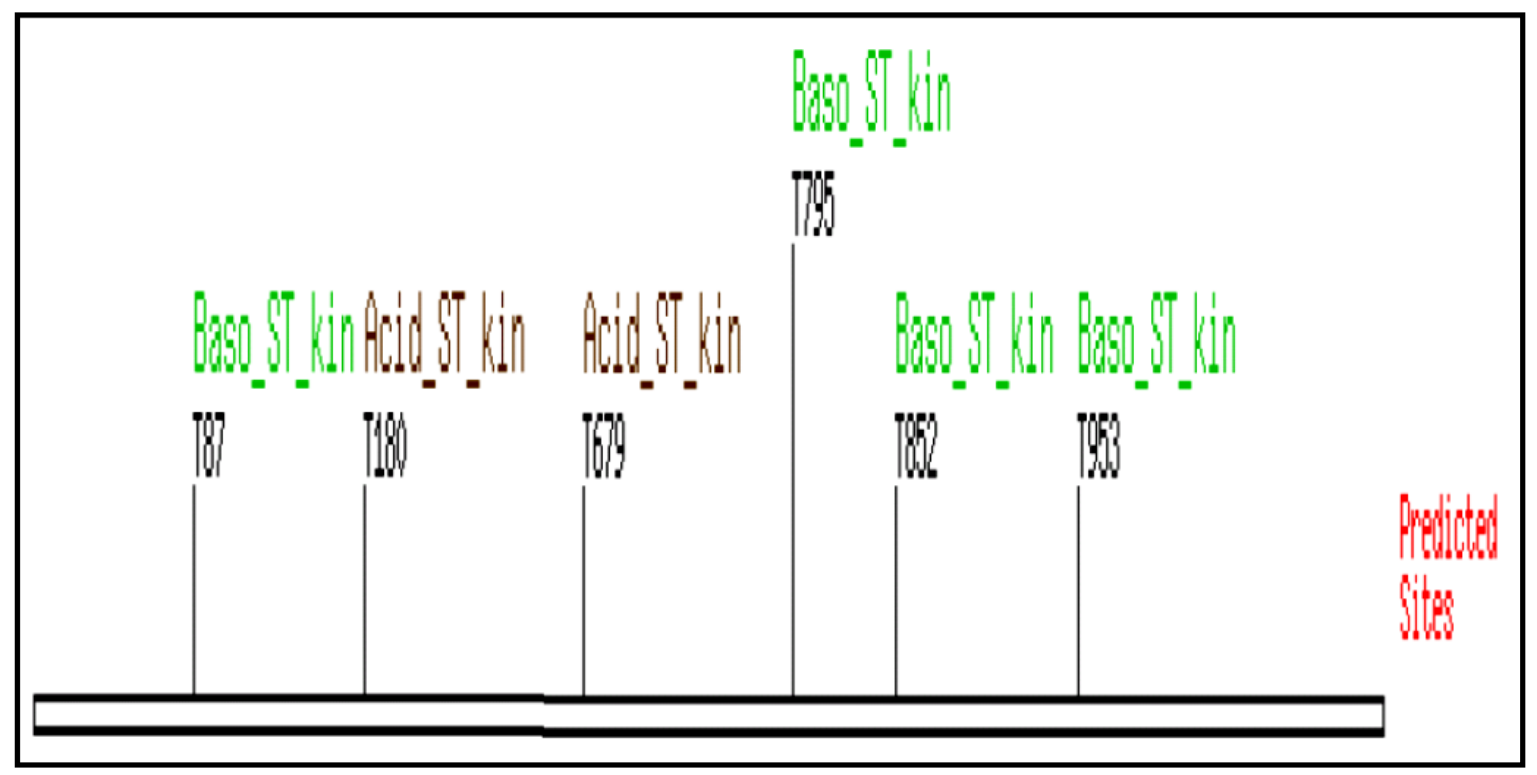

Figure 3.10: High stringency ScanSite Motif Scan output for AtMPK3 protein sequence indicating multiple protein phosphorylation sites. (See Appendix 1 for database analysis).

Microarray data mining was performed using the Genevestigator database to study the responses of $A t M P K 3$ to various treatments or expression patterns in different developmental stages or in different tissues. Figure 3.11 indicates that FB1/MetOH did not enhance AtMPK3 expression in Arabidopsis root culture. SA was tested in several different experiments. SA treatment of Arabidopsis thaliana leaves caused an upregulation of AtMPK3 expression (Figure 3.12). 


\section{Fumonisin Bl/MetOH treated root culture sample(4h)}

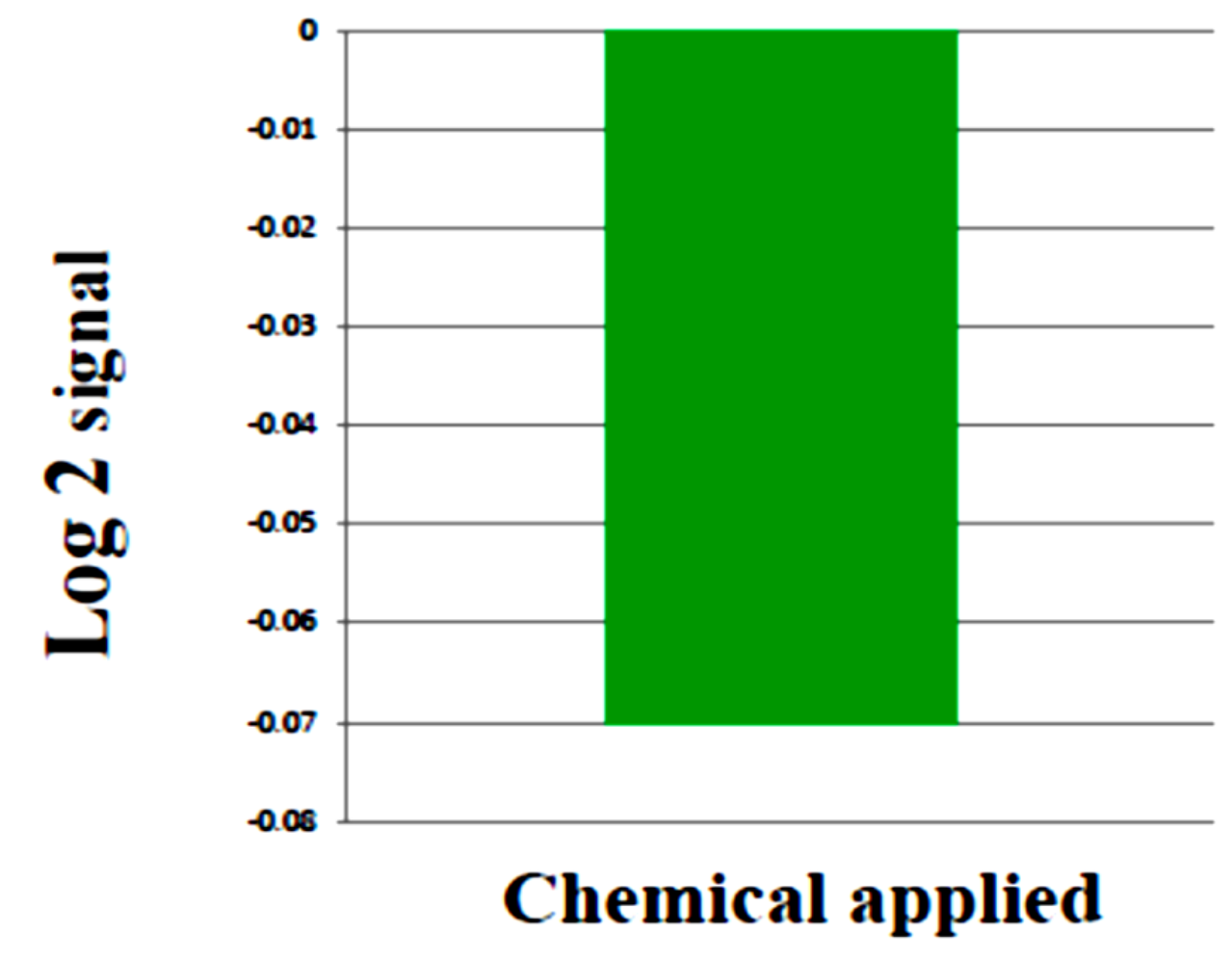

Figure 3.11: Effect of FB1/MetOH on AtMPK3 expression in Arabidopsis thaliana root culture. The graph was generated using pre-existing transcriptome data obtained from Genevestigator database. 


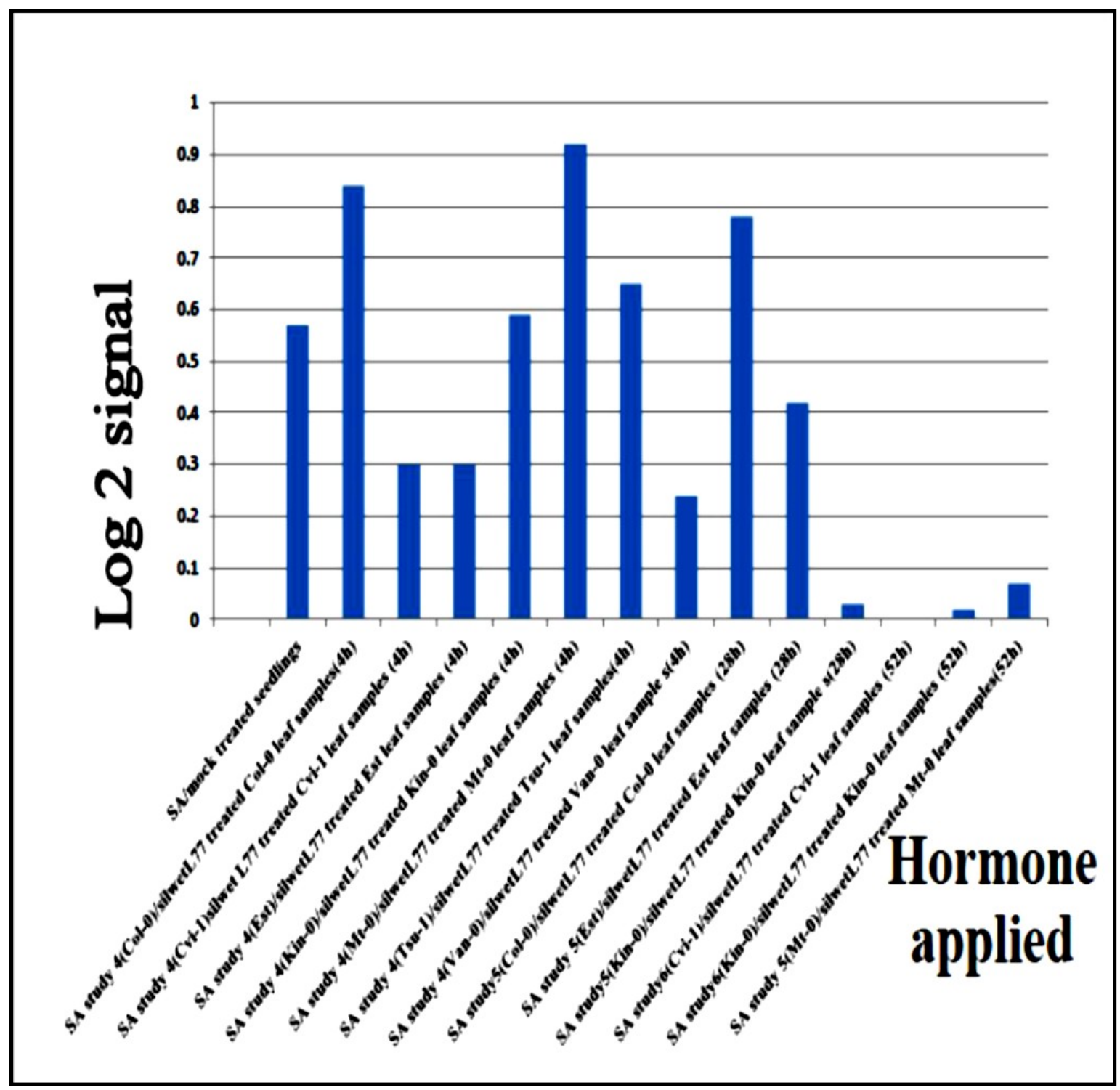

Figure 3.12: Effect of SA on AtMPK3 expression in Arabidopsis thaliana leaves. The graph was generated using pre-existing transcriptome data obtained from Genevestigator database. 
AtMPK3 expression levels in rosette leaves and in different developmental stages were examined using the anatomy and development tools in Genevestigator. Development and anatomy data have indicated that the expression level of AtMPK3 in Arabidopsis thaliana leaves does not change significantly through developmental stages or in different tissues, such as petiole, juvenile leaf, adult leaf, senescent leaf, axillary bud, and cauline leaf (Figures 3.13 and 3.14).

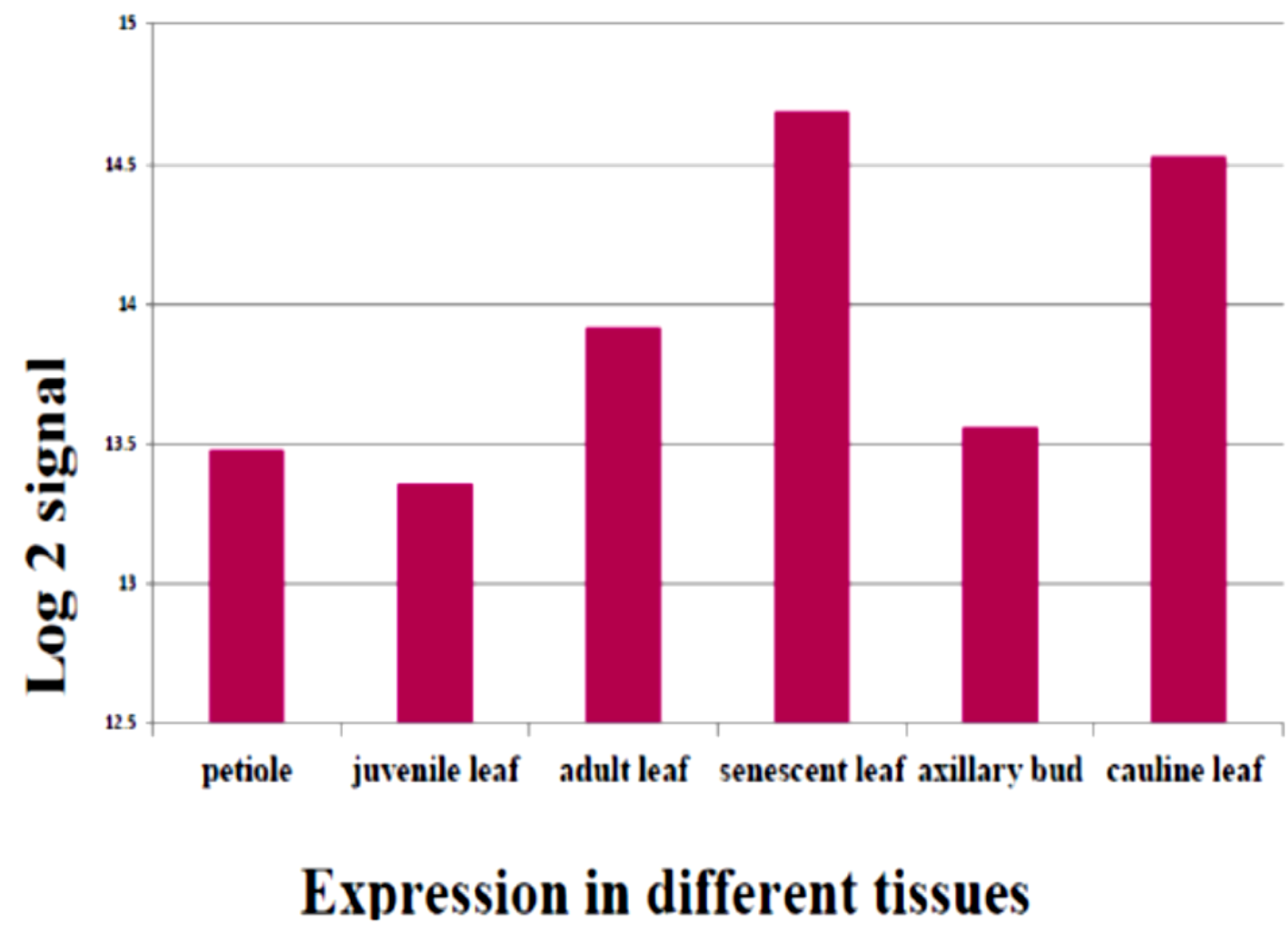

Figure 3.13: Expression levels of AtMPK3 in rosette leaves of Arabidopsis thaliana at different stages of their development. Genevestigator database was used to generate the chart based on pre-existing microarray data. 


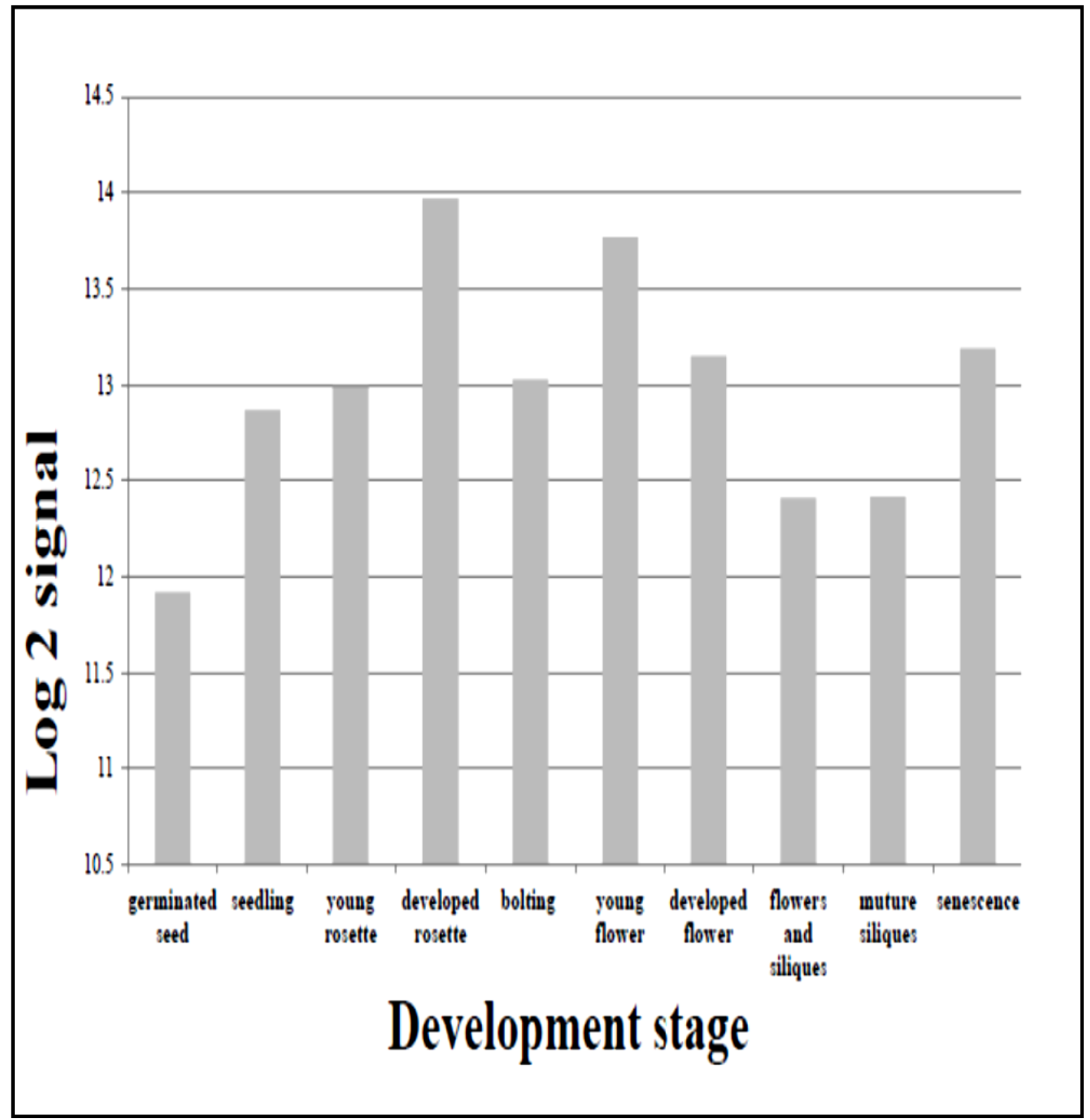

Figure 3.14: Overall expression of AtMPK3 across different stages of development. Genevestigator database was used to generate the graph based on pre-existing microarray data. 


\subsubsection{Analysis of AtMPK6 (NM 129941)}

There are a total of 25 genes that could co-express with AtMPK6 based on the Pearson's correlation coefficient calculation of gene pairs. AT4G31080 (protein of unknown function DUF2296) and AT3G07890 (Ypt/Rap-GAP domain of gyp1p super family protein, which is involved in the regulation of Rab GTPase activity) are the most correlated genes to AtMPK6 ( Figure 3.15).

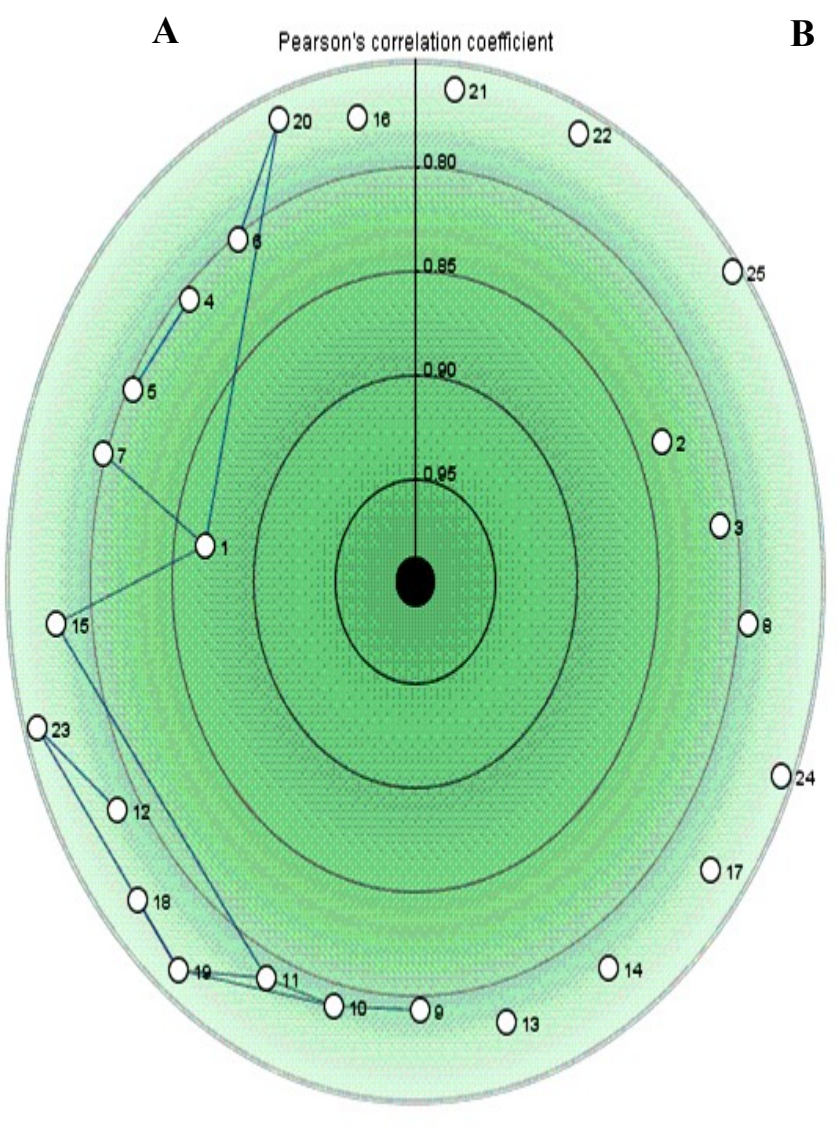

Description of the most correlated genes (top 25)

\begin{tabular}{|c|c|c|}
\hline Gene & Score & Description \\
\hline AT4G31080 & 0.87 & Protein of unknown function (DUF2296) \\
\hline AT3G07890 & 0.83 & YptRab-GAP domain of gyp1p superfamily protein \\
\hline AT2G42520 & 0.81 & P-loop containing nucleoside triphosphate hydrola... \\
\hline AT5G53310 & 0.81 & myosin heavy chain-related \\
\hline AT5G27840 & 0.80 & Calcineurin-like metallo-phosphoesterase superfa... \\
\hline AT5G22000 & 0.80 & RING-H2 group $F 2 A$ \\
\hline AT3G2871... & 0.80 & [AT3G28715, ATPase, V0/AO complex, subunit C/D];... \\
\hline AT5G60170 & 0.79 & RNA binding (RRM/RBD/RNP motifs) family protein \\
\hline AT2G47960 & 0.79 & unknown protein; CONTAINS InterPro DOMAIN/s: Pr... \\
\hline AT1G79090 & 0.79 & FUNCTIONS IN: molecular_function unknown; INV... \\
\hline AT1G75660 & 0.79 & $5: 3$ ' exoribonuclease 3 \\
\hline AT5G19400 & 0.79 & Telomerase activating protein Est1 \\
\hline AT2G4250... & 0.78 & [AT2G42500, protein phosphatase 2A-3];:[AT3G585... \\
\hline AT4G04910 & 0.78 & AAA-type ATPase family protein \\
\hline AT5G22030 & 0.78 & ubiquitin-specific protease 8 \\
\hline AT5G61960 & 0.77 & MEI2-like protein 1 \\
\hline AT2G23310 & 0.77 & Rer1 family protein \\
\hline AT5G60410 & 0.77 & DNA-binding protein with MIZ/SP-RING zinc finger, ... \\
\hline AT1G33980 & 0.76 & Smg-4/UPF3 family protein \\
\hline AT2G02970 & 0.76 & GDA1/CD39 nucleoside phosphatase family protein \\
\hline AT1G55520 & 0.76 & TATA binding protein 2 \\
\hline AT1G51350 & 0.76 & ARM repeat superfamily protein \\
\hline AT3G4806... & 0.76 & [AT3G48060, BAH domain ;TFIIS helical bundle-like... \\
\hline AT1G79830 & 0.76 & golgin candidate 5 \\
\hline $25 \quad$ AT1G73670 & 0.75 & MAP kinase 15 \\
\hline
\end{tabular}

Figure 3.15: A. The co-expression analysis of AtMPK6 gene; B. Description of the most correlated genes to AtMPK6 (top 25). The image was generated using pre-existing transcriptome data obtained from Genevestigator database. 
Using the STRING tool, proteins that are predicted to co-express with AtMPK6 were examined. About 10 proteins are shown to potentially interact with AtMPK6. As in the case of AtMPK3, AtMPK6 may also interact with WRKY22, NDPK, AtMPK1, PP2C5, MKP2 and MKK4. Table 3.2 summarizes the prediction and function of cooccurred proteins with AtMPK6.

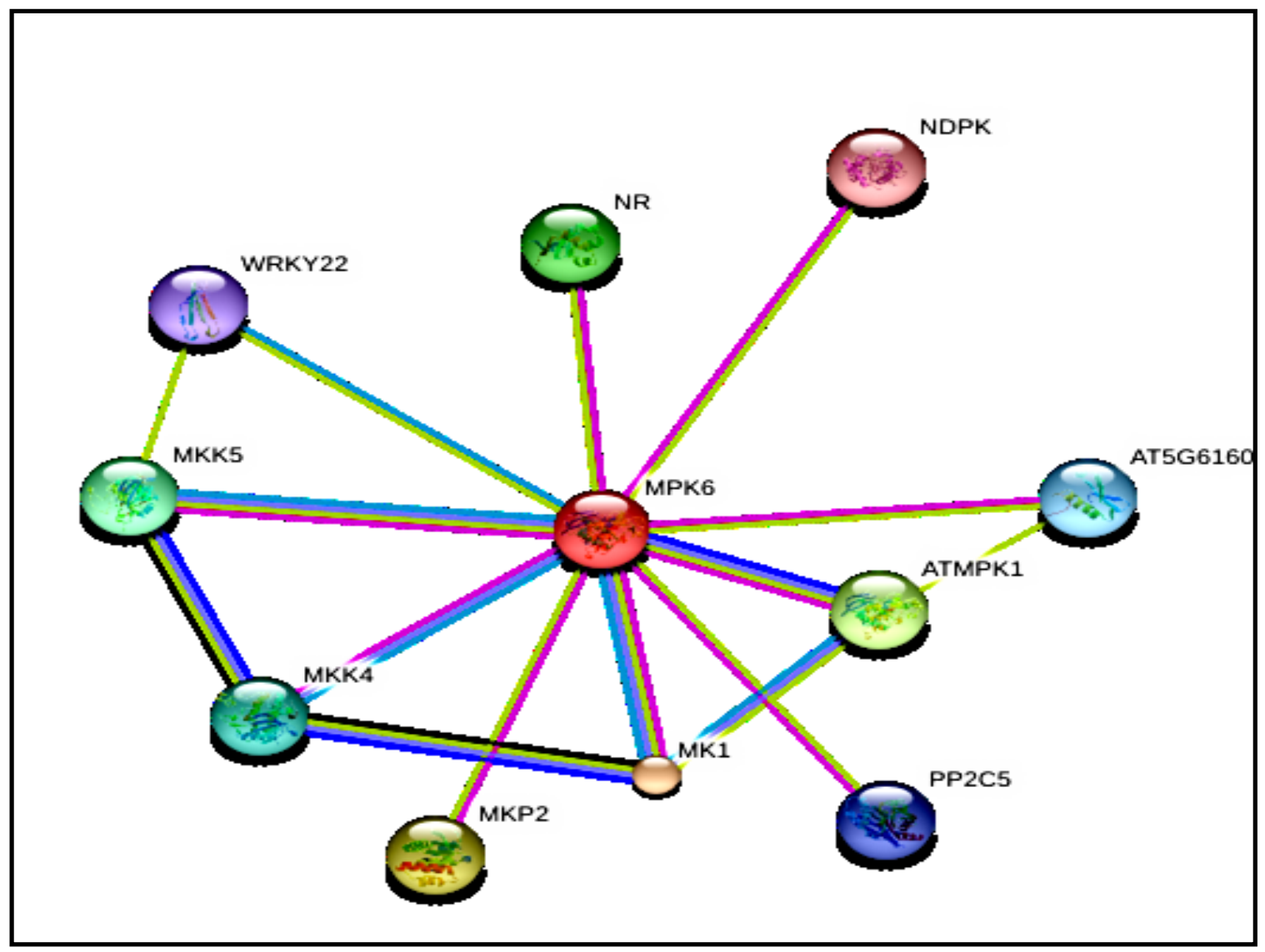

Figure 3.16: Proteins that are predicted to co-occur with AtMPK6. Purple lines indicate that the interactions are supported by experiment evidence. Data were obtained using STRING (http://string-db.org). 


\begin{tabular}{|c|c|c|c|c|}
\hline \multicolumn{2}{|r|}{ Protein ID } & \multirow{2}{*}{$\begin{array}{l}\begin{array}{l}\text { Manner of } \\
\text { Prediction }\end{array} \\
\text { Experiments/ } \\
\text { Databases / } \\
\text { Text mining/ } \\
\text { Homology }\end{array}$} & \multirow{2}{*}{\begin{tabular}{l}
\multicolumn{1}{c}{ Main Function } \\
Involved in the cold and \\
salinity stress-mediated \\
MAP kinase signaling \\
cascade
\end{tabular}} & \multirow{2}{*}{$\begin{array}{l}\text { References } \\
\text { (Braun et al., } \\
\text { 2011) }\end{array}$} \\
\hline MK1 & $\begin{array}{l}\text { ATMKK2 Arabidopsis } \\
\text { thaliana MAP Kinase } \\
\text { Kinase } 2\end{array}$ & & & \\
\hline MKP2 & MAPK Phosphatase 2 & $\begin{array}{l}\text { Experiments/ } \\
\text { Text mining }\end{array}$ & $\begin{array}{l}\text { Encodes a nuclear- } \\
\text { localized MAP kinase } \\
\text { phosphatise }\end{array}$ & $\begin{array}{l}\text { (Lumbreras et al., } \\
\text { 2010) }\end{array}$ \\
\hline ATMPK1 & $\begin{array}{l}\text { Arabidopsis thaliana } \\
\text { Mitogen-Activated } \\
\text { Protein Kinase } 1\end{array}$ & $\begin{array}{l}\text { Co-curance/ } \\
\text { Experiments/ } \\
\text { Text mining/ } \\
\text { Homology }\end{array}$ & Encodes AtMPK1 & $\begin{array}{l}\text { (Ulm et al., } \\
\text { 2002) }\end{array}$ \\
\hline NR & $\begin{array}{l}\text { NIA2 (Nitrate } \\
\text { Reductase2) }\end{array}$ & $\begin{array}{l}\text { Experiments/ } \\
\text { Text mining }\end{array}$ & $\begin{array}{l}\text { Involved in nitrate } \\
\text { assimilation }\end{array}$ & $\begin{array}{l}\text { (Wang et al., } \\
\text { 2010a) }\end{array}$ \\
\hline ATMKK5 & $\begin{array}{l}\text { Arabidopsis thaliana } \\
\text { Mitogen-Activated } \\
\text { Protein Kinase } \\
\text { Kinase } 5\end{array}$ & $\begin{array}{l}\text { Co-expression/ } \\
\text { Experiments/ } \\
\text { Databases/ } \\
\text { Text mining/ } \\
\text { Homology }\end{array}$ & $\begin{array}{l}\text { Involved in innate } \\
\text { immunity }\end{array}$ & $\begin{array}{l}\text { (Jensen et al., } \\
2009 \text { ) }\end{array}$ \\
\hline ATMKK4 & $\begin{array}{l}\text { Arabidopsis thaliana } \\
\text { Mitogen-Activated } \\
\text { Protein Kinase } \\
\text { Kinase } 4 \\
\end{array}$ & $\begin{array}{l}\text { Experiments/ } \\
\text { Databases/ } \\
\text { Homology }\end{array}$ & $\begin{array}{l}\text { Involved in innate } \\
\text { immunity }\end{array}$ & $\begin{array}{l}\text { (Braun et al., } \\
\text { 2011) }\end{array}$ \\
\hline AT5G61600 & $\begin{array}{l}\text { Arabidopsis thaliana } \\
5 \mathrm{G} 61600\end{array}$ & $\begin{array}{l}\text { Experiments/ } \\
\text { Text mining }\end{array}$ & $\begin{array}{l}\text { Acts as a transcriptional } \\
\text { activator }\end{array}$ & $\begin{array}{l}\text { (Bethke et al., } \\
\text { 2009) }\end{array}$ \\
\hline PP2C5 & $\begin{array}{l}\text { Arabidopsis thaliana } \\
\text { phosphatase } 2 \mathrm{C} 5\end{array}$ & $\begin{array}{l}\text { Experiments/ } \\
\text { Text mining }\end{array}$ & $\begin{array}{l}\text { Involved in protein } \\
\text { amino acid } \\
\text { dephosphorylation }\end{array}$ & $\begin{array}{l}\text { (Brock et al., } \\
\text { 2010) }\end{array}$ \\
\hline WRKY22 & $\begin{array}{l}\text { Member of the plant } \\
\text { WRKY ranscription } \\
\text { Factor Group }\end{array}$ & $\begin{array}{l}\text { Databases/ } \\
\text { Text mining }\end{array}$ & $\begin{array}{l}\text { Involved in the } \\
\text { expression of defense } \\
\text { genes in innate immune } \\
\text { response of plants }\end{array}$ & $\begin{array}{l}\text { (Asai et al., } \\
\text { 2002) }\end{array}$ \\
\hline NDPK & $\begin{array}{l}\text { Nucleoside } \\
\text { Diphosphate Kinase } 2\end{array}$ & $\begin{array}{l}\text { Experiments/ } \\
\text { Text mining }\end{array}$ & $\begin{array}{l}\text { Involved in } \\
\text { phytochrome-mediated } \\
\text { light signaling }\end{array}$ & $\begin{array}{l}\text { (Moon et al., } \\
\text { 2003) }\end{array}$ \\
\hline
\end{tabular}

Table 3.2: Summary of prediction and function of proteins that co-occur with AtMPK6. 
Using the ScanSite tool, motif analysis of Arabidopsis AtMPK6 has indicated the presence of two possible protein phosphorylation sites (at S215 and T338) as well as a potential Src homology3 (SH3) domain-binding site (at P303). The Baso_ST_kin is a basophilic serine/threonine kinase group.
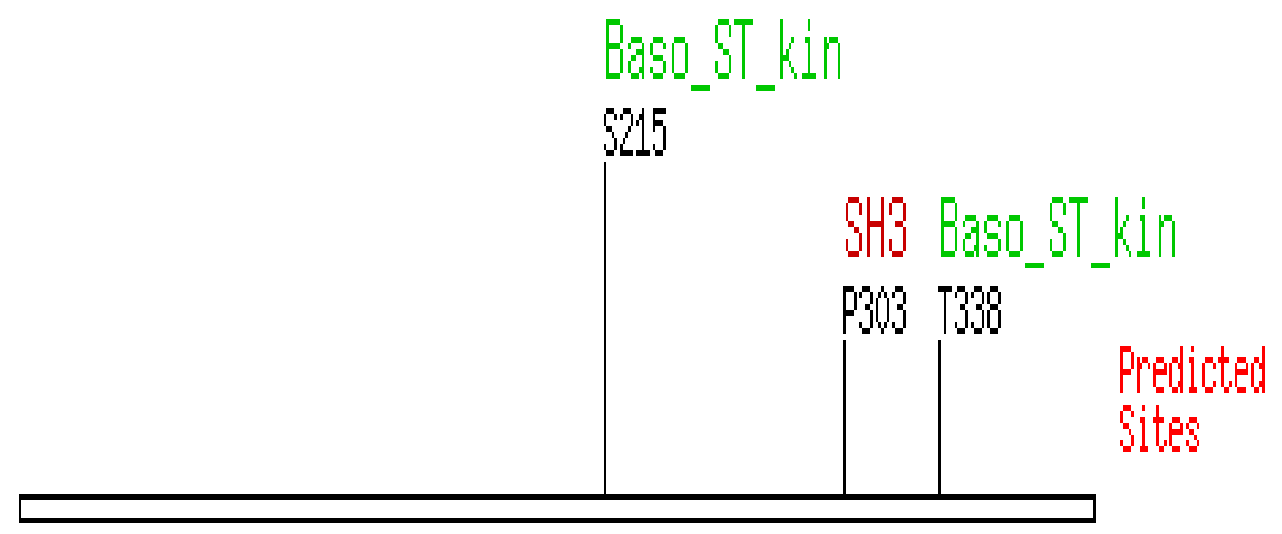

Figure 3.17: High stringency ScanSite Motif Scan output for AtMPK6 protein sequence indicating potential protein phosphorylation sites and a SH3 binding site. (See Appendix 2 for database analysis).

Similar to AtMPK3, microarray data mining was done using Genevestigator database to study the responses of AtMPK6 to various treatments and expression patterns in different developmental stages or in different tissues. Figure 3.18 indicates that FB1/MetOH enhanced modestly AtMPK6 expression in Arabidopsis protoplast. Figure 3.19 presents AtMPK6 gene expression response to SA. SA effect was also examined in several different experiments. 


\section{Fumonisin B1/MetOH treated protoplast samples}

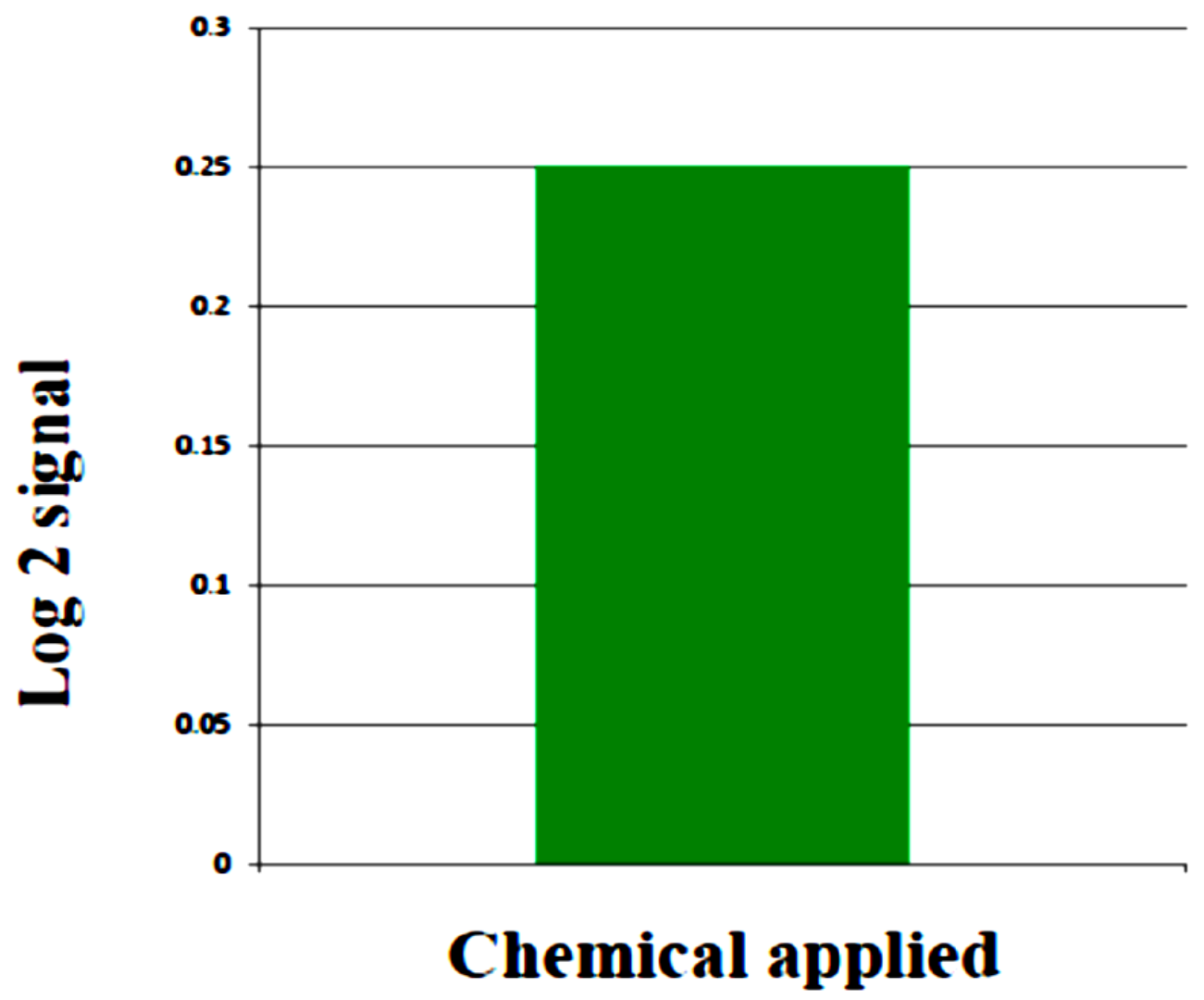

Figure 3.18: Effect of FB1/MetOH on AtMPK6 expression in Arabidopsis thaliana protoplast. The graph was generated using pre-existing transcriptome data obtained from Genevestigator database. 


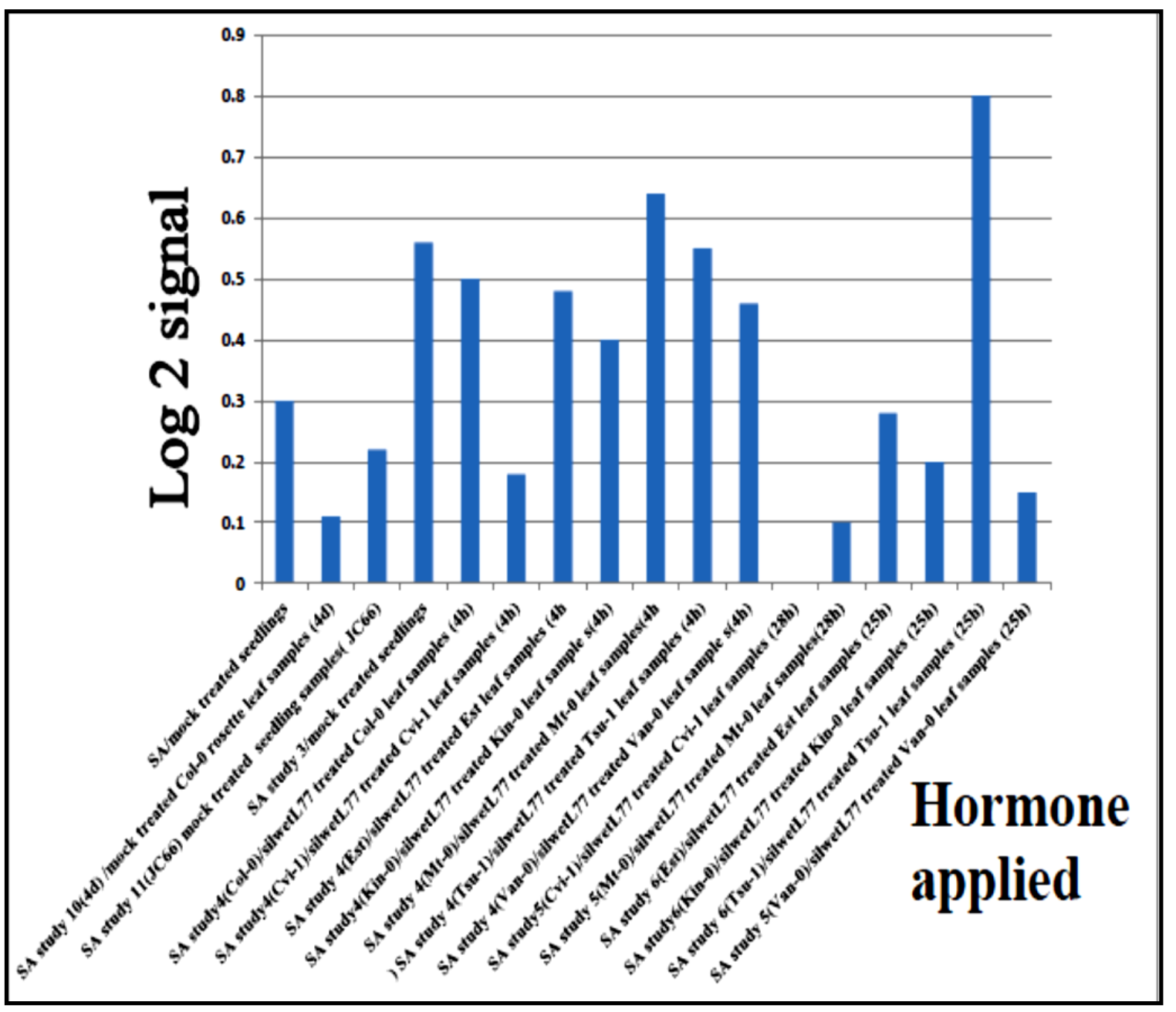

Figure 3.19: Effect of SA on AtMPK6 expression in Arabidopsis thaliana leaves. The figure was generated using pre-existing transcriptome data obtained from Genevestigator database. 
AtMPK6 expression levels in rosette leaves of Arabidopsis thaliana in different tissues were examined using the anatomy tool in Genevestigator, whereas overall expression of AtMPK6 was obtained using the development tool in Genevestigator. AtMPK6 expression level does not change significantly throughout developmental stages or in different tissues such as petiole, juvenile leaf, adult leaf, senescent leaf, axillary bud, and cauline leaf (Figures 3.20 and 3.21).

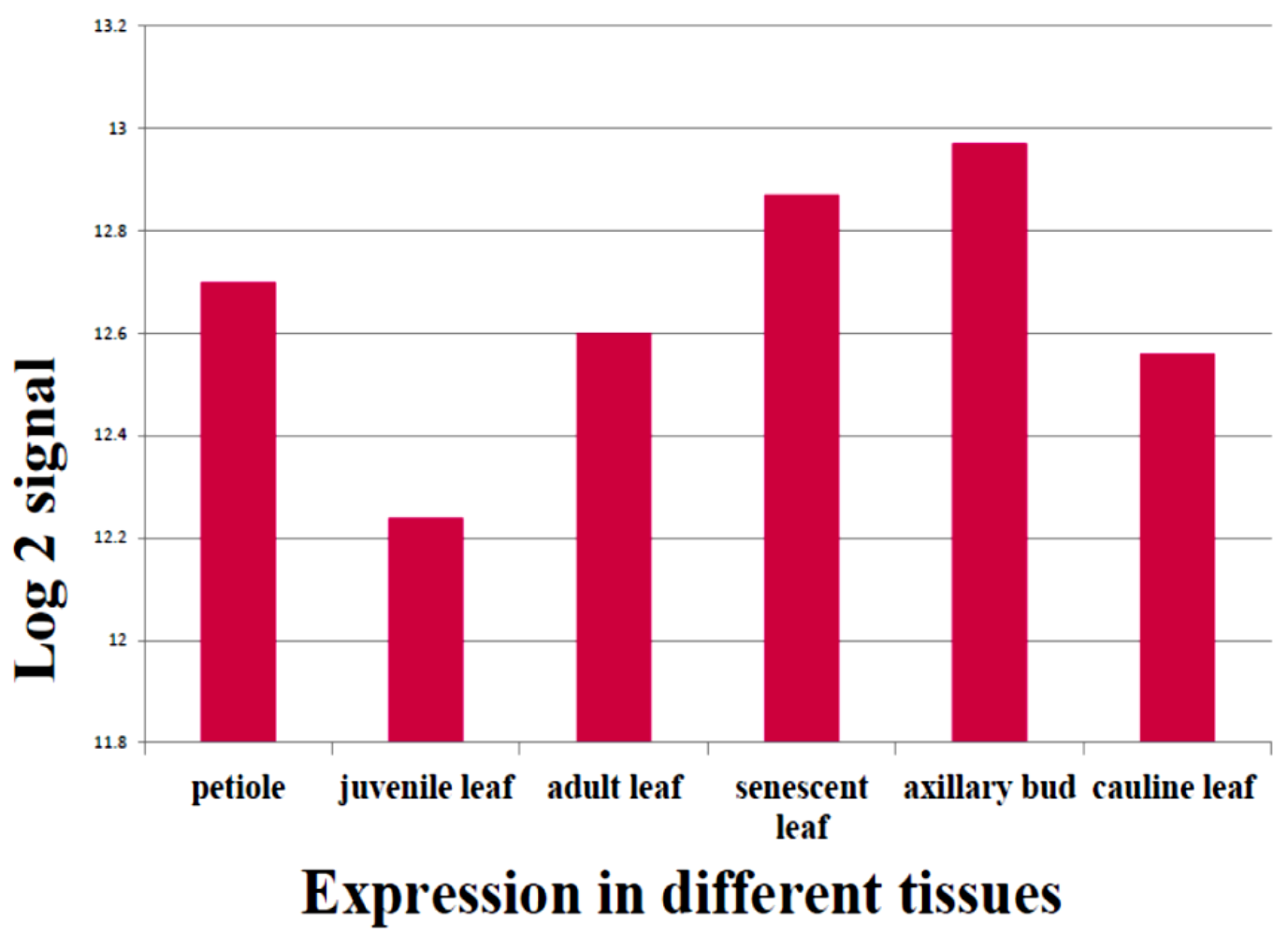

Figure 3.20: Expression levels of AtMPK6 in rosette leaves of Arabidopsis thaliana at different stages of their development. Genevestigator database was used to generate the graph based on pre-existing microarray data. 


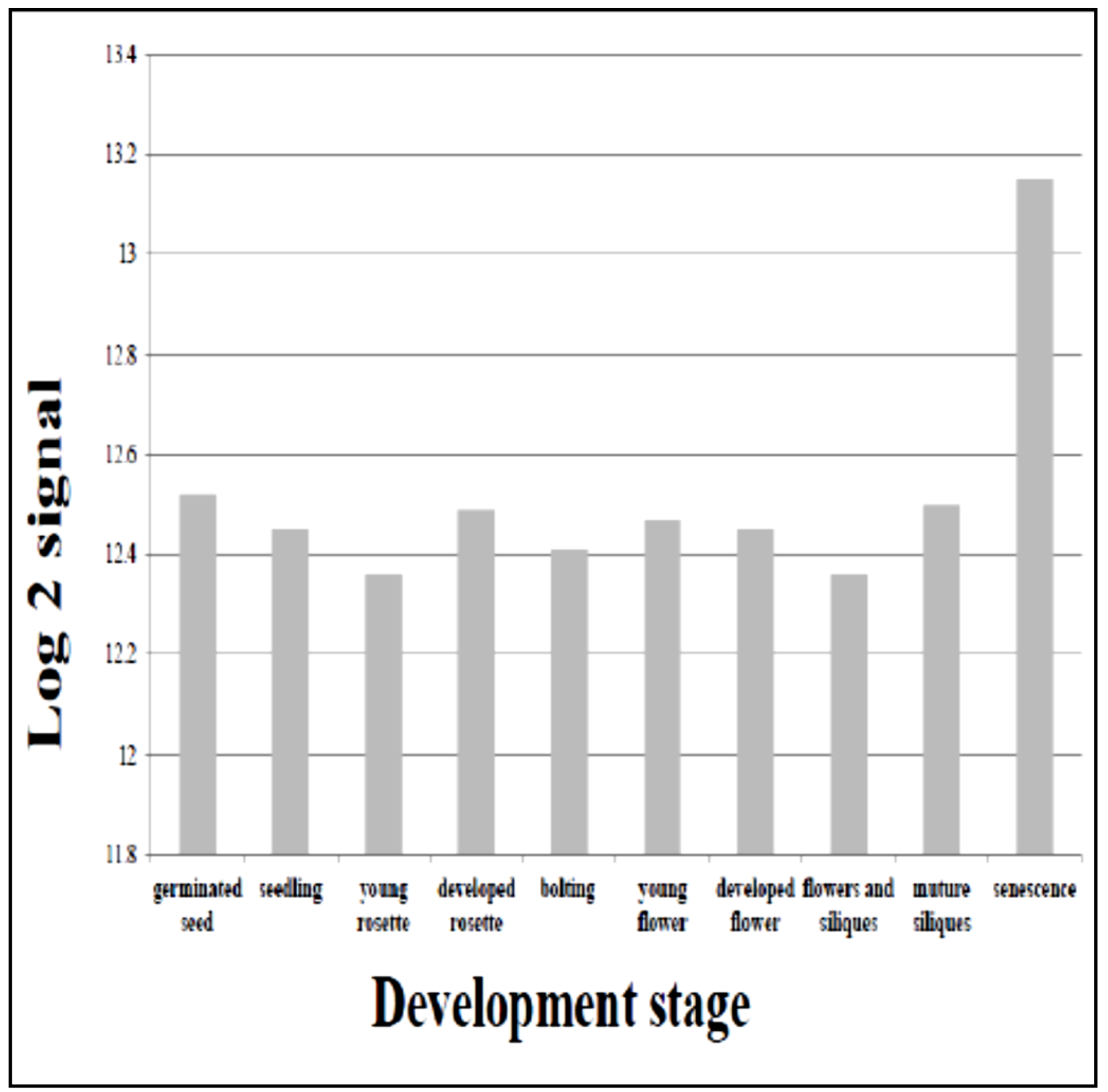

Figure 3.21: Overall expression of AtMPK6 across different stages of development. Genevestigator database was used to generate the graph based on pre-existing microarray data. 


\subsubsection{Analysis of $A t N D P K(A t 5 g 63310)$}

Pearson correlation was used to determine the correlation in gene expression patterns in multiple pathways. Figure 3.22 presents the top 25 genes that tend to be always highly reverse correlated with the expression of AtNDPK gene. The negative value indicates that these 25 genes in the table have a very remote relation (if any) with AtNDPK.

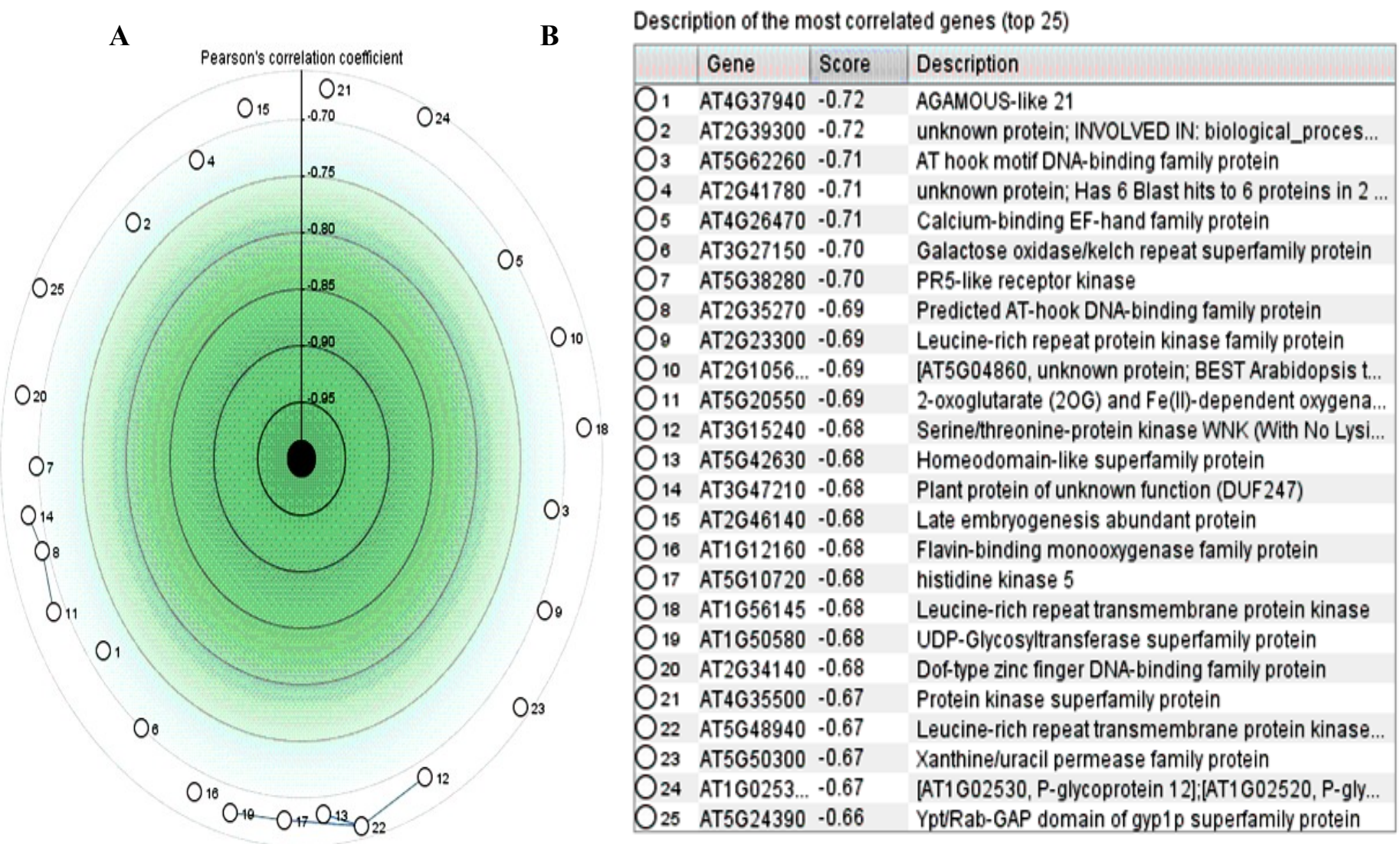

Figure 3.22: A. The co-expression analysis of $A t N D P K$ gene; B. Description of the most correlated genes to $A t N D P K$ (top 25). The image was generated using pre-existing transcriptome data obtained from Genevestigator database. 
Using the STRING tool, proteins that are predicted to be co-expressed with AtNDPK were examined. AtNDPK was also confirmed to interact with both Arabidopsis thaliana AtMAPK3 and AtMPK6 by experimental evidence. Table 3.3 summarizes the prediction and function of co-occurred proteins with AtNDPK.

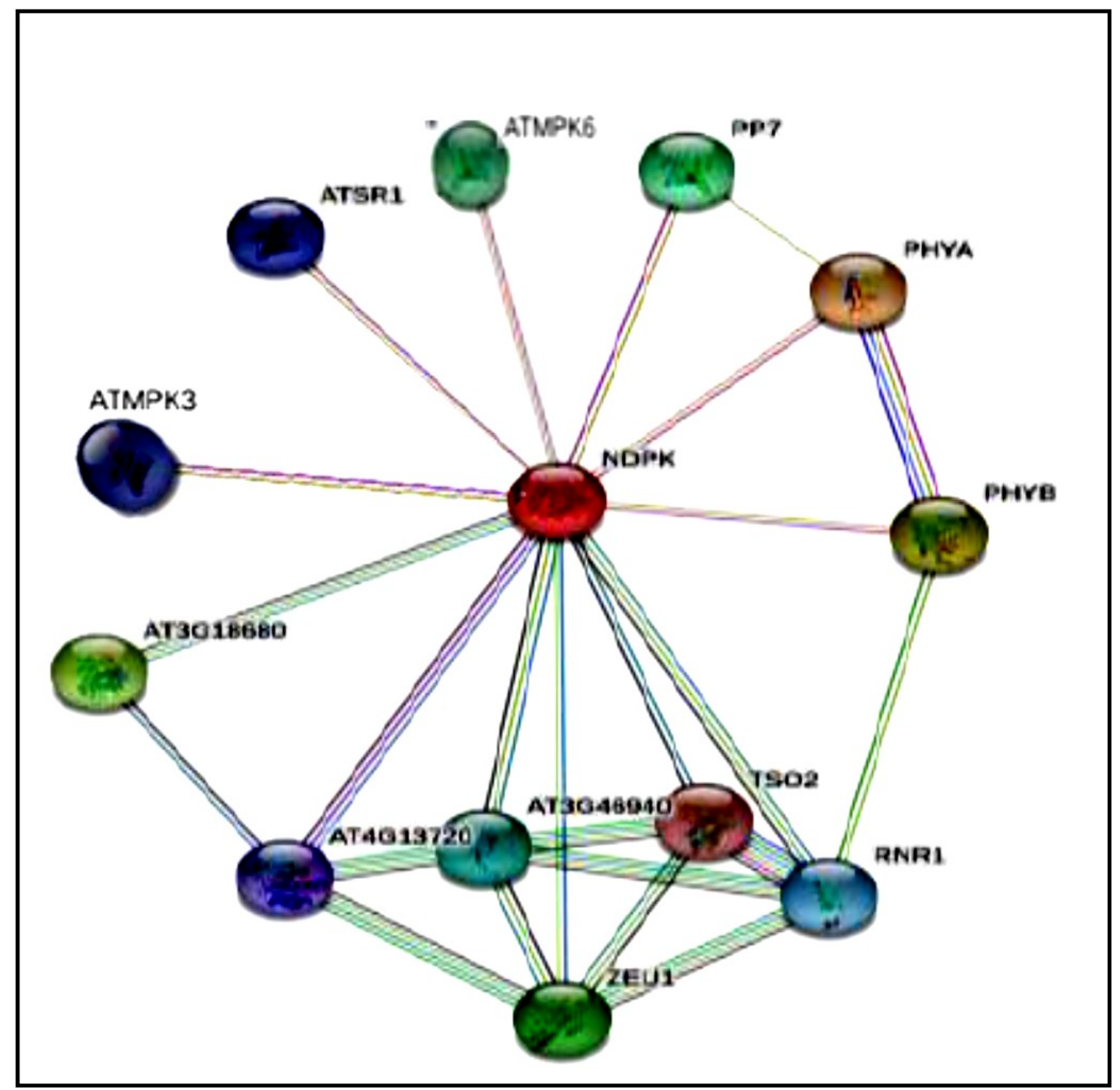

Figure 3.23: Proteins that are predicted to co-occur with AtNDPK. Purple lines indicate that the interactions are supported by experimental evidence. Data were obtained using STRING (http://string-db.org). 


\begin{tabular}{|c|c|c|c|c|}
\hline \multicolumn{2}{|c|}{ Protein ID } & \multirow{2}{*}{$\begin{array}{l}\begin{array}{l}\text { Manner of } \\
\text { Prediction }\end{array} \\
\text { Experiments/ } \\
\text { Text mining }\end{array}$} & \multirow{2}{*}{\begin{tabular}{l}
\multicolumn{1}{|c}{ Main Function } \\
$\begin{array}{l}\text { Involved in the regulation of } \\
\text { photomorphogenesis }\end{array}$
\end{tabular}} & \multirow{2}{*}{$\begin{array}{l}\text { References } \\
\text { (Im et al., } \\
2004)\end{array}$} \\
\hline PHYA & Phtytochrome A & & & \\
\hline PHYB & Phytochrome B & $\begin{array}{l}\text { Experiments/ } \\
\text { Text mining }\end{array}$ & $\begin{array}{l}\text { Involved in the light-promotion } \\
\text { of seed germination and in the } \\
\text { shade avoidance response }\end{array}$ & $\begin{array}{l}\text { (Shen et al., } \\
\text { 2005) }\end{array}$ \\
\hline At3G18680 & $\begin{array}{l}\text { Arabidopsis thaliana } \\
\text { 3G18680 }\end{array}$ & $\begin{array}{l}\text { Co-expression/ } \\
\text { Databases/ } \\
\text { Text mining }\end{array}$ & $\begin{array}{l}\text { Involved in amino acid } \\
\text { biosynthetic process }\end{array}$ & $\begin{array}{l}\text { (Jensen et al., } \\
\text { 2009) }\end{array}$ \\
\hline ZEU1 & $\begin{array}{l}\text { Arabidopsis thaliana } \\
\text { ZEU1 }\end{array}$ & $\begin{array}{l}\text { Databases/ } \\
\text { Text mining }\end{array}$ & $\begin{array}{l}\text { Required for localization to the } \\
\text { mitochondrion }\end{array}$ & $\begin{array}{l}\text { (Jensen et al., } \\
2009)\end{array}$ \\
\hline PP7 & $\begin{array}{l}\text { Serine/Threonine } \\
\text { Phosphatase } 7\end{array}$ & $\begin{array}{l}\text { Experiments/ } \\
\text { Text mining }\end{array}$ & $\begin{array}{l}\text { Act as a positive regulator of } \\
\text { cryptochrome signaling involved } \\
\text { in hypocotyl growth inhibition } \\
\text { and cotyledon expansion under } \\
\text { white and blue light conditions }\end{array}$ & $\begin{array}{l}\text { (Genoud et al., } \\
2008 \text { ) }\end{array}$ \\
\hline AT3G46940 & $\begin{array}{l}\text { Arabidopsis thaliana } \\
\text { AT3G46940 }\end{array}$ & $\begin{array}{l}\text { Databases/ } \\
\text { Text mining/ } \\
\text { Co-occurance }\end{array}$ & $\begin{array}{l}\text { Involved in 2'-oxyribonucleotide } \\
\text { metabolic process }\end{array}$ & $\begin{array}{l}\text { (Jensen et al., } \\
\text { 2009) }\end{array}$ \\
\hline RNR1 & $\begin{array}{l}\text { Ribonucleotide } \\
\text { Reductase } 1\end{array}$ & $\begin{array}{l}\text { Databases/ } \\
\text { Text mining/ } \\
\text { Co-occurance }\end{array}$ & $\begin{array}{l}\text { Involved in the production of } \\
\text { deoxyribonucleoside } \\
\text { triphosphates (dNTPs) for DNA } \\
\text { replication and repair }\end{array}$ & $\begin{array}{l}\text { (Braun et al., } \\
\text { 2011) }\end{array}$ \\
\hline ATSR1 & $\begin{array}{l}\text { Arabidopsis thaliana } \\
\text { Serine/Threonine } \\
\text { Protein Kinase } 1\end{array}$ & $\begin{array}{l}\text { Experiments/ } \\
\text { Text mining }\end{array}$ & $\begin{array}{l}\text { Regulated NAF domain of CIPK } \\
\text { protein }\end{array}$ & $\begin{array}{l}\text { (Jensen et al., } \\
\text { 2009) }\end{array}$ \\
\hline AT4G13720 & $\begin{array}{l}\text { Arabidopsis thaliana } \\
\text { AT4G13720 }\end{array}$ & $\begin{array}{l}\text { Experiments/ } \\
\text { Co-occurance/ } \\
\text { Databases }\end{array}$ & Involved in biological process & $\begin{array}{l}\text { (Jensen et al., } \\
\text { 2009) }\end{array}$ \\
\hline TSO2 & $\begin{array}{l}\text { Arabidopsis thaliana } \\
\mathrm{TSO} 2\end{array}$ & $\begin{array}{l}\text { Co-expression/ } \\
\text { Databases }\end{array}$ & $\begin{array}{l}\text { Critical for cell cycle } \\
\text { progression, DNA damage repair } \\
\text { and plant development }\end{array}$ & $\begin{array}{l}\text { (Jensen et al., } \\
2009)\end{array}$ \\
\hline
\end{tabular}




\begin{tabular}{|l|l|l|l|l|}
\hline ATMPK3 & $\begin{array}{l}\text { Arabidopsis thaliana } \\
\text { Mitogen-Activated } \\
\text { Protein Kinase3 }\end{array}$ & $\begin{array}{l}\text { Experiments/ } \\
\text { Text mining }\end{array}$ & $\begin{array}{l}\text { Involved in oxidative stress- } \\
\text { mediated signaling cascade to } \\
\text { oxidative (such as ozone). } \\
\text { Involved in the innate immune } \\
\text { MAP kinase signaling }\end{array}$ & $\begin{array}{l}\text { (Moon et al., } \\
\text { 2003) }\end{array}$ \\
\hline ATMPK6 & $\begin{array}{l}\text { Arabidopsis thaliana } \\
\text { Mitogen-Activated } \\
\text { Protein kinase6 }\end{array}$ & $\begin{array}{l}\text { Experiments/ } \\
\text { Text mining }\end{array}$ & $\begin{array}{l}\text { Involved in oxidative stress- } \\
\text { mediated signaling cascade } \\
\text { (such as ozone). Involved in the } \\
\text { innate immune MAP kinase } \\
\text { signaling cascade (MEKK1, } \\
\text { MKK4/MKK5 and MPK3/ } \\
\text { MPK6). May be involved in } \\
\text { hypersensitive response (HR)- } \\
\text { mediated signaling }\end{array}$ & (Moon et al ., \\
\hline
\end{tabular}

Table 3.3: Summary of prediction and function of proteins that co-occur with AtNDPK.

Using the ScanSite tool, motif analysis of Arabidopsis AtNDPK has indicated the presence of a potential protein phosphorylation site (at S65). A possible SH2 binding site (at Y87) was predicted too, which may suggest the possible interaction of AtNDPK with other proteins (Figure 3.24).
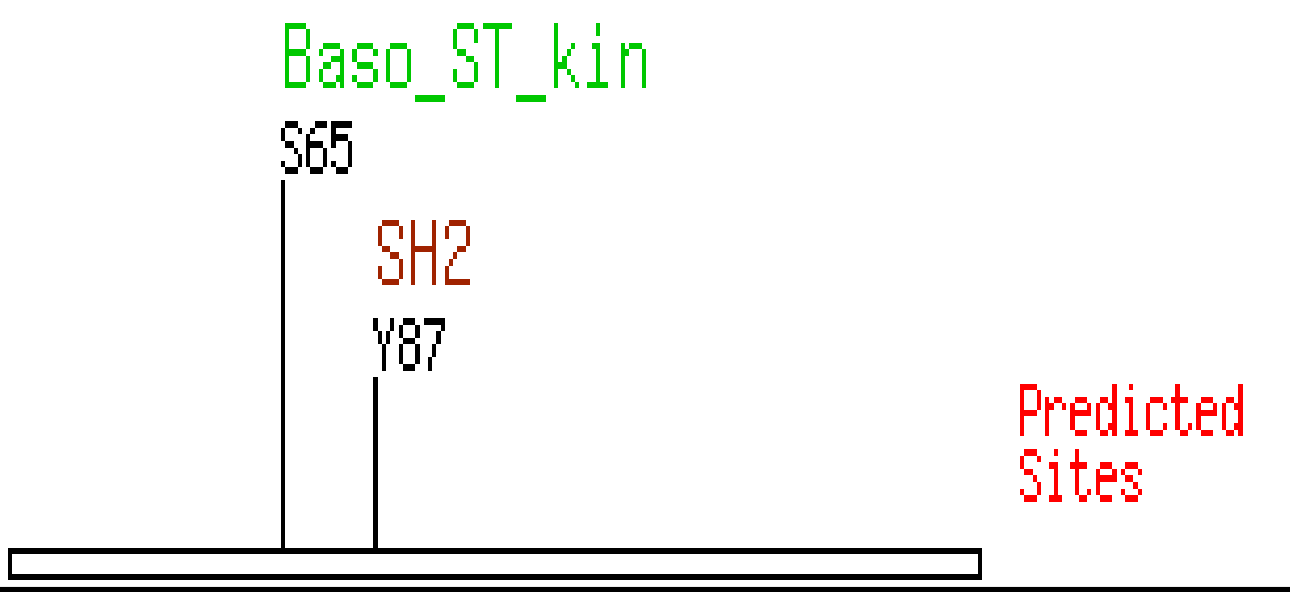

Figure 3.24: High stringency ScanSite Motif Scan output for AtNDPK protein sequence.

(See Appendix 3 for database analysis). 
Through the Genevestigator database, transcriptome data mining was also utilised to study the responses of $A t N D P K$ to FB1 and SA. Figure 3.25 indicates that FB1/MetOH increased AtNDPK expression in Arabidopsis protoplast. Figure 3.26 illustrates AtNDPK gene expression response to SA. It appears that SA treatment of Arabidopsis thaliana leaves resulted in an up-regulation in $A t N D P K$ expression.

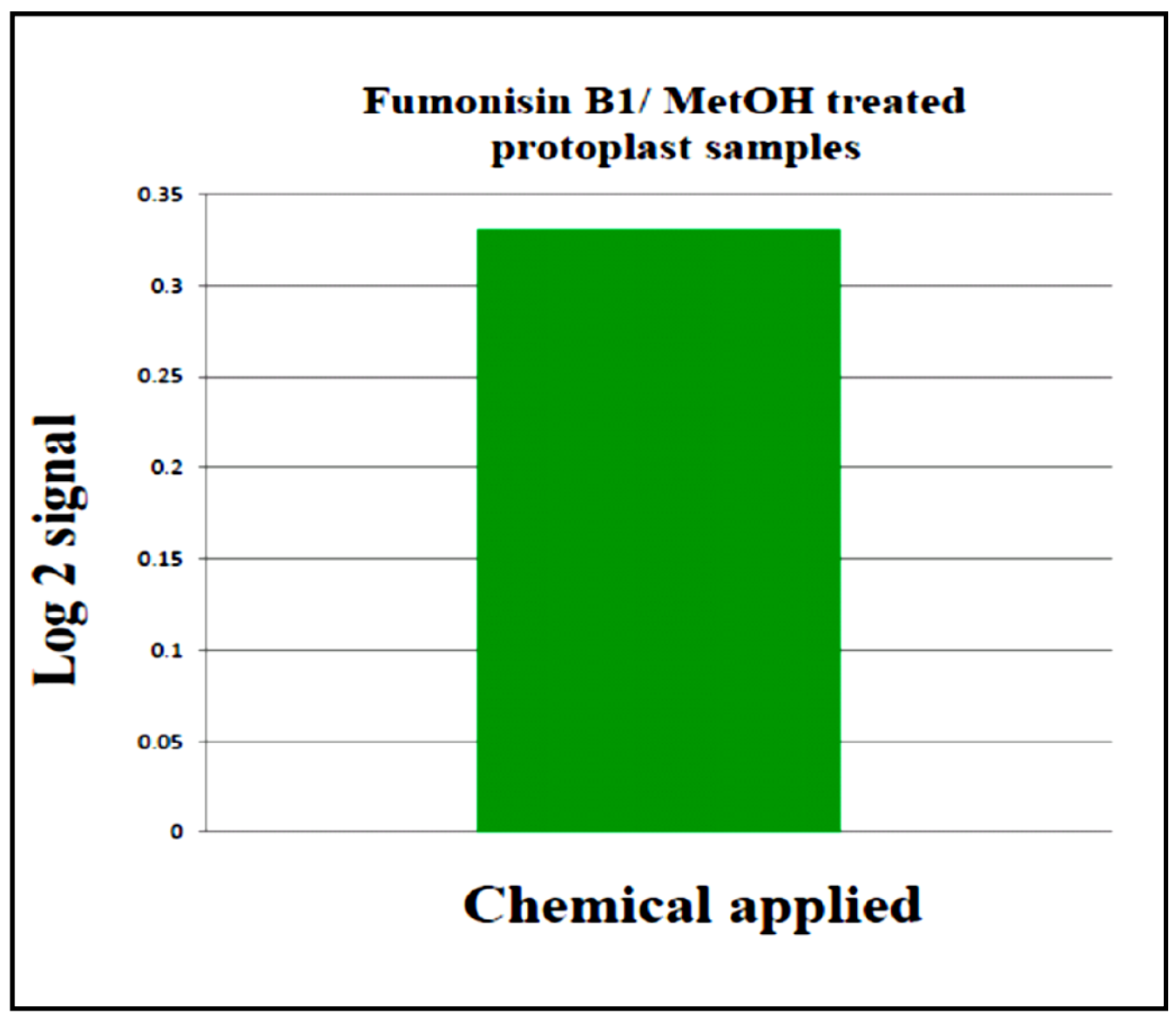

Figure 3.25: Effect of FB1/MetOH on AtNDPK expression in Arabidopsis thaliana protoplast samples. Genevestigator database was used to generate the figure based on a single pre-existing microarray data set. 


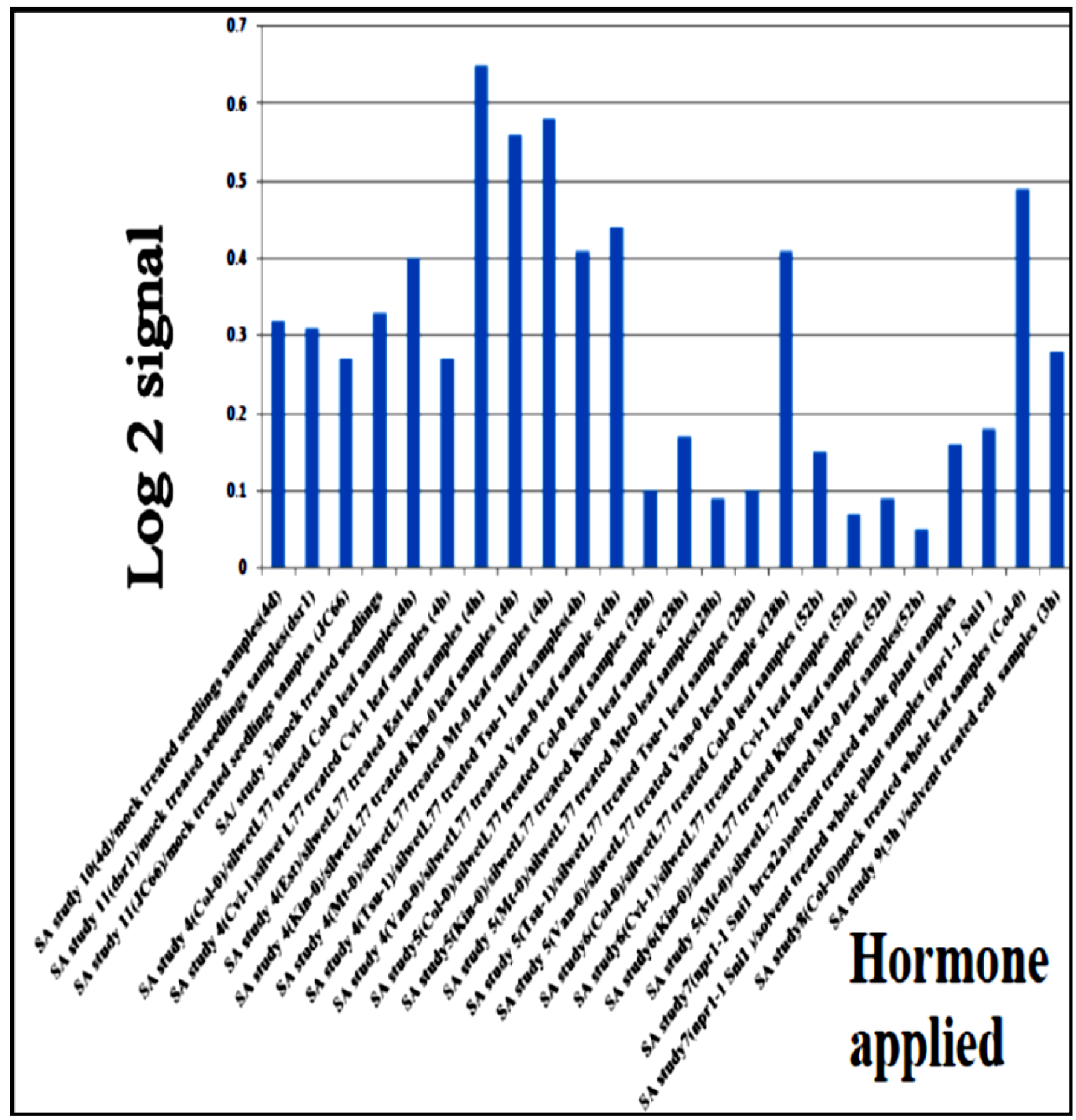

Figure 3.26: Effect of SA on AtNDPK expression in Arabidopsis thaliana leaves.

Genevestigator database was used to generate the chart based on pre-existing microarray data. 
Anatomy in Genevestigator was used to examine AtNDPK expression levels in Arabidopsis leaves or in different tissues, while overall expression pattern of AtNDPK throughout development was obtained using the development tool in Genevestigator. It appears that there is no significant difference in $A t N D P K$ expression levels in leaves of different development stages. The overall expression levels in different plant developmental stages do not vary significantly (Figures 3.27 and 3.28).

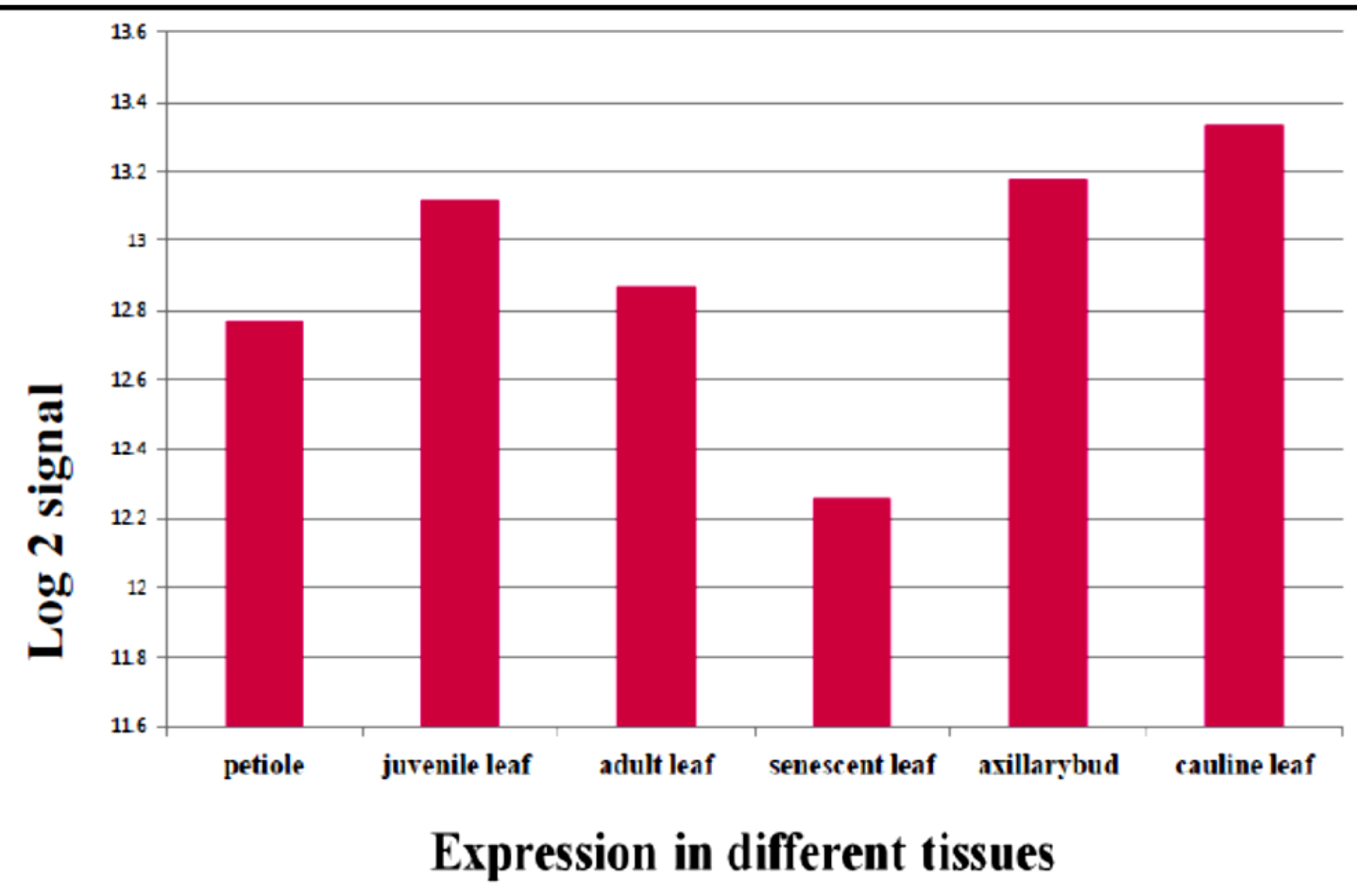

Figure 3.27: Expression levels of AtNDPK in rosette leaves of Arabidopsis thaliana at different stages of their development. Genevestigator database was used to generate the graph based on pre-existing microarray data. 


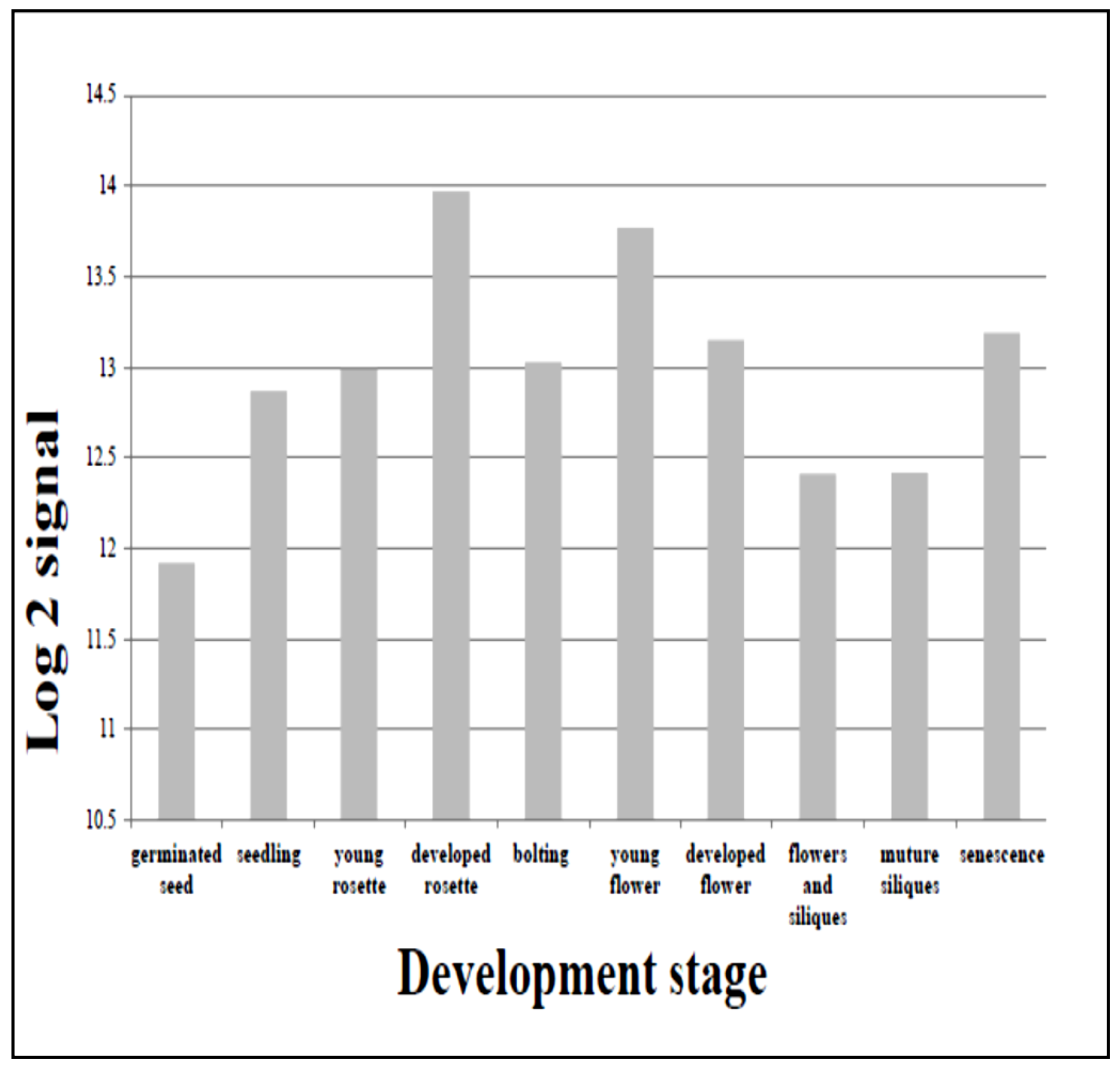

Figure 3.28: Overall expression level of $A t N D P K$ across different stages of development.

Genevestigator database was used to generate the graph based on pre-existing microarray data. 


\subsubsection{Motif analysis of Solanum lycopersicum LeMPK3}

LeMPK3 cDNA is 1122 base pairs in length and therefore makes 373 amino acids. Figure 3.29 shows the alignment of LeMPK3 of Solanum lycopersicum, Arabidopsis thaliana MPK1 and human ERK kinase MPK1 at the amino acid level, and it indicates that they all have a TEY phosphorylation motif.

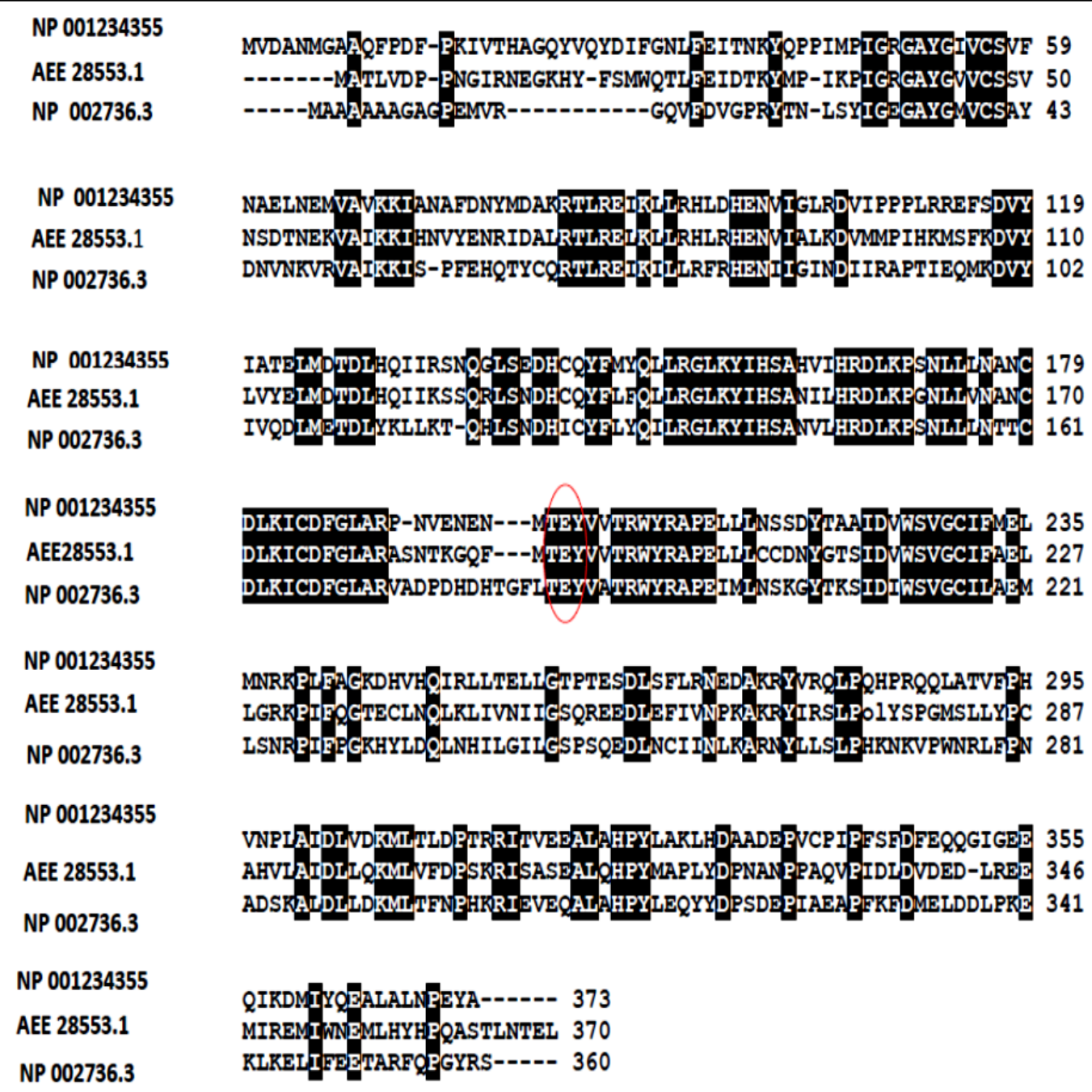

VNPIAIDIVDKMLTLDPTRRITVEDALAHPYLARLHDAADEPVCPIPFSEDFEQQGIGEE 355 AHVIAIDLLQKMLVFDPSKRI SASEALQHPYMAPLYDPNAN PPAQVPIDIDVDED-LREE 346

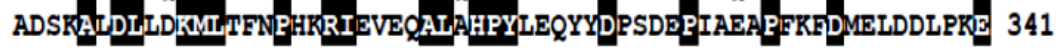

Figure 3.29: Amino acid sequence alignment of Solanum lycopersicum leMPK3, Arabidopsis thaliana AtMPK1, and human ERK Kinase MPK1 (GenBank accession numbers NP_001234360, AEE28553.1 and NP_002736.3, respectively). Amino acids that are shaded in black are shared by at least two sequences. 


\subsection{Finding the appropriate annealing temperature for $L e M P K 3, T A B 2, P R 1$ and}

\section{PDF1.2 primers}

Gradient PCR was used to find the appropriate annealing temperature to amplify a specific DNA fragment from each gene of interest.. The temperatures tested ranged from $55.0^{\circ} \mathrm{C}$ to $75.0^{\circ} \mathrm{C}$. As seen in Figure 3.30 the bands of brightest intensity for each gene were obtained at different temperatures. Thus the temperature used as the annealing temperature in RT-PCR to amplify our genes of interest were $63.5^{\circ} \mathrm{C}$ for $L e M P K 3$, $64.8^{\circ} \mathrm{C}$ for $T A B 2,60.0^{\circ} \mathrm{C}$ for $P R 1$, and $66.9^{\circ} \mathrm{C}$ for $P D F 1.2$.

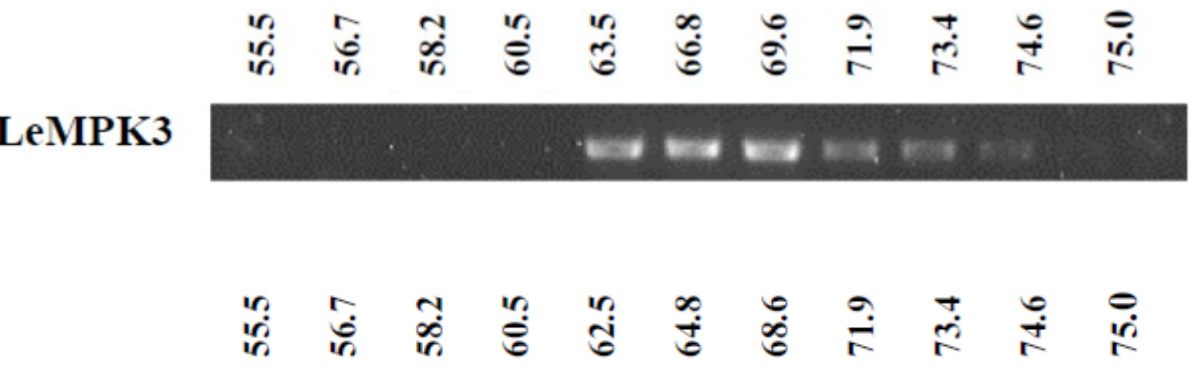

TAB2

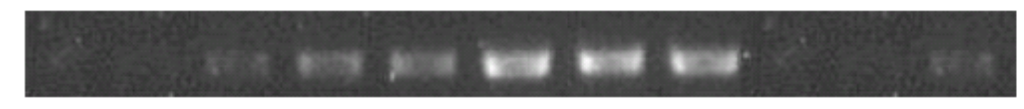

in

PR1

$$
\text { ம }
$$

PDF1.2

Figure 3.30: Results of gradient PCR with temperatures ranging from $55.0^{\circ} \mathrm{C}$ to $75.0^{\circ} \mathrm{C}$ for LeMPK3, TAB2, PR1 and PDF1.2 amplification. 


\subsection{Effect of SA and FB1 on LeMPK3 and TAB2 transcription}

Gel loading was adjusted using actin gene as an internal control. PR1 gene was used as a positive control for SA effect, while the PDF1.2 gene was used as a positive control for FB1 effect.

Generally, SA and FB1 enhanced the expression of their respective marker genes as well as $L e M P K 3$. The expression of $L e M P K 3$ and $P R 1$ was strongly induced at $30 \mathrm{~min}$ under SA treatment, whereas LeMPK3 and PDF1.2 expression level under FB1 treatment was induced at 2 h. TAB2 expression was not affected by the treatments (Figure 3.31). Three independent biological experiments were repeated, and in all of them, the same results were observed. 
The first batch infiltration

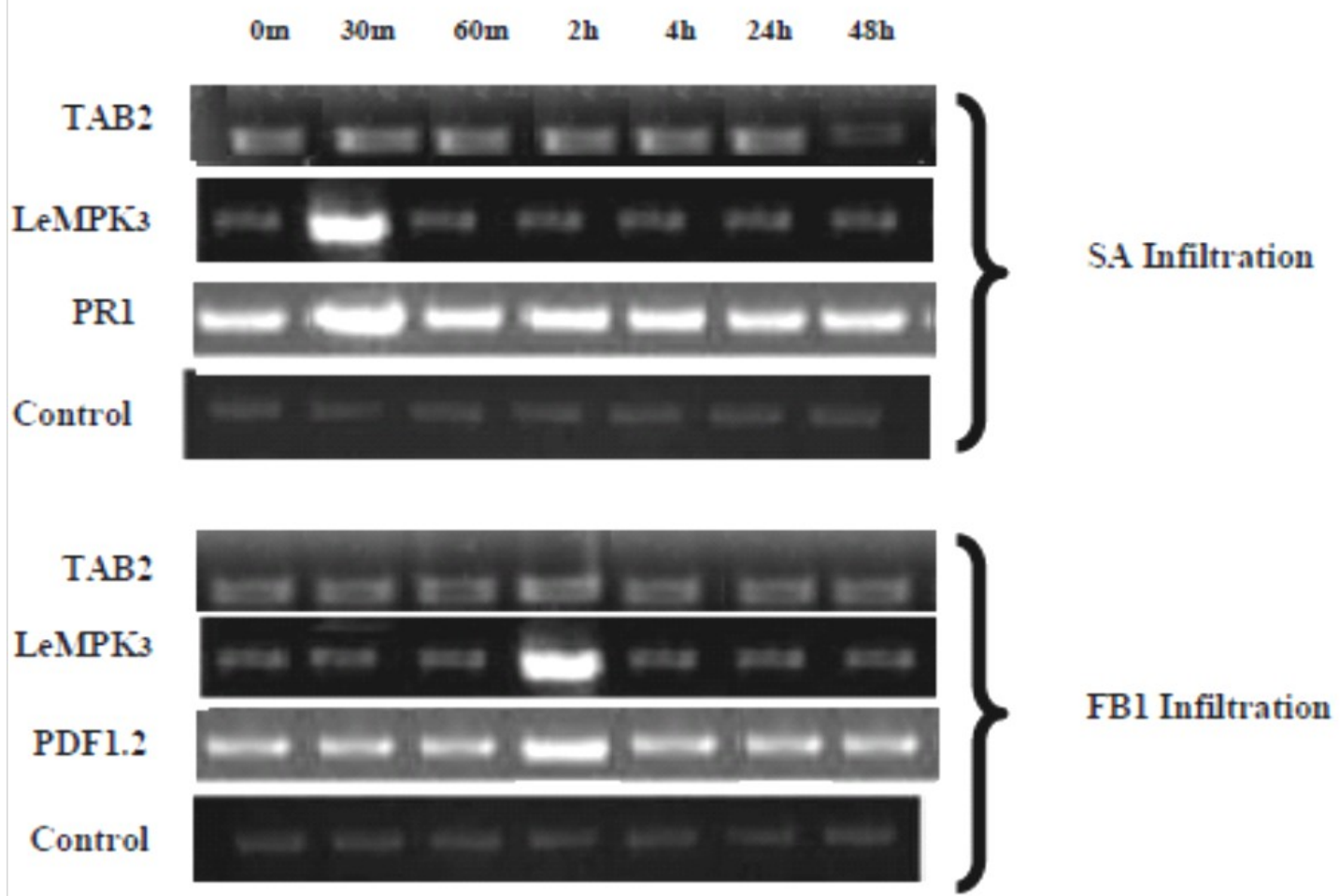

The first batch Spray and Q-tip

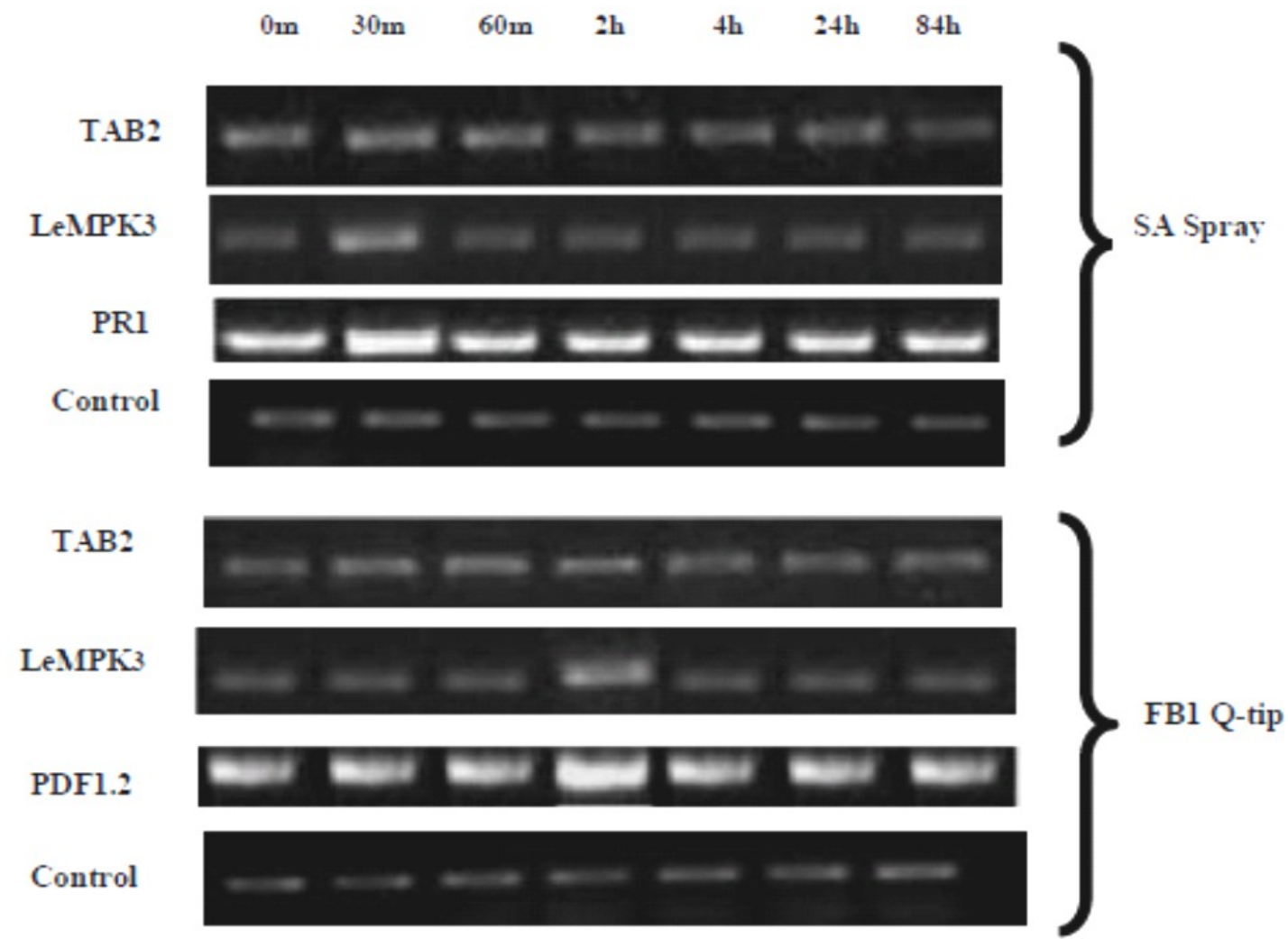




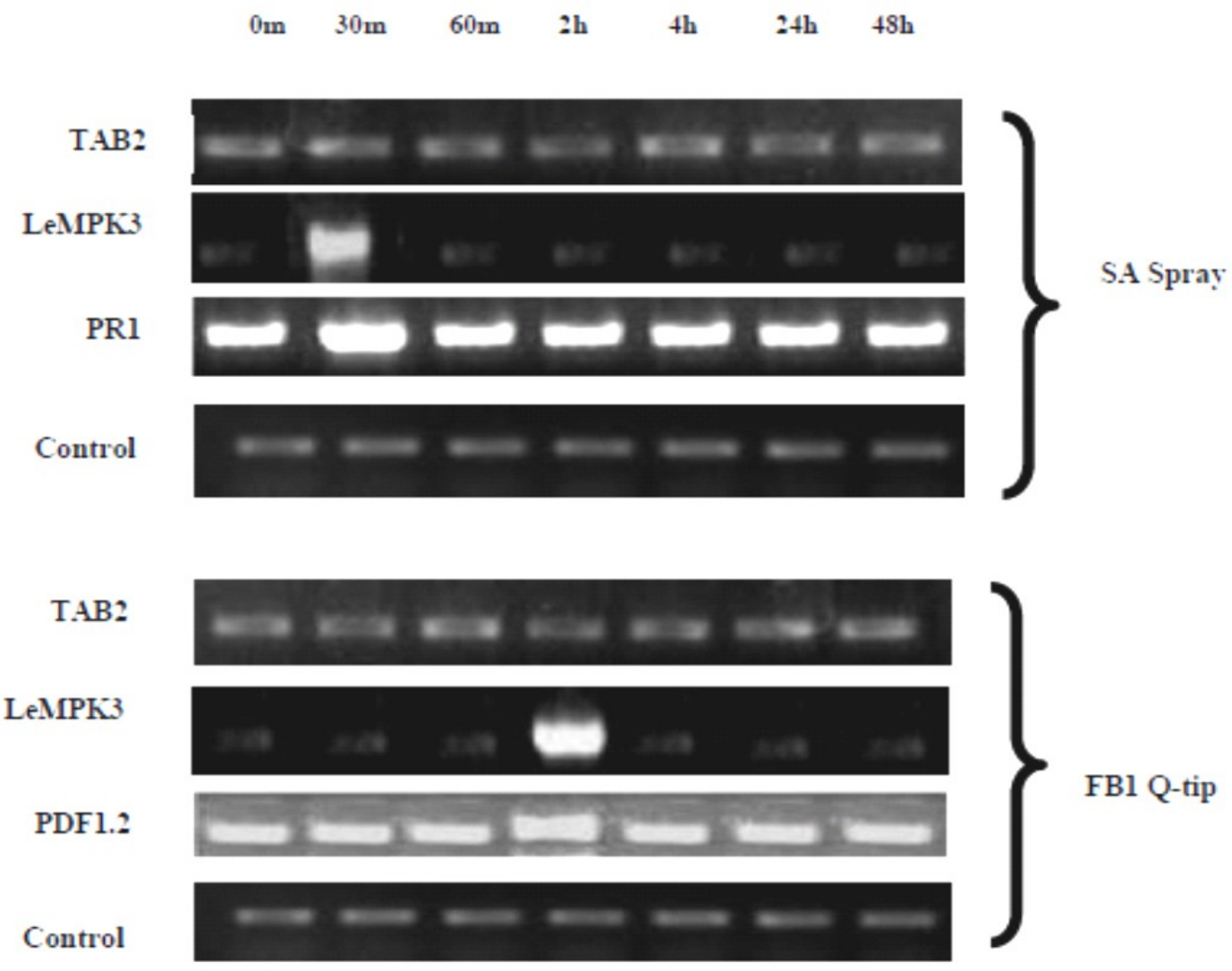

Figure 3.31: RT-PCR determination of Solanum lycopersicum LeMPK3 and TAB2 expression. The three batches were grown under the same conditions at different times. Actin was used as an internal standard. Salicylic acid used in this experiment was at $100 \mu \mathrm{M}$, and FB1 was at $5 \mu \mathrm{M}$. This experiment was done three times with similar results. 


\subsection{Effect of ERK inhibitor with SA and ERK inhibitor with FB1 on LeMPK3 transcription}

Actin gene was used in order to have an equivalent amount of cDNA from each treatment, $P R 1$ gene was used as a positive marker of SA effect while PDF1.2 gene was used as a positive marker of FB1 effect.

Similar to the previous experiment, SA and FB1 induced the expression of their related genes. LeMPK3 and $P R 1$ expression level under SA treatment was increased in 30 min while LeMPK3 and PDF1.2 expression level was increased at $2 \mathrm{~h}$ under FB1 treatment. This increase was not significantly altered by the ERK inhibitor (Figure 3.32). Three independent experiments were carried out, and same results were obtained. 

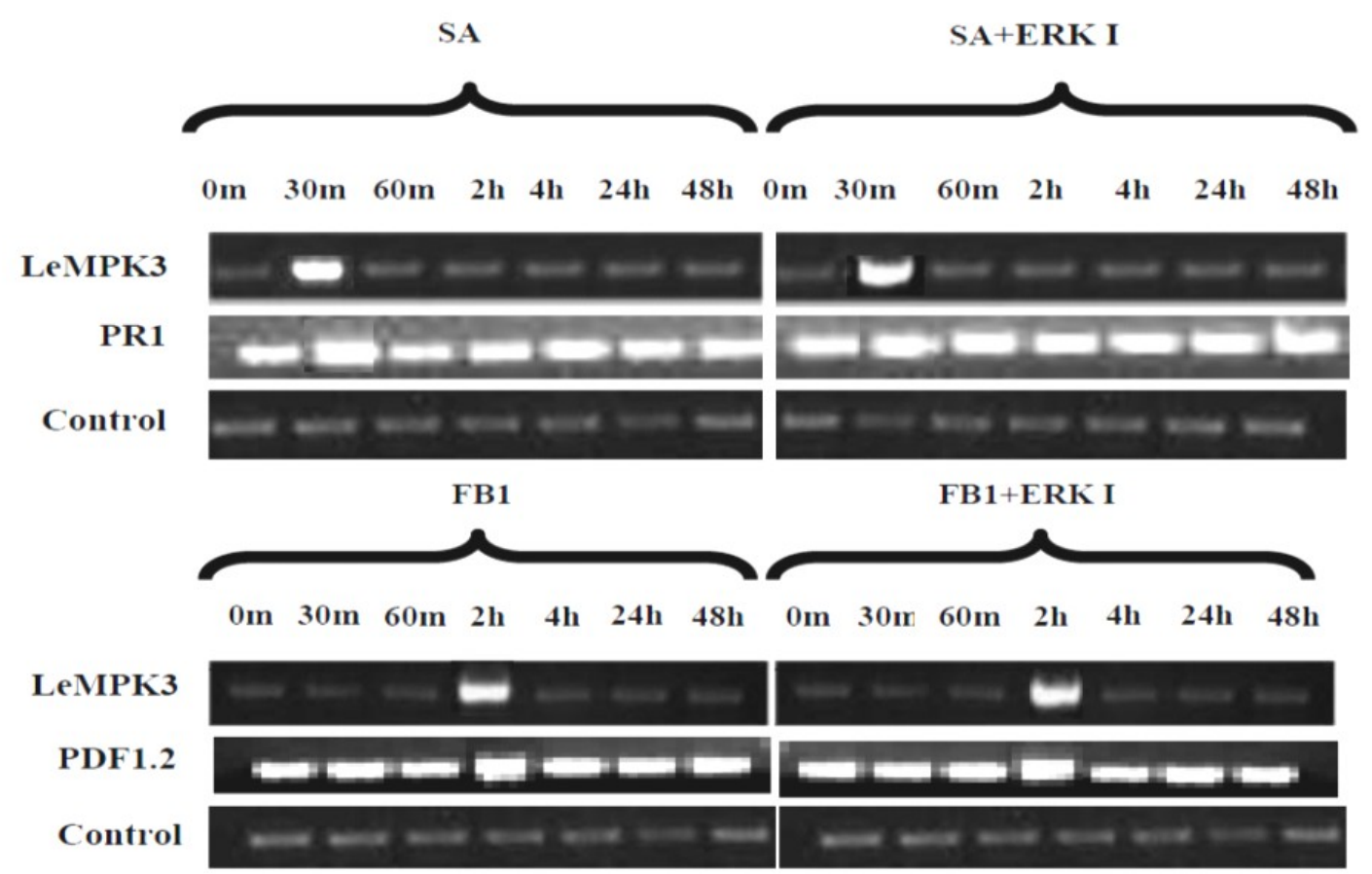

2
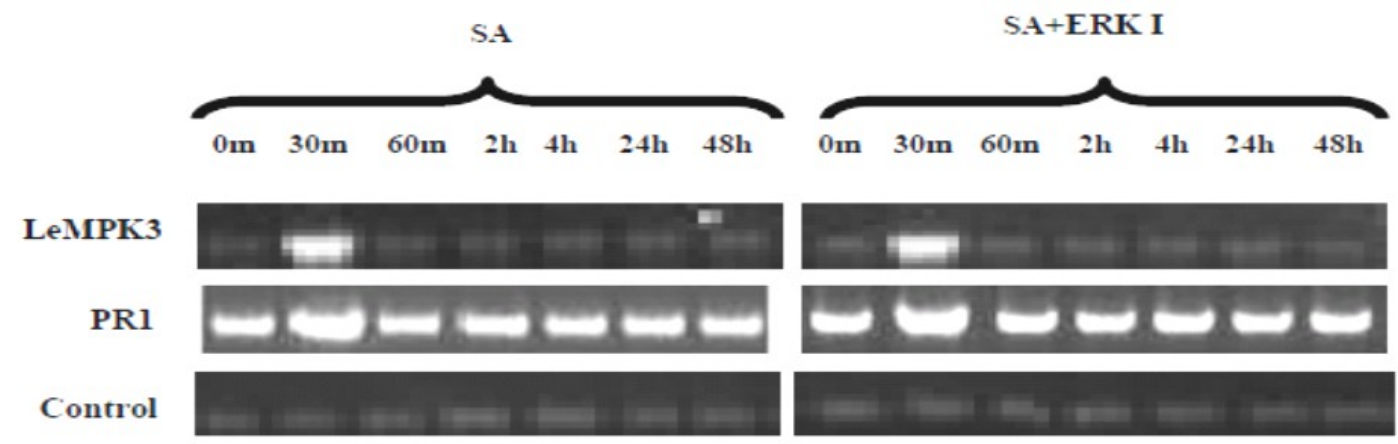

FB1
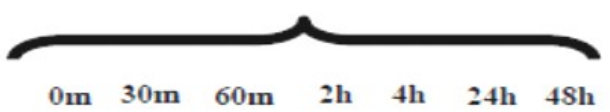

LeMPK3

PDF 1.2

Control
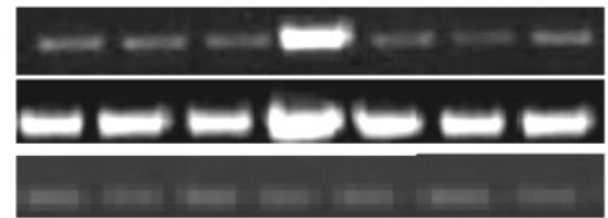

FB 1+ERK I

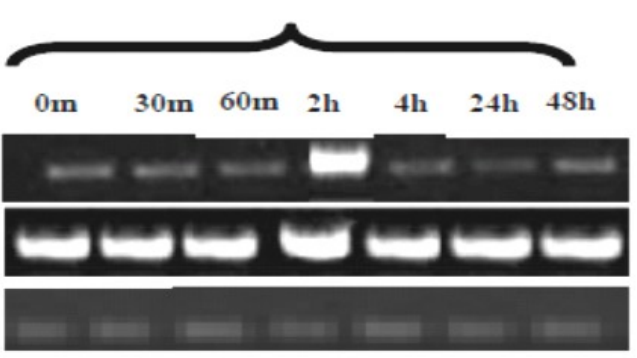



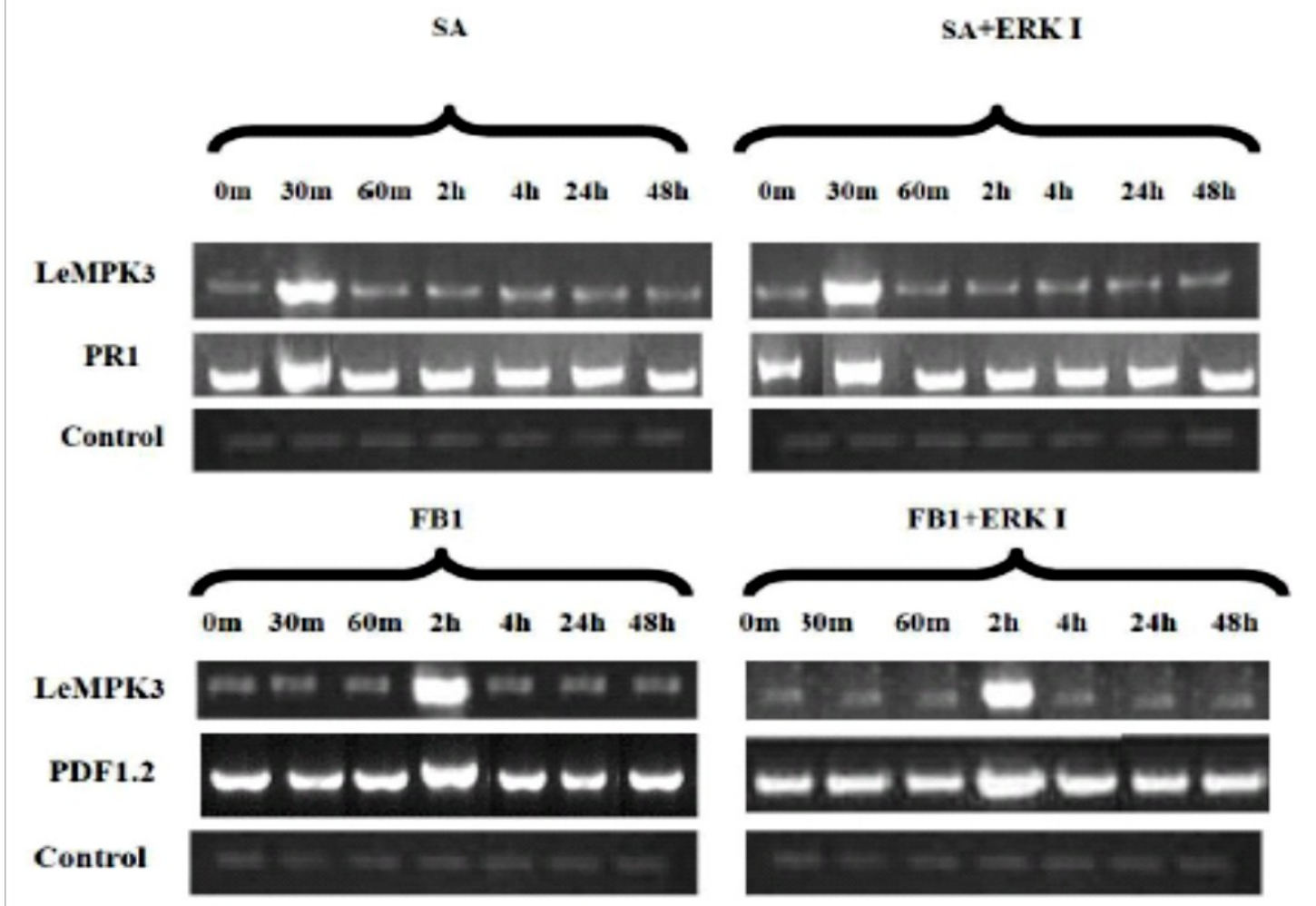

Figure 3.32: RT-PCR determination of Solanum lycopersicum LeMPK3 expression. The three batches were grown under the same conditions at different times. Actin was used as an internal standard. Salicylic acid used in this experiment was at $100 \mu \mathrm{M}, \mathrm{FB} 1$ was at $5 \mu \mathrm{M}$, and ERK inhibitor was at $250 \mu \mathrm{M}$. Data were obtained from three independent experiments with similar results. 


\subsection{Microscopic analysis of the effect of SA, FB1, and ERK inhibitor on cell death}

Tomato leaves were infiltrated with $\mathrm{H}_{2} \mathrm{O}$ (as control), SA, FB1, and ERK inhibitor. According to the microscopic images, it seems that both SA and FB1 stimulated cell death, as indicated by the increase of dark spots stained by trypan blue (Figure 3.33). The ERK inhibitor reversed the cell death induced by SA or FB1 with the infiltration method (Figure 3.33). The experiment was repeated with the spray and Q-tip methods, and similar results were obtained (Figure 3.34). 


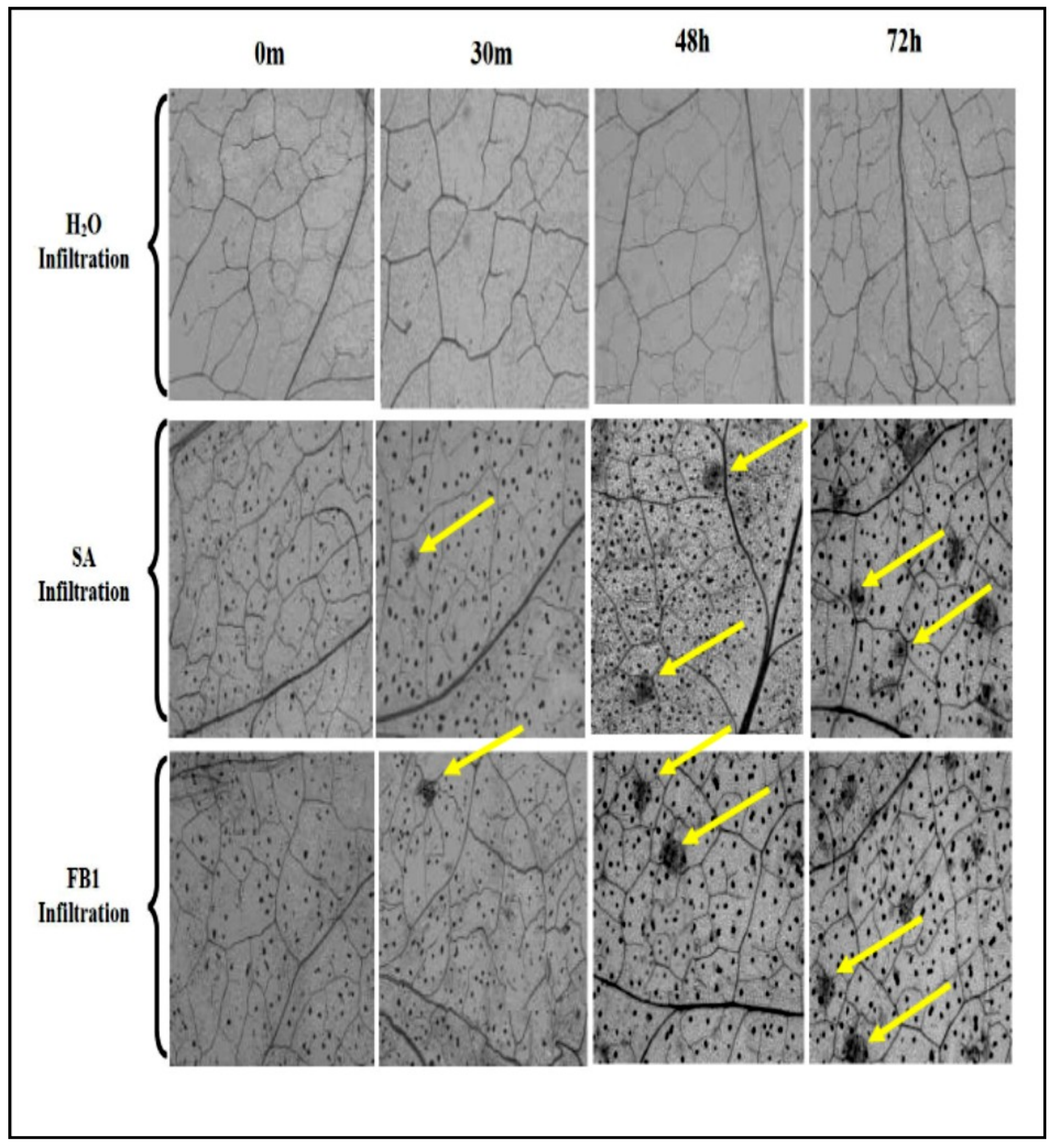




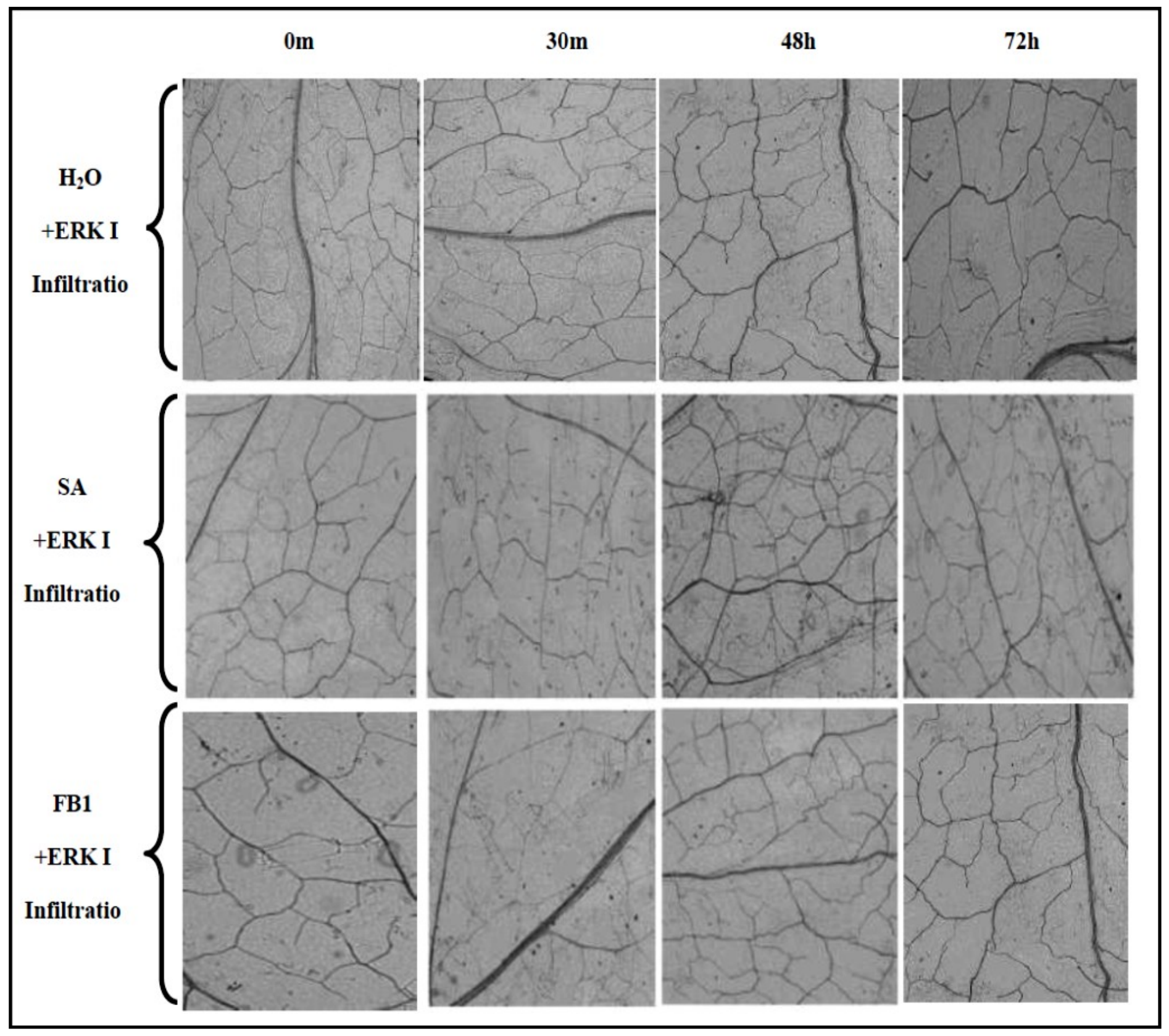

Figure 3.33: The effect of SA, FB1 and ERK inhibitor on cell death examined microscopically using infiltration method. Water was used as control. The stress was induced by using salicylic acid at $100 \mu \mathrm{M}, \mathrm{FB} 1$ at $5 \mu \mathrm{M}$, and ERK inhibitor at $250 \mu \mathrm{M}$. Five random fields per treatment were viewed for the same slide. The experiment was done three times with similar results. Arrows indicate cell death areas. 


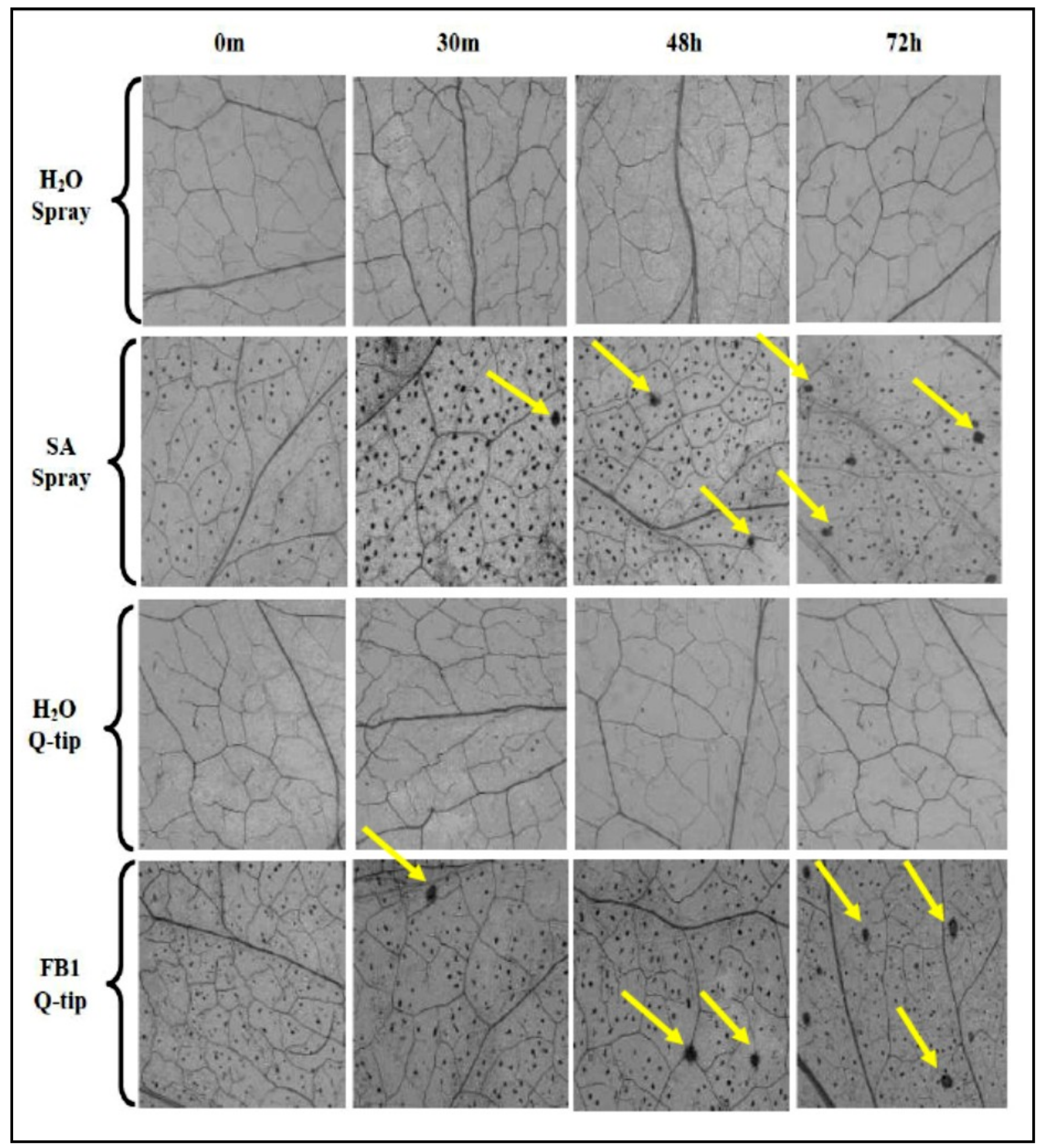




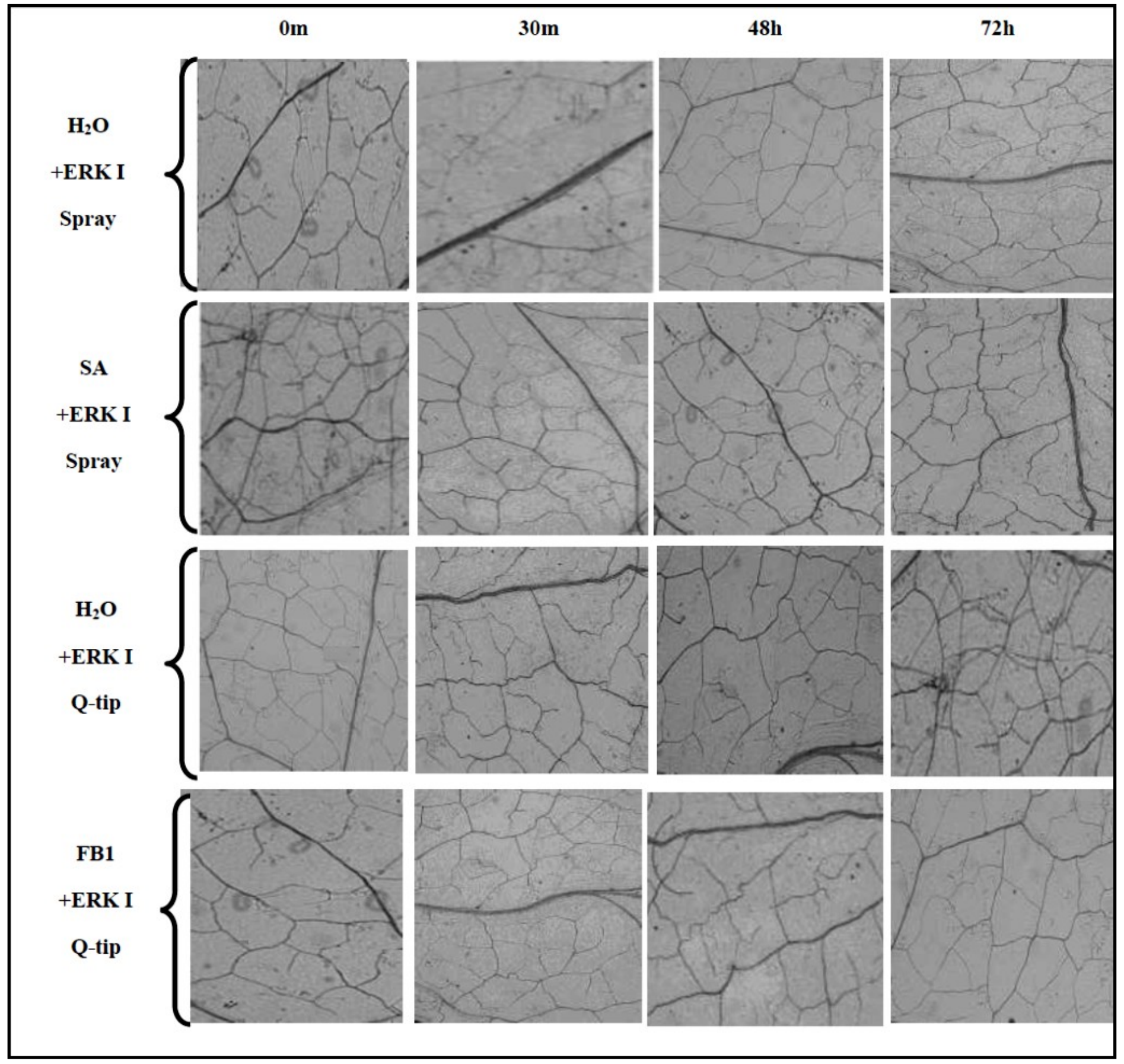

Figure 3.34: The effect of SA, FB1 and ERK inhibitor on cell death examined microscopically using spray and Q-tip methods. Water was used as control. The stress was induced by using salicylic acid at $100 \mu \mathrm{M}, \mathrm{FB} 1$ at $5 \mu \mathrm{M}$, and ERK inhibitor at $250 \mu \mathrm{M}$.

Five random fields per treatment were viewed for the same slide. The experiment was done three times with similar results. Arrows indicate cell death areas. 


\subsection{PCR-directed mutagenesis of LeMPK3}

PCR-directed mutagenesis is a molecular biology technique used to create specific and intentional changes in a known DNA sequence of a gene. Primers designed with mutations can introduce small sequence variations in DNA sequence. This molecular technique allows researchers to study the impact of sequence changes or help elucidate the functional effect of the mutation. Primers designed with mutations can be introduced into the sequence to replace the original sequence (Clore et al., 2011).

Previous work carried out in our laboratory has indicated that $L e M P K 3$ as well as $T A B 2$ expression levels were increased by pathogen attacks. Thus, we have decided to introduce mutations into LeMPK3 key phosphorylation motif (TEY), which was identified in the amino acid sequence (Figure 3.29), to create an activated LeMPK3 via PCR-directed mutagenesis. Since the phosphorylation introduces a negative charge to the protein at $\mathrm{T}$ and $\mathrm{Y}$, negatively charged residues aspartic acid (D) and glutamic acid (E) are often introduced to TXY. This would allow us to test whether this site is important for the function of LeMPK3.

Mutation to replace $\mathrm{T}$ and $\mathrm{Y}$ residues with amino acid $\mathrm{D}$ was carried out, and the PCR product was run on an agarose gel to confirm the size of PCR product. The image presented below in Figure 3.35 indicates the result of the first round of PCR. Two parts of LeMPK $3^{M U T}$ gene were generated.

Figure 3.36 shows the recovery of the two segments after gene clean using Wizard® SV Gel and PCR Clean-Up System. The second round of PCR using the PCR products from the first round as primers generated a full length $L e M P K 3^{M U T}$ (Figure 3.37). The mutation will be confirmed by sequencing. 


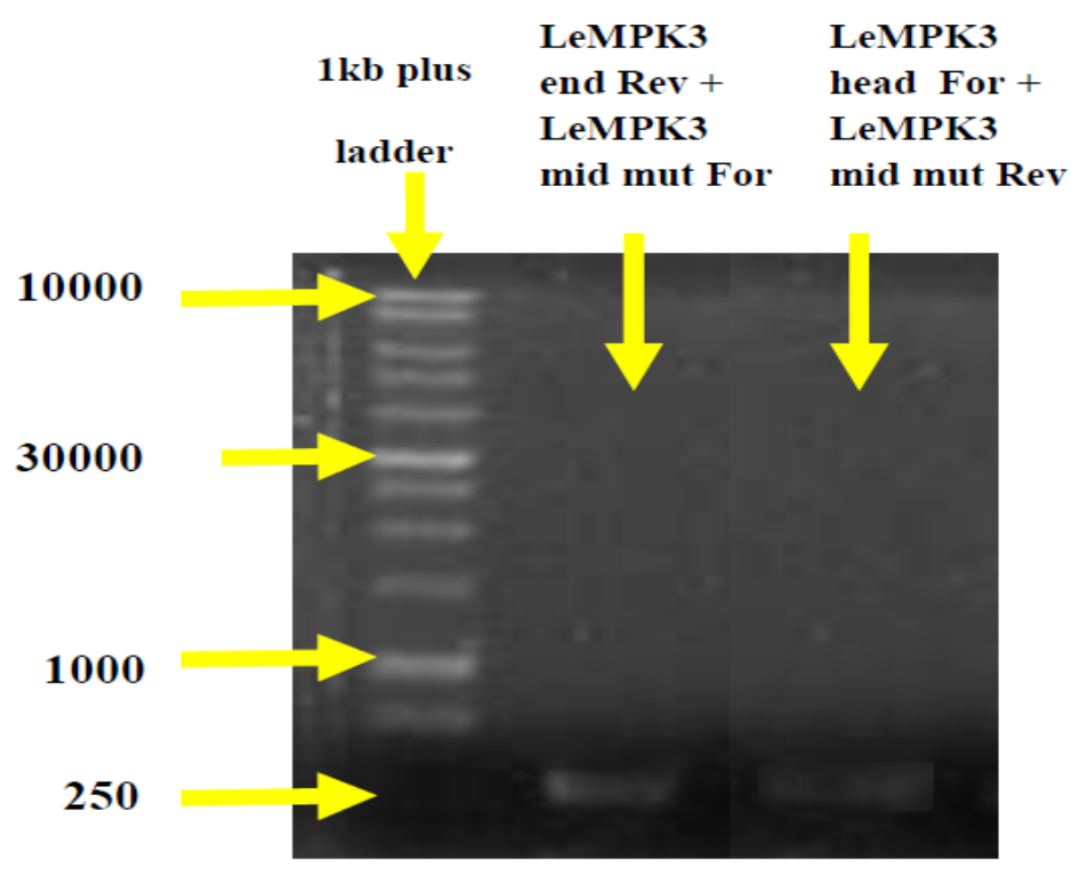

Figure 3.35: The first round of PCR using LeMPK3 end Rev plus LeMPK3 mid mut For and LeMPK3 head For plus LeMPK3 mid mut Rev.

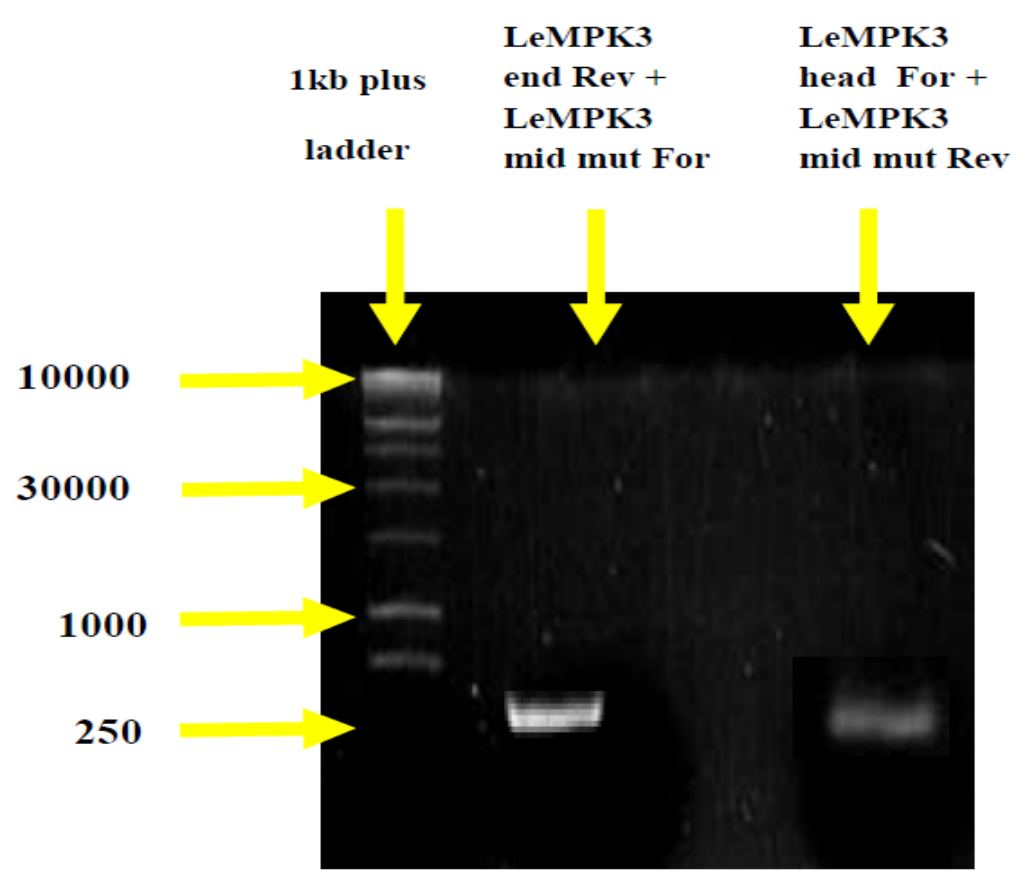

Figure 3.36: The recovery of $L e M P K 3$ PCR products after gen clean by Wizard ${ }^{\circledR} S V$ Gel and PCR Clean-Up System. 


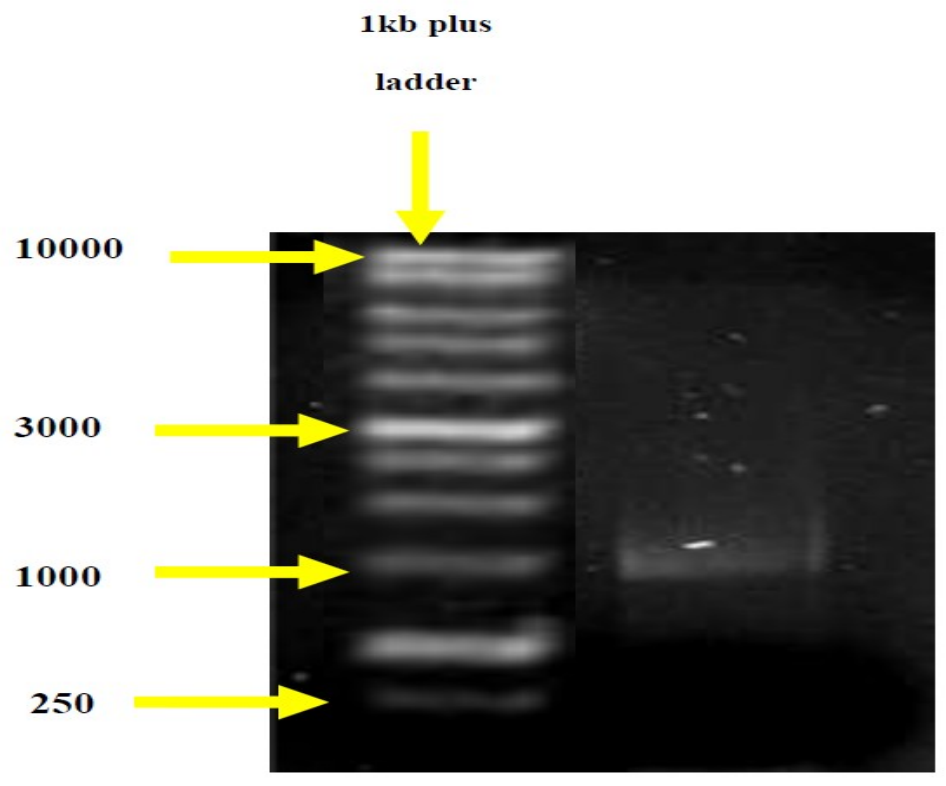

Figure 3.37: Second round of PCR using the two PCR products from the first round of PCR as primers. 


\section{CHAPTER IV \\ DISCUSSION AND CONCLUSION}

\subsection{Bioinformatics analysis}

One of the most widely used applications of bioinformatics is transcriptome data mining. It assists us in gaining knowledge about gene expression patterns during plant response to different stimuli, such as chemicals, drugs, pathogen attacks, and hormones. Bioinformatics can also help predict protein motifs, protein post-translational modifications, subcellular localisation, and protein folding. Microarray data mining contributes to integrated planning and designing of experiments. If the data of our gene of interest are not present yet, available information on a homologous gene from a different species could be helpful.

We used Genevestigator for microarray data mining. As no data were found for tomato LeMPK3, data for Arabidopsis thaliana MAPKs were examined. Phylogenetic trees were built (Figures 3.2 and 3.3), and the analysis indicated that Arabidopsis thaliana AtMPK3 (AT3G45640) and AtMPK6 (NM129941) are highly homologous to Solanum lycopersicum LeMPK3. Mayrose et al. (2004) has also reported that Solanum lycopersicum LeMPK3 shows high homology to the Arabidopsis thaliana AtMPK3. Alignment analysis of Solanum lycopersicum leMPK3 with Arabidopsis thaliana AtMPK3 and AtMPK6 has indicated that LeMPK3 is more homologous to AtMPK3 than to AtMPK6 at DNA level, whereas LeMPK3 is much more homologous to AtMPK6 than to AtMPK3 at the amino acid level (Figure 3.4 , 3.5, 3.6, and 3.7 ). Consequently, bioinformatics analysis was done on the expression patterns of these Arabidopsis genes, 
and whenever applicable, to study protein interactions so that we could predict that the same interactions could occur to Solanum lycopersicum LeMPK3.

\subsection{Analysis of Arabidopsis AtMPK3, AtMPK6, and AtNDPK}

A total of 25 genes could co-express with AtMPK3 and AtMPK6, according to the calculation of the Pearson's correlation coefficients for the gene pairs. Figure 3.8 shows that NSL1 (Necrotic Spotted Lesions1 AT1G28380), which is related to cell death, and a leucine-rich repeat transmembrane protein kinase gene (AT2G31880), which is related to protein kinase family, are the most correlated genes to Arabidopsis AtMPK3 as they had high correlation coefficients. AT4G31080 (protein of unknown function) and AT3G07890 (Ypt/Rap-GAP domain of gyp1p super family protein), which is involved in the regulation of Rab GTPase activity, are the most correlated genes to AtMPK6 (Figure 3.15). In AtNDPK case, all the 25 genes seem to be remotely related (if any) to the expression of AtNDPK gene (Figure 3.22).

Through the application of bioinformatics tools, proteins that may interact with AtMPK3 and AtMPK6 were predicted. As seen in Figures 3.9 and 3.16, WRKY22 (a transcription factor), NDPK (a nucleoside diphosphate kinase), AtMPK1 (Arabidopsis thaliana MAPK1), PP2C5 (Arabidopsis thaliana PP2 catalytic 5), MKP2 (MAPK phosphatase 2), and MKK4 (Arabidopsis thaliana MAPKK4) were predicted to interact with AtMPK3 and AtMPK6.

Arabidopsis WRKY proteins are a super family of transcription factors (e.g. 74 in Arabidopsis and 90 in rice) that form a complex network in many plant species (Pandey and Somssich, 2009). Overall, AtWRKYs contribute to diverse plant processes, and they generate a complex defense response toward diverse biotic (including biotrophic and 
necrotrophic pathogens) and abiotic stresses. Additionally, they respond to the endogenous signaling molecule salicylic acid (Pandey and Somssich, 2009). AtWRKYs have also been revealed to adjust cross-talk between jasmonate- and salicylate-regulated disease response pathways that mediate resistance against microbial pathogens (Zheng et al., 2006). AtWRKYs also control the expression of defense-related genes, including PR1 (pathogenesis-related protein 1) and NPR1 (non-expressor of PR1), which modulate SAdependent defense and SAR (Pandey and Somssich, 2009). Even though there is a large body of indirect evidence implicating plant WRKY proteins in plant defense responses, data about the biological roles of specific WRKY proteins in plant disease resistance is still very limited.

Among the AtWRKYs, WRKY22 protein shows the highest correlation to the resistance of Arabidopsis to Pseudomonas syringae attack. In addition, this protein induces innate immunity markers, such as flg22-induced receptor-like kinases1 (FRK1) and WRKY53 (Hsu et al., 2013). AtWRKY22 is involved in MAPK signaling pathways in response to abiotic stresses, particularly wounding and salt (Zhou et al., 2011). In the defense signaling response, analysis of stress-induced AtWRKY22 has indicated that it is positively controlled by the salicylic acid signaling pathway (Zarate et al., 2007). AtWRKY53 is an important transcription factor that acts as a positive regulator of resistance toward various pathogens, for example, the necrotrophic fungal pathogens Botrytis cinerea and Alternaria brassicicola (Hu et al., 2012; Pandey and Somssich, 2009; Zheng et al., 2006).

Arabidopsis MAPK phosphatase family plays an essential role in the regulation of many physiological responses. AtMKP2 is one important member of this family that 
regulates pathogen defense responses during Botrytis cinerea and is a key regulator of MPK3 and MPK6 networks controlling both abioitic and specific pathogen responses in plants (Lumbreras et al., 2010). PP2C5 is a member of the protein phosphatase $2 \mathrm{C}$ family in Arabidopsis that directly interacts with and regulates stress-induced MAPK cascades including MPK3, MPK4, and MPK6 through dephosphorylation of Ser and Thr residues. Thus, it can readily act as an MAPK phosphatase and altered PP2C5 levels could affect MAPK activation (Brock et al., 2010).

Nucleoside diphosphate protein kinase (NDP kinase) is a ubiquitous housekeeping enzyme but has been shown to play a significant role in signal transduction and regulate cellular protein functions in eukaryotes and prokaryotes (Pan et al., 2000; Xing et al., 2008; Yang et al., 2003). AtNDPK was predicted to interact with AtMPK3 and AtMPK6, both of which are LeMPK3 homologues, and this interaction was also confirmed by bench experiment (Moon et al., 2003). AtNDPK expression also correlated with $\mathrm{H}_{2} \mathrm{O}_{2}$-mediated MAPK signaling in Arabidopsis and it interacted with AtMPK3 and AtMPK6 (Moon et al., 2003). TAB2, of particular interest, a tomato NDPK was shown to enhance plant disease resistance when overexpressed (Xing et al., 2008).

Motif analysis using the ScanSite tool has indicated the presence of multiple protein phosphorylation sites in AtMPK3 and a potential SH3 binding site in AtMPK6. The presence of SH3 binding site may suggest a possible interaction of Arabidopsis AtMPK6 with other proteins (Figures 3.10 and 3.17). A possible protein phosphorylation site and SH2 binding site are also predicted in AtNDPK motif analysis, which may suggest the possible interaction of AtNDPK with other proteins (Figure 3.24). 
AtMPK3, AtMPK6, and AtNDPK response to various chemicals or hormones, and the expression patterns in different developmental stages or in different tissues were examined through transcriptome data mining. Figure 3.11 indicates that FB1/MetOH did not enhance AtMPK3 expression level, while SA up-regulated AtMPK3 transcription (Figure 3.12). Both $\mathrm{FB} 1 / \mathrm{MetOH}$ and $\mathrm{SA}$ were shown to up-regulate AtMPK6 transcription (Figures 3.18 and 3.19). Figure 3.25 shows that FB1/MetOH increased $A t N D P K$ expression, and Figure 3.26 seems to indicate that SA up-regulates AtNDPK in various cases.

There was no significant change in the expression levels of AtMPK3, AtMPK6, or AtNDPK in different developmental stages of Arabidopsis or in different tissues, such as petiole, juvenile leaf, adult leaf, senescent leaf, axillary bud, and cauline leaf (Figures $3.13,3.14,3.20,3.21,3.27$, and 3.28).

\subsection{LeMPK3 protein and TEY motif}

Alignment analysis at the amino acid level of Solanum lycopersicum LeMPK3, Arabidopsis thaliana MPK1, and human ERK kinase MPK1 has indicated that they all have a TEY motif, which confirmed that LeMPK3 is an ERK-type MAPK (Figure 3.29). ERK-type MAPKs are activated by dual phosphorylation of the TEY motif, and this activation may regulate the expression of pathogenesis-related genes, HR-like cell death, systemic acquired resistance, and the expression of protective genes (Xing et al., 2002).

\subsection{Effect of SA and FB1 on LeMPK3 and TAB2 Expression}

SA, which is implicated in plant defense against pathogen attacks, was shown to cause strong induction of $P R 1$ expression in Arabidopsis (Wu et al., 2012). Accordingly, 
the effect of $100 \mu \mathrm{M}$ SA on LeMPK3 and PR1 (the positive control of SA effect) was examined by RT-PCR.

A very fast response of $L e M P K 3$ and $P R I$ was detected under SA treatment, and the expression was increased at $30 \mathrm{~min}$ and then dropped down to background level in both infiltration and spray approaches (Figure 3.31). This increase may suggest that LeMPK3 is involved in plant defense response. Studies have suggested that SA and LeMPK3 signaling pathways are involved in regulating Solanum lycopersicum defense against bacterial wilt caused by the soil-borne bacterium Ralstonia solanacearum, making LeMPK3 connected to plant immunity (Chen et al., 2009). Data mining was then used to investigate Arabidopsis AtMPK3 and AtMPK6 response to SA. SA up-regulated AtMPK3 and AtMPK6 transcription (Figure 3.12 and 3.19). This result was expected and agrees to a previous study, where SA was found to cause an early and strong upregulation of LeMPK3 as well as PR1 in tomato (Wu et al., 2012). Another study showed that the transcript level of ZmMPK3 increased markedly and rapidly when maize seedlings were subjected to exogenous SA (Wang et al., 2010).

FB1 has been indicated to activate MAPK (Wattenberg et al., 1996). Thus, the effect of $5 \mu \mathrm{M}$ FB1 on LeMPK3 and PDF1.2 (the positive control of FB1 effect) was examined by RT-PCR. The expression level of LeMPK3 and PDF1.2 under FB1 treatment was increased at $2 \mathrm{~h}$ and then dropped down to the background level (Figure 3.31). In fact, this agrees to the result of bioinformatics analysis on Arabidopsis AtMPK6 transcription, where it was up-regulated by FB1 (Figure 3.18). Asano et al. (2012) reported that the expression of PDF1.2 in Arabidopsis was significantly induced by Fusarium sporotrichioides. 
Our previous work has indicated that tomato TAB2, which is downstream of LeMPK3, physically interacts with LeMPK3 at the protein level, and this interaction is involved in the tMEK2-mediated disease resistance pathway (Xing et al., 2008). Proteinprotein interaction prediction in my current work has also suggested that Arabidopsis AtNDPK may interact with both AtMPK3 and AtMPK6 proteins (Figures 3.9 and 3.16). Additionally, both AtMPK3 and AtMPK6 were shown to interact with AtNDPK in bench experiments.

However, it was found that the expression of $T A B 2$ remained unchanged during the tested period of treatment by either FB1 or SA (Figure 3.31). We only examined the correlation of TAB2 and LeMPK3 at transcript level by RT-PCR and the transcript level may not be the best marker for phosphorylation activity. Further experiments should be performed, especially at protein level and at phosphorylation level, to elaborate on the results.

\subsection{Effect of ERK Inhibitor with SA or ERK Inhibitor with FB1 on LeMPK3 Transcription}

The ERK docking domain inhibitor (3-(2-Aminoethyl)-5-((4-ethoxyphenyl) methylene)-2, 4-thiazolidinedione hydrochloride) was used to examine whether the effect of SA and FB1 on the defense response genes was mediated by ERK-like MAPKs. The ERK inhibitor was combined with SA or FB1 to test this relationship between SA, FB1, ERK-type MAPKs, and LeMPK3. Motif analysis at high stringency scan also predicted the existence of multiple protein phosphorylation sites as well as potential $\mathrm{SH} 3$ binding site for Arabidopsis AtMPK3, suggesting that LeMPK3 may interact with other proteins. So the interaction of LeMPK3 (as an ERK type kinase) with other proteins should be 
critical to its function. When ERK inhibitor is applied, it is expected that LeMPK3 docking process (i.e. interaction with some other proteins) will be affected.

As specified earlier, SA and FB1 treatment enhanced the expression of their defense response genes, $P R 1$ and $P D F 1.2$, respectively (Figure 3.32), and of tMEK2 (Xing Lab, unpublished). When ERK inhibitor is added, the increase of PRI and PDF1.2 expression was not significantly altered, indicating that SA- or FB1-induced expression changes of $P R 1$ and $P D F 1.2$ genes may not involve LeMPK3. Previous work of this lab has suggested a pathway including tMEK2, LeMPK3, TAB2, and defense response genes, but my current data may indicate that LeMPK3 may not responsible for $P R 1$ and $P D F 1.2$ induction in my experimental conditions. Alternatively, ERKI may not be effective on LeMPK3 in my conditions.

\subsection{Microscopic Analysis of the Effect of SA, FB1, and ERK Inhibitor on Cell Death}

The effect of FB1, SA, and ERK inhibitor on the cell death of tomato leaves was studied microscopically. Trypan blue was used in this experiment to determine the permanent membrane damage and the degree of cell death (Tang et al., 1999). Dark blue spots were centred in the middle of the tomato leaves treated with either SA or FB1 for $30 \mathrm{~min}$. These dark spots indicate the presence of dead cells. They visibly accumulated in many fields of the whole leaf surface when the leaves were incubated for $72 \mathrm{~h}$. Our data are similar to what was reported recently for cell death in tomato, where the high concentrations of SA stimulated programmed cell death in tomato suspension cultured cells and caused the death of cells within 1week of exposure (Poor et al., 2012). Li et al. (2008) found that the development of damaged cells, lesion, and the dry necrotic areas in Arabidopsis leaves was enhanced after infiltration of leaf tissue with the PCD-eliciting 
fungal toxin FB1. Also, our previous studies in wheat has indicated that both SA and FB1 triggered programmed cell death in the cultivar Frontana and Roblin, and it was suggested that this cell death could be associated with the defense against Fusarium head blight (Gao et al., 2011).

Zhuang and Schnellmann (2006) showed that inhibition of ERK-type MAP kinase improved cell survival and in some cases reduced the extent of tissue damage. ERK docking domain inhibitor (3-(2-Aminoethyl)-5-((4-ethoxyphenyl) methylene)-2, 4thiazolidinedione hydrochloride) was used in this experiment to inhibit ERK-type MAPKs.

Our microscopic images have indicated that the ERK inhibitor may have reversed the cell death induced by SA and FB1 (Figures 3.33 and 3.34). It seems that ERK-type MAPKs could be involved in SA- or FB1-induced cell death. Three independent biological experiments were repeated using infiltration, spray, and Q-tip methods. In all of them, the same results were observed except that the form of the dead cells was more significant in the microscope image of the tomato leaves infiltrated by vacuum due to the involvement of mechanical stress (wounding damage) (Xing Lab, unpublished).

\subsection{PCR-directed Mutagenesis of LeMPK3}

Amino acid sequence alignment revealed that LeMPK3 shared high identity with ERK-type MAPKs (Figure 3.29). ERK subfamily, to which LeMPK3 belongs, is activated by dual phosphorylation of TEY motif. In PCR-directed mutagenesis, the replacement of $\mathrm{T}$ and $\mathrm{Y}$ in TEY motif by negatively charged amino acid D may mimick the phosphorylation of TEY. Several studies confirmed that phosphorylation of only one 
residue in the highly conserved TXY motif of MAPKs is sufficient to increase their activity (Brock et al., 2010).

The mutation in $\mathrm{T}$ and $\mathrm{Y}$ residues was carried out and the mutation will be confirmed by sequencing. Cloning of LeMPK ${ }^{\mathrm{MUT}}$ into $\mathrm{pET14b}$ vector will be performed.

\subsection{Conclusion and Future Work}

My project focused on LeMPK3, which is downstream of tMEK2/LeMKK2 but upstream of TAB2 (Xing et al., 2008). Our data revealed that SA and FB1 treatment enhanced the expression of LeMPK3 and their defense response marker genes at the transcriptional level. We found that this increase of LeMPK3 and SA or FB1 defense response genes was not affected by an ERK inhibitor, suggesting that LeMPK3, which is an ERK-type MAPK, may not be involved in SA-induced $P R 1$ and FB1-induiced $P D F 1.2$ expression. Also, our data have shown that SA and FB1 stimulated cell death and the ERK inhibitor could reverse the cell death induced by SA and FB1. In this project we have introduced mutations into LeMPK3 key phosphorylation motif TEY to create an activated LeMPK3 via PCR-directed mutagenesis. We generated a full length LeMPK $3^{M U T}$. The mutation will be confirmed by sequencing.

We reported that LeMPK3 is up-regulated by SA and FB1, but it was only examined at mRNA level. Future studies will test whether the phosphorylation of LeMPK3 proteins at the conserved TEY motif is enhanced by SA and FB1 via immunoblotting (using anti-phospho-p44/42 MAP kinase (Erk1/2) antibody) to detect the dual phosphorylation on $\mathrm{T}$ and $\mathrm{Y}$ residues. It is hoped that our study will help us in the development of strategies to enhance plant disease resistance. 


\section{REFERENCES}

Asai, T., Stone, J.M., Heard, J.E., Kovtun, Y., Yorgey, P., Sheen, J., and Ausubel, M.F. 2000. Fumonisin B1-Induced Cell Death in Arabidopsis Protoplasts Requires Jasmonate-, Ethylene-, and Salicylate-Dependent Signaling Pathways. Plant Cell. 12: 1823-1835.

Asai, T., Tena, G., Plotnikova, J., Willmann, M. R., Chiu, W. L., Gomez-Gomez, L., Boller, T., Ausubel, F.M., and Sheen, J. 2002. MAP kinase Signalling Cascade in Arabidopsis Innate Immunity. Nature. 415:977-983.

Asano, T., Kimura, M., and Nishiuchi, T. 2012. The Defense Response in Arabidopsis Thaliana against Fusarium sporotrichioides. Proteome Science. 10:1-10.

Bethke, G., Unthan, T., Uhrig, J. F., Poschl, Y., Gust, A. A., Scheel, D., and Lee, J. 2009. Flg22 Regulates the Release of an Ethylene Response Factor Substrate from MAP kinase 6 in Arabidopsis Thaliana via Ethylene Signaling. Proceedings of National Academy of Science of the USA .106: 8067-8072.

Braun, P., Carvunis, A.R., Charloteaux, B., Dreze, M., Ecker, J.R., Hill, D.E., Roth, F.P., Vidal, M., Galli, M., Balumuri, P., Bautista, V., Chesnut, J. D., Kim, R.C., De Los Reyes, C., Gilles, P., Kim, C.J., Matrubutham, U., Mirchandani, J., Olivares, E., Patnaik, S., Quan, R., Ramaswamy, G., Shinn, P., Swamilingiah, G.M., Wu, S., Ecker, J.R., Dreze, M., Byrdsong, D., Dricot, A., Duarte, M., Gebreab, F., Gutierrez, B.J., MacWilliams, A., Monachello, D., Mukhtar, M.S., Poulin, M.M., Reichert, P., Romero, V., Tam, S., Waaijers, S., Weiner, E.M., Vidal, M., Hill, D.E., Braun, P., Galli, M., Carvunis, A.R., Cusick, M.E., Dreze, M., Romero, V., Roth, F.P., Tasan, M., Yazaki, J., Braun, P., Ecker, J.R., Carvunis, A.R., Ahn, Y.Y., Barabsi, A.L., Charloteaux, B., Chen, H., Cusick, M.E., Dangl, J.L., Dreze, M., Ecker, J.R., Fan, C., Gai, L., Galli, M., Ghoshal, G., Hao, T., Hill, D.E., Lurin, C., Milenkovic, T., Moore, J., Mukhtar, M.S., Pevzner, S.J., Przulj, N., Rabello, S., Rietman, E.A., Rolland, T., Roth, F.P., Santhanam, B., Schmitz, R.J., Spooner, W., Stein, J., Tasan, M., Vandenhaute, J., Ware, D., Braun, P., and Vidal, M. 2011. Evidence for Network Evolution in an Arabidopsis Interactome Map. Science. 333:601-607.

Brock, A.K., Willmann, R., Kolb, D., Grefen, L., Lajunen, H.M., Bethke, G., Lee, J., Nuernberger, T., and Gust, A.A. 2010. The Arabidopsis Mitogen-Activated Protein Kinase Phosphatase PP2C5 Affects Seed Germination, Stomatal Aperture, and Abscisic Acid-Inducible Gene Expression. Plant Physiology. 153:1098-111.

Cao, H., Glazebrook, J., Clarke, J. D., Volko, S., and Dong, X. 1997.The Arabidopsis NPRI Gene that Controls Systemic Acquired Resistance Encodes a Novel Protein Containing Ankyrin Repeats. Cell. 88: 57-63.

Chen, Y.Y., Lina, Y.M., Chaoa, T.C., Wang, J.F., Liua, A.C., Ho, F.I., and Chenga, C.P. 2009. Virus-Induced Gene Silencing Reveals the Involvement of Ethylene- Salicylic 
Acid- and Mitogen-Activated Protein Kinase-Related Defense Pathways in the Resistance of Tomato to Bacterial Wilt. Physiological Plant. 136:324-335.

Chuang, S.M., Wang, I.C., and Yang, J.L. 2000. Roles of JNK, P38 and ERK MitogenActivated Protein Kinases in the Growth Inhibition and Apoptosis Induced by Cadmium. Carcinogenesis. 21:1423-1432.

Clore, A., Reinertson, B., and Rose, S. (2011). Site-Directed Mutagenesis. In J .Sabel (Eds) Mutagenesis Application Guide Experimental Overview, Protocol, Troubleshooting. pp 5-19.

Cvetkovska, M., Rampitsch, C., Bykova, N., and Xing, T. 2005. Genomic Analysis of MAP Kinase Cascades in Arabidopsis Defense Responses. Plant Molecular Biology Reporter. 23: 331-343.

Desai, K., Sullards, M.C., Allegood, J., Wang, E., Schmelz, E.M., Hartl, M., Humpf, H.U., Liotta, D.C., Peng, Q., and Merrill, A.H. 2002. Fumonisins and Fumonisin Analogs as Inhibitors of Ceramide Synthase and Inducers of Apoptosis. Molecular \& Cell Biology of Lipids. 1585:188-192.

Ekengren, S. K., Liu, Y., Schiff, M., Dinesh-Kumar, S.P., and Martin, G.B. 2003. Two MAPK Cascades, NPR1, and TGA Transcription Factors Play a Role in Pto-Mediated Disease Resistance in Tomato. Plant Journal. 36:905-917.

Gao, Y., Liu, X., Stebbing, J. A., He, D., Laroche, A., Gaudet, D., and Xing, T. 2011. TaFLRS, a Novel Mitogen-Activated Protein Kinase in Wheat Defense Responses. European Journal of Plant Pathology.131:643-651.

Genoud, T., Santa Cruz, M.T., KuXlisic, T., Sparla, F., Fankhauser, C., and Metraux, J.P. 2008. The Protein Phosphatase 7 Regulates Phytochrome Signaling in Arabidopsis. PLoS ONE. 3: 2699.

Greenberg, T. J.1996. Programmed Cell Death: A way of Life for Plants. National Academy for Science .93:12094-12097.

Hamel, L.P., Nicole, M.C., Sritubtim, S., Morency, M. j., Ellis, M., Ehlting, J., Beaudoin, N., Barbazuk, B., Klessig, D., Lee, J., Martin, G., Mundy, J., Ohashi, Y., Scheel, D., Sheen, J., Xing, T., Zhang, S., Seguin, A., and Ellis, B.E. 2006. Ancient Signals: Comparative Genomics of Plant MAPK and MAPKK Gene Families. Trends in Plant Science.11:192-198.

Hsu, F.C., Chou, M.Y., Chou, S.J., Li, Y.R., Peng, H.P., and Shih, M. C. 2013. Submergence Confers Immunity Mediated by the WRKY22 Transcription Factor in Arabidopsis. Plant.Cell. 25: 2699-2713 
Hu, Y., Dong, Q., and Yu, D. 2012. Arabidopsis WRKY46 Coordinates with WRKY70 and WRKY53 in Basal Resistance against Pathogen Pseudomonas syringae. Plant Science. 185: 288-297.

Im, Y.J., Kim, J.I., Shen, Y., Na, Y., Han, Y.J., Kim, S.H., Song, P.S., and Eom, S.H. 2004. Structural Analysis of Arabidopsis Thaliana Nucleoside Diphosphate Kinase-2 for Phytochrome-Mediated Light Signaling. Journal of Molecular Biology. 343:659-670.

Jensen, L.J., Kuhn, M., Stark, M., Chaffron, S., Creevey, C., Muller, J., Doerks ,T., Julien, P., Roth, A., Simonovic, M., Bork, P., and Von Mering, C. 2009. STRING 8--a global view on proteins and their functional interactions in 630 organisms. Nucleic Acids Research 37(Database issue):D412-416.

Kandoth, P. K., Ranf, S., Pancholi, S.S., Jayanty, S., Walla, M.D., Miller, W., Howe, G.A., Lincoln, D.E., and Stratman, J.W. 2007.Tomato MAPKs LeMPK1, LeMPK2, and LeMPK3 Function in the Systemin-Mediated Defense Response against Herbivorous Insects. Proceedings of National Academy of Sciences of theUSA.104:12205-12210.

Li, J., Brader, G., and Palva, E. T. 2008.Kunitz Trypsin Inhibitor: an Antagonist of Cell Death Triggered by Phytopathogens and Fumonisin B1 in Arabidopsis. Molecular Plant .1: 482-495.

Lumbreras, V., Vilela, B., Irar, S., Sole, M., Capellades, M., Valls, M., Coca, M., and Pages, M. 2010. MAPK Phosphatase MKP2 Mediates Disease Responses in Arabidopsis and Functionally Interacts with MPK3 and MPK6. Plant Journal. 63:1017-1030.

Mao, G., Meng, X., Liu, Y., Zheng, Z., Chen, Z., and Zhang, S.2011. Phosphorylation of a WRKY Transcription Factor by Two Pathogen-Responsive MAPKs Drives Phytoalexin Biosynthesis in Arabidopsis. Plant Cell. 23:1639-1653.

Mayrose, M., Bonshtien, A., and Sessa, G. 2004. LeMPK3 is a Mitogen- Activated Protein Kinase with Dual Specificity Induced during Tomato Defense and Wounding Responses. Journal of Biological Chemistry .279:14819-14827.

Melech-Bonfil, S., and Sessa, G. 2010. Tomato MAPKKKe is a Positive Regulator of Cell-Death Signaling Networks Associated with Plant Immunity. Plant Journal. 64: 379391.

Mitsuhara, I., Iwai, T., Seo, S., Yanagawa, Y., Kawahigasi, H., Hirose, S., Ohkawa, Y., and Ohashi, Y. 2008.Characteristic Expression of Twelve Rice PRI Family Genes in Response to Pathogen Infection, Wounding, and Defense-Related Signal Compounds (121/180). Molecular Genetics \& Genomics. 279:415-427.

Moon, H., Lee, B., Choi, G., Shin, D., Prasad, D.T., Lee, O., Kwak, S.S., Kim, D.H., Nam, J., Bahk, J., Hong, J.C., Lee, S.Y., Cho, M.J., Lim, C.O., and Yun, D.J. 2003. NDP Kinase 2 Interacts with Two Oxidative Stress-Activated MAPKs to Regulate Cellular 
Redox State and Enhances Multiple Stress Tolerance in Transgenic Plants. Proceedings of the National Academy of Sciences of the USA.100:358-363.

Nakagami, H., Pitzschke, A., and Hirt, H. 2005. Emerging MAPK Pathways in Plant Stress Signalling. Trends in Plant Science.10: 339-346.

Oh, C.S., and Martin, G.B. 2011.Tomato 14-3-3 Protein TFT7 Interacts with a MAP Kinase Kinase to Regulate Immunity-Associated Programmed Cell Death Mediated by Diverse Disease Resistance Proteins. Journal of Biology Chemistry. 286: 14129-14136.

Pan, L., Kawai, M., Yano, A., and Uchimiya, H. 2000. Nucleoside Diphosphate Kinase Required for Coleoptile Elongation in Rice. Plant Physiology.122: 447-452.

Pandey, P. S., and Somssich, E. I. 2009. The Role of WRKY Transcription Factors in Plant Immunity. Plant Physiology.150:1648-1655.

Plett, J.M., Cvetkovska, M., Makenson, P., Xing, T., and Regan, S. 2009. Arabidopsis Ethylene Receptors have Different Role in Fumonisin B1-Induce Cell Death. Physiological \& Molecular Plant Pathology.74:18-26.

Poor, P., Szopko, D., and Tari, I. 2012. Ionic Homeostasis Disturbance is involved in Tomato Cell Death Induced by $\mathrm{NaCl}$ and Salicylic Acid. In Vitro Cellular \& Developmental Biology Plant. 48:377-382.

Qi, M., and Elion, E.A. 2005. MAP Kkinase Pathways. Journal of Cell Science. 118: 3569-3572.

Rick, C.M., and Yoder, J. I. 1988.Classical and Molecular Genetics of Tomato: Highlights and Perspectives. Annual Review of Genetics. 22: 281-300.

Shen, Y., Kim, J.I., and Song, P.S. 2005. NDPK2 as a Signal Transducer in the Phytochrome-Mediated Light Signaling. Journal of Biology Chemistry. 280:5740-5749.

Stone, J.M., Heard, J. E., Asai, T., and Ausubel, F.M. 2000. Simulation of FungalMediated Cell Death by Fumonisin B1 and Selection of Fumonisin B1-Resistant ( $f b r$ ) Arabidopsis Mutants. Plant Cell . 12:1811-1822.

Stulemeijer, I.J., Stratmann, J.W., Joosten, M.H. 2007.Tomato Mitogen-Activated Protein Kinases LeMPK1, LeMPK2, and LeMPK3 are Activated during the Cf-4/Avr4-Induced Hypersensitive Response and have Distinct Phosphorylation Specificities. Plant Physiology.144:1481-1494.

Tang, X., Xie, M., Kim, Y. J., Zhou, J., Klessig, D.F., and Martin, G. B. 1999. Overexpression of Pto Activates Defense Responses and Confers Broad Resistance. Plant Cell.11:15-29. 
The Tomato Genome Consortium. 2012. The Tomato Genome Sequence Provides Insights into Fleshy Fruit Evolution. Nature. 485: 635-641.

Thurston, G., Regan, S., Rampitsch, C., and Xing, T. 2005. Proteomic and Phosphoproteomic Approaches to Understand Plant-Pathogen Interactions. Physiological \& Molecular Plant Pathology.66: 3-11.

Ulm, R., Ichimura, K., Mizoguchi, T., Peck, S.C., Zhu, T., Wang, X., Shinozaki, K., and Paszkowski, J. 2002. Distinct Regulation of Salinity and Genotoxic Stress Responses by Arabidopsis MAP Kinase Phosphatase 1. Molecular Biology Journal. 21:6483-6493.

Van Loon, L.C., Rep, M., and Pieterse, C.M .2006. Significance of Inducible DefenseRelated Proteins in Infected Plants. Annual Review of Phytopathology. 44:135-162.

Wang, P., Du, Y., Li, Y., Ren, D., and Song, C.P. 2010a. Hydrogen Peroxide-Mediated Activation of MAP Kinase 6 Modulates Nitric Oxide Biosynthesis and Signal Transduction in Arabidopsis. Plant Cell. 22:2981-2998.

Wang, J., Ding, H., Zhang, A., Ma, F., Cao, J., and Jiang, M. 2010b. A Novel MitogenActivated Protein Kinase Gene in Maize (Zea mays), ZmMPK3, is Involved in Response to Diverse Environmental Cues. Journal of Integrative Plant Biology. 52: 442-452.

Wattenberg, E., Badria, F.A., and Shier, W.T. 1996. Activation of Mitogen Activated Protein Kinase by the Carcinogenic Mycotoxin Fumonosin B1. Biochemical \& Biophysical Research Comminications. 227:622-627.

Wu, W., Ding, Y., Wei, W., Davis, R. E., Lee, M., Hammond, R.W., and Zhao, Y. 2012. Salicylic Acid-Mediated Elicitation of Tomato Defense against Infection by Potato Purple Top Phytoplasma. Annals of Applied Biology.161: 6-45.

Xing, T. 2007. Signal Transduction Pathways and Disease Resistant Genes and Their Applications to Fungal Disease Control. In: Biotechnology and Plant Disease Management, (Punja Z.K., Be Boer S.H., Sanfaçon H. ed.), pp 1-15, CAB International, UK.

Xing, T., Fan, T., Han, S.Y., Djuric-Ciganovic, S., Jordan, M., and Wang, X.J. 2005. Programmed Cell Death in Plant Disease Resistance: Pathways and Components. Recent Research Developments in Bioenergetics 3:33-44.

Xing, T., and Jordan, M. 2000. Genetic Engineering of Plant Signal Transduction Mechanisms. Plant Molecular Biology Reporter. 18: 309-318.

Xing, T., and Laroche, A. 2011. Revealing Plant Defense Signalling Getting More Sophisticated with Phosphoproteomics. Plant Signaling \& Behavior.6:1-6. 
Xing, T., Malik, K., Martin, T., and Mik, B.L. 2001. Activation of Tomato PR and Wound-Related Genes by a Mutagenized Tomato MAP Kinase Kinase through Divergent Pathways. Plant Molecular Biology.46:109-120.

Xing, T., Ouellet, T., and Miki, B.L. 2002. Towards Genomic and Proteomic Studies of Protein Phosphorylation in Plant-Pathogen Interactions. Trends in Plant Science. 7:224230.

Xing, T., Rampitsch, C., Sun, S., Romanowski, A., Conroy, C., Stebbing, J.A., and Wang, X. 2008. TAB2, a Nucleoside Diphosphate Protein Kinase, is a Component of the tMEK2 Disease Resistance Pathway in Tomato. Physiological \& Molecular Plant Pathology.73: 33-39.

Yang, A. K., Moon, H., Kim, G., Lim, J. C., Hong, C.J., Lim, O.C., and Yun, D. 2003.

NDP Kinase2 Regulates Expression of Antioxidant Genes in Arabidopsis. Proceedings of the Japan Academy. Series B Physical and biological sciences.79: 86-91.

Yang, C. H., Huang, C. C., and Hsu, K. S. 2012. A Critical Role for Protein Tyrosine Phosphatase Nonreceptor Type 5 in Determining Individual Susceptibility to Develop Stress-Related Cognitive and Morphological Changes. Journal of Neuroscience. 32:7550 -7562 .

Young, A.S., Mina, G. J., Denny, W. P., and Terry, K. S. 2012. Sphingolipid and Ceramide Homeostasis: Potential Therapeutic Targets. Biochemistry Research International. 2012: 1-12.

Zarate, I. S., Kempema, A. L., and Walling, L. L. 2007. Silverleaf Whitefly Induces Salicylic Acid Defenses and Suppresses Effectual Jasmonic Acid Defenses. Plant Physiology.143: 866-875.

Zheng, Z., Abu Qamar, S., Chen, Z., and Mengiste, T.2006. Arabidopsis WRKY33 Transcription Factor is required for Resistance to Necrotrophic Fungal Pathogens. Plant Journal.48: 592-605.

Zhou, X., Jiang, Y., and Yu, D. 2011 .WRKY22 Transcription Factor Mediates DarkInduced Leaf Senescence in Arabidopsis. Molecular Cells.31:303-13.

Zhuang, S., and Schnellmann, R.G. 2006. A Death-Promoting Role for Extracellular Signal-Regulated Kinase. Journal of Pharmacology \& Experimental Therapeutics. 319:991-997. 


\section{APPENDIX}

Appendix 1: ScanSite Database Analysis of Arabidopsis AtMPK3 Protein.
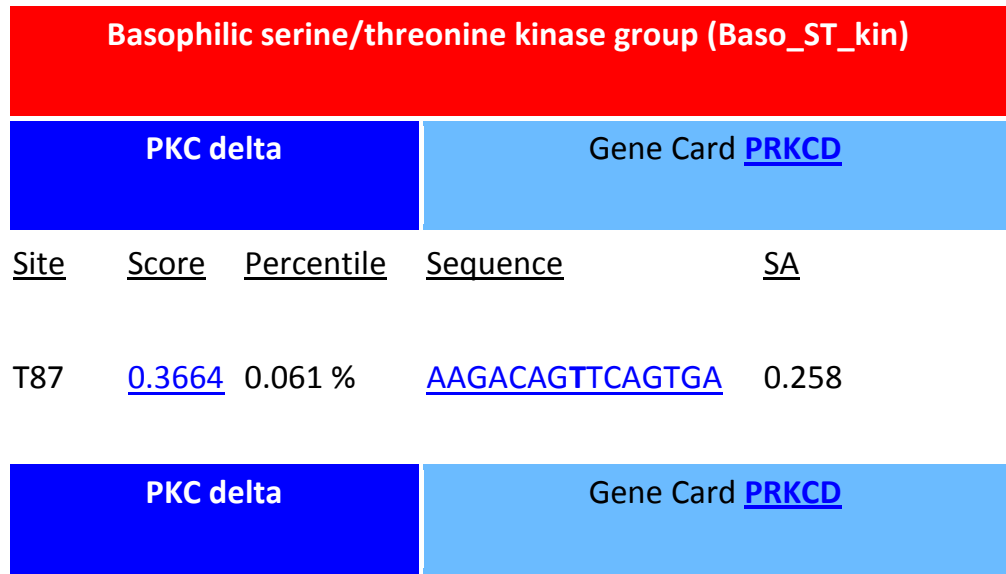

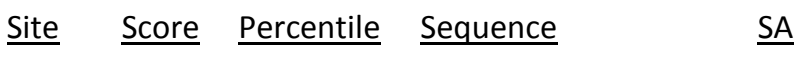

$\begin{array}{lllll}\text { T795 } & \underline{0.3664} & 0.061 \% \quad \underline{\text { AACATTATTCATAGG }} & 0.377\end{array}$

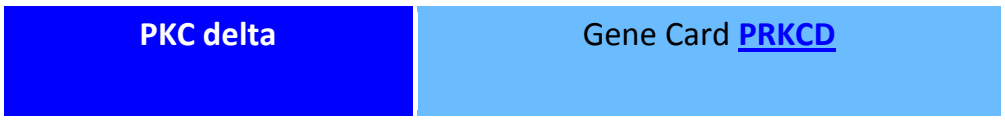

Site Score Percentile Sequence $\underline{\text { SA }}$

$\begin{array}{lllll}\text { T852 } & \underline{0.3542} \quad 0.043 \% \quad \underline{\text { AATCTGATCTCGGTT }} & 0.137\end{array}$

Acidophilic serine/threonine kinase group (Acid_ST_kin)

Casein Kinase 1

$\underline{\text { Site }} \underline{\text { Score }} \underline{\text { Percentile }}$ Sequence $\underline{S A}$

$\begin{array}{llll}180 \quad \underline{0.3741} & 0.175 \% \quad \underline{\text { TGTTTGGTCTGTTGG }} & 0.248\end{array}$ 
Appendix 2: ScanSite Database Analysis of Arabidopsis AtMPK6 Protein.

\begin{tabular}{|c|c|c|c|}
\hline \multicolumn{4}{|c|}{ Src homology 3 group (SH3) } \\
\hline \multicolumn{2}{|r|}{ Sre SH3 } & \multicolumn{2}{|c|}{ Gene Card $\underline{\text { SRC }}$} \\
\hline Site & $\underline{\text { Percentile }}$ & Sequence & $\underline{\mathrm{SA}}$ \\
\hline P303 & $\underline{0.3977} 0.100 \%$ & KRYIRQLPPYPRQSI & 1.896 \\
\hline
\end{tabular}

Grb2 SH3

$\underline{\text { Site }} \underline{\text { Score }} \underline{\text { Percentile }} \underline{\text { Sequence }} \underline{\text { SA }}$

P303 $\quad \underline{0.4547} \quad 0.159 \% \quad \underline{\text { KRYIRQLPPYPRQSI }} 1.896$

p85 SH3 mode1

Gene Card PIK3R1

9Site $\underline{\text { Score }}$ Percentile Sequence

$\underline{\mathrm{SA}}$

P303 $\underline{0.4818} \quad 0.102 \% \quad \underline{\text { KRYIRQLPPYPRQSI }} 1.896$

\section{Basophilic serine/threonine kinase group (Baso_ST_kin)}

Protein Kinase A

$\underline{\text { Site }} \underline{\text { Score }}$ Percentile Sequence

$\mathrm{T} 338 \underline{\underline{0.2943}} \quad 0.085 \%$

\section{AMP_Kinase}

$\underline{\text { Site }} \underline{\text { Score }}$ Percentile Sequence

Gene Card PRKAA1

Gene Card PRKACG

$\underline{\mathrm{SA}}$

FDPRRRITVLDALAH 0.464

S215 $\underline{0.5250} \quad 0.127 \% \quad \underline{\text { FGLARVTSESDFMTE }} 1.275$ 
Appendix 3: ScanSite Database Analysis of Arabidopsis AtNDPK Protein.

\begin{tabular}{|c|c|c|c|}
\hline \multicolumn{4}{|c|}{ Src homology 2 group (SH2) } \\
\hline $\mathbf{P L}$ & g C-terminal SH2 & \multicolumn{2}{|c|}{ Gene Card PLCG1 } \\
\hline$\underline{\text { Site }}$ & $\underline{\text { Score }} \underline{\text { Percentile }}$ & $\underline{\text { Sequence }}$ & $\underline{\mathrm{SA}}$ \\
\hline Y87 & $\underline{0.3758} 0.153 \%$ & MEDVEE & 0.462 \\
\hline \multicolumn{4}{|c|}{ Basophilic serine/threonine kinase group (Baso_ST_kin) } \\
\hline \multicolumn{2}{|r|}{ Clk2 Kinase } & \multicolumn{2}{|c|}{ Gene Card CLK2 } \\
\hline Site & Percentile & Sequence & $\underline{\mathrm{SA}}$ \\
\hline S65 & $\underline{0.4261} 0.055 \%$ & RRRLRAS & 0.97 \\
\hline
\end{tabular}




\section{Appendix4: Analysis of Solanum lycopersicum PR1.}

A

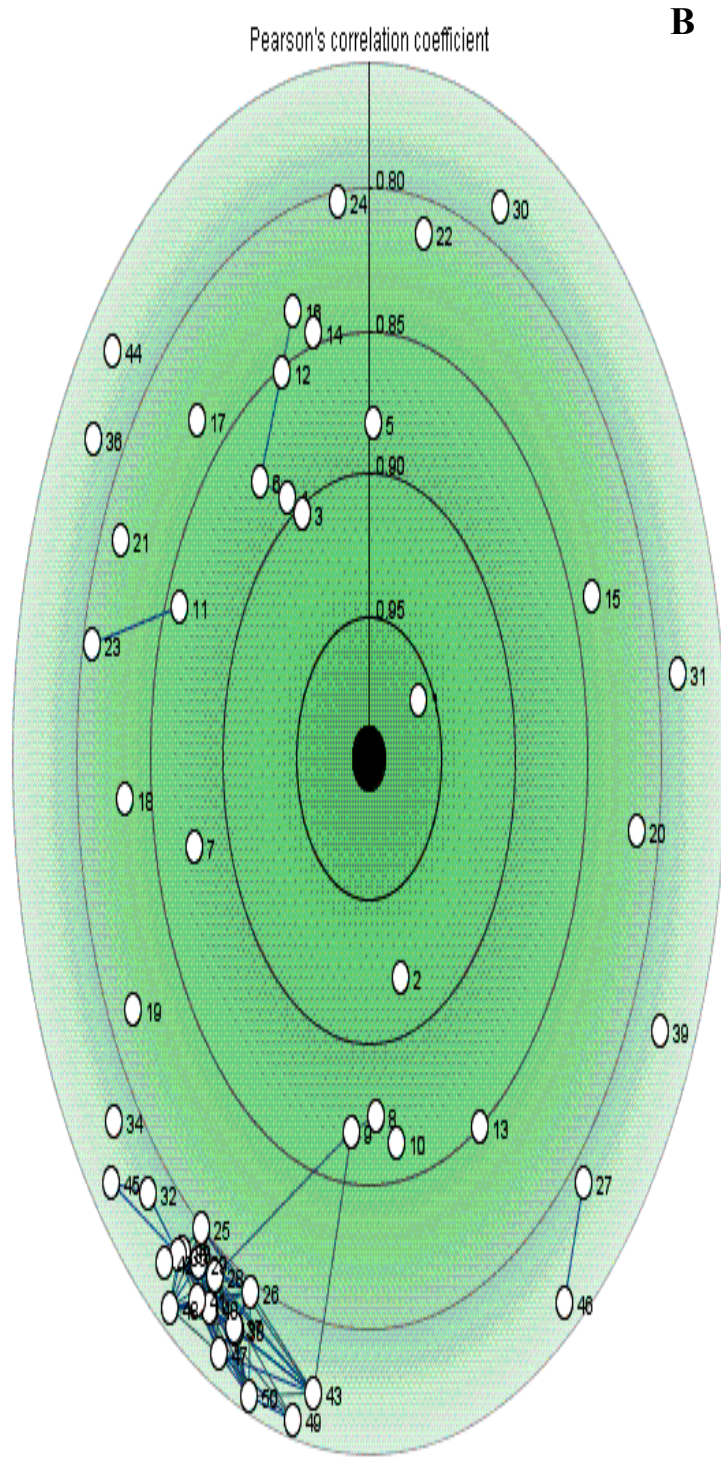

Description of the most correlated genes (top 50)

\begin{tabular}{|c|c|c|c|}
\hline & Gene & Score & Description \\
\hline & Solyc03g09... & 0.96 & ITAG: Solyc03g096550.2.1 genomic_reference:SL2... \\
\hline & Solyc01 g07... & 0.92 & ITAG: Solyc01g073820.2.1 genomic_reference:SL2... \\
\hline & Solyc05g04... & 0.90 & ITAG: Solyc05g041920.2.1 genomic_reference:SL2... \\
\hline & Les.3528.1... & 0.89 & UniGene: Les.3826| Aldehyde oxidase, DFCI LeGI: ... \\
\hline & Solyc10g08... & 0.88 & Gene Symbol LE: lin6| Invertase 6, ITAG: Solyc10g0... \\
\hline & Solyc09g01... & 0.88 & Gene Symbol LE: ctu1| Glutation-S-transferase, ITA.. \\
\hline & Solyc01 g06... & 0.88 & Gene Symbol LE: AF033194| Dehydroquinate dehy... \\
\hline & Solyc07g00... & 0.87 & ITAG: Solyc07g005090.2.1 genomic_reference:SL2... \\
\hline & Les. $3809.2 \ldots$ & 0.87 & UniGene: Les.3809| Exon 1 of NIT2 gene, GenBank... \\
\hline 10 & Solyc04g07... & 0.86 & ITAG: Solyc04g072000.2.1 genomic_reference:SL2... \\
\hline 11 & Solyc03g09... & 0.86 & ITAG: Solyc03g096430.1.1 evidence_code:10F0H0... \\
\hline 12 & Solyc12g01... & 0.85 & ITAG: Solyc12g014010.1.1 evidence_code:10F0H1 ... \\
\hline 13 & Solyc07g00... & 0.85 & ITAG: Solyc07g008240.2.1 genomic_reference:SL2 $\ldots$ \\
\hline 14 & Les.4307.1... & 0.85 & UniGene: Les.4307| PR5-like protein, DFCI LeGI: T... \\
\hline 15 & Solyc01g05... & 0.84 & Gene Symbol LE: TOMB13GLUB| Beta-1,3-glucana... \\
\hline 16 & Solyc12g01... & 0.83 & ITAG: Solyc12g014010.1.1 evidence_code:10F0H1 ... \\
\hline 17 & Solyc03g09... & 0.83 & ITAG: Solyc03g095780.1.1 evidence_code:10F1H1 ... \\
\hline 18 & Solyc09g01... & 0.83 & ITAG: Solyc09g011590.2.1 genomic_reference:SL2... \\
\hline 19 & Solyc06g07... & 0.82 & ITAG: Solyc06g071060.1.1 evidence_code:10F0H1 ... \\
\hline 20 & Solyc05g05... & 0.82 & Gene Symbol LE: Coi1| Coronatine-insensitive 1, IT... \\
\hline 21 & Solyc07g06... & 0.81 & ITAG: Solyc07g061960.2.1 genomic_reference:SL2... \\
\hline & Solyc05g01... & 0.81 & ITAG: Solyc05g011920.2.1 genomic_reference:SL2... \\
\hline 23 & Solyc06g07... & 0.81 & ITAG: Solyc06g071060.1.1 evidence_code \\
\hline 24 & Les.5229.1... & 0.80 & UniGene: Les.5229| Clone 132251R, mRNA seque... \\
\hline 5 & Solyc00g07... & 0.80 & ITAG: Solyc00g072400.2.1 genomic_reference:SL2... \\
\hline 26 & Solyc09g01... & 0.80 & ITAG: Solyc09g011510.2.1 genomic_reference:SL2... \\
\hline 27 & Solyc08g00... & 0.79 & ITAG: Solyc08g006470.2.1 genomic_reference:SL2... \\
\hline 28 & Les. $3480.1 \ldots$ & 0.79 & UniGene: Les.3480 이 Sulfate transporter 1, DFCI Le... \\
\hline 9 & Solyc00g07... & 0.79 & ITAG: Solyc00g072400.2.1 genomic_reference:SL2... \\
\hline 30 & Solyc01g09... & 0.79 & ITAG: Solyc01 g094840.2.1 genomic_reference:SL2... \\
\hline 31 & Solyc08g08... & 0.79 & Gene Symbol LE: pldb1| Phospholipase PLDb1, IT... \\
\hline 32 & Solycos & 0.79 & ITAG: Solyc09g009520.2.1 genomic_reference:SL2... \\
\hline 3 & lyc05g05... & 0.78 & ITAG: Solyc05g056550.2.1 genomic_reference:SL2... \\
\hline 4 & Solyc11 g00... & 0.78 & ITAG: Solyc11 g007570.1.1 evidence_code:10F1H1 ... \\
\hline & Solyc02g08... & 0.78 & Gene Symbol LE: AY344539| Alpha-DOX1, ITAG: So... \\
\hline & Solyc07g06... & 0.78 & ITAG: Solyc07g062500.2.1 genomic_reference:SL2... \\
\hline & Solyc02g07... & 0.78 & ITAG: Solyc02g070130.1.1 evidence_code:10F0H1 ... \\
\hline & Solyc09g01... & 0.78 & ITAG: Solyc09g011510.2.1 genomic_reference:SL2... \\
\hline 39 & Solyc06g07... & 0.78 & ITAG: Solyc06g072650.1.1 evidence_code:10F1H0... \\
\hline & Solyc07g04... & 0.78 & Gene Symbol LE: EU503151| Laccase, ITAG: Solyc... \\
\hline & Solyc $04 \mathrm{~g} 00 \ldots$ & 0.78 & ITAG: Solyc04g005620.2.1 genomic_reference:SL2... \\
\hline 42 & Solyc02g07... & 0.77 & UniGene: Les.8547| Transcribed locus, weakly sim... \\
\hline 43 & Solyc07g04... & 0.77 & Gene Symbol LE: tpx2I TOMTPX2A peroxidase, ITA... \\
\hline 44 & Les. $3735.1 \ldots$ & 0.77 & DFCI LeGI: TC225942 weakly similar to UniRef1 00... \\
\hline 45 & Solyc10g08... & 0.77 & ITAG: Solyc10g084120.1.1 evidence_code:10F0H1 ... \\
\hline 46 & Solyc08g00... & 0.77 & ITAG: Solyc08g006470.2.1 genomic_reference:SL2... \\
\hline & Solyc01 g10... & 0.77 & Gene Symbol LE: mdip1| Germin, ITAG: Solyc01g1... \\
\hline & Solyc02g08... & 0.76 & ITAG: Solyc02g084780.2.1 genomic_reference:SL2... \\
\hline & Solyc09g08... & 0.76 & ITAG: Solyc09g082300.2.1 genomic_reference:SL2... \\
\hline 50 & Solyc09g01... & 0.76 & 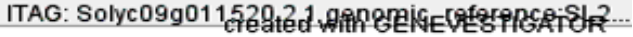 \\
\hline
\end{tabular}

Figure 1: A. The co-expression analysis of Solanum lycopersicum PR1 gene; B.

Description of the most correlated genes to PR1 (top 50). 


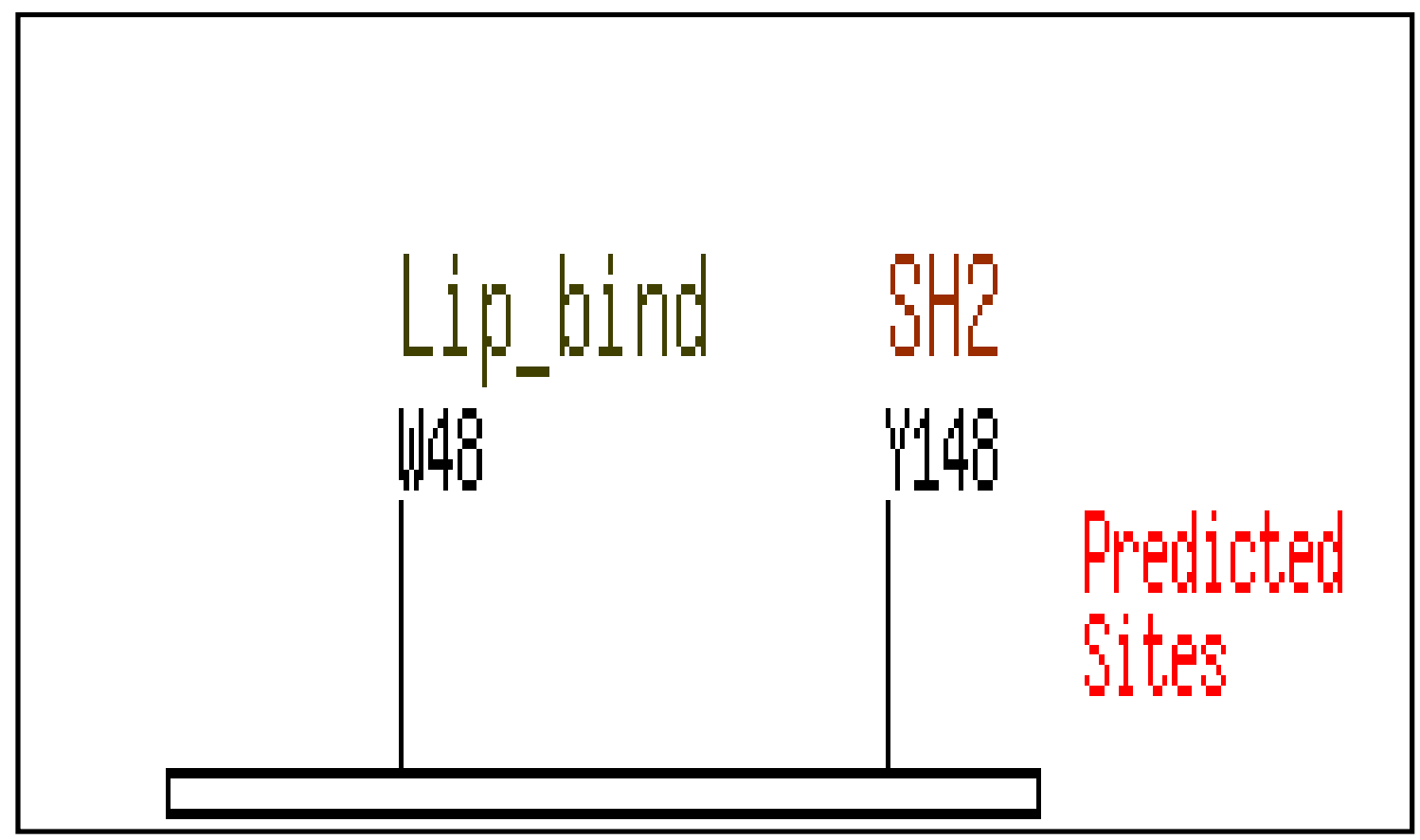

Figure 2: Medium stringency ScanSite Motif scan output for Solanum lycopersicum PR1 protein sequence indicating a potential SH2 binding site and lipid binding $\mathrm{PH}$ domain. 


\begin{tabular}{|c|c|c|}
\hline \multicolumn{3}{|c|}{ Src homology 2 group (SH2) } \\
\hline \multicolumn{2}{|r|}{ Nck SH2 } & Gene Card NCK1 \\
\hline Site & Score Percentile & Sequence \\
\hline Y148 & $\underline{0.5017} 0.998 \%$ & WYFITCNYDPPGNWR 1.283 \\
\hline \multicolumn{3}{|c|}{ Lipid binding group (Lip_bind) } \\
\hline & P3-binding PH & Gene Card PIP3-E \\
\hline
\end{tabular}

Figure 3: ScanSite database analysis of Solanum lycopersicum PR1 protein. 


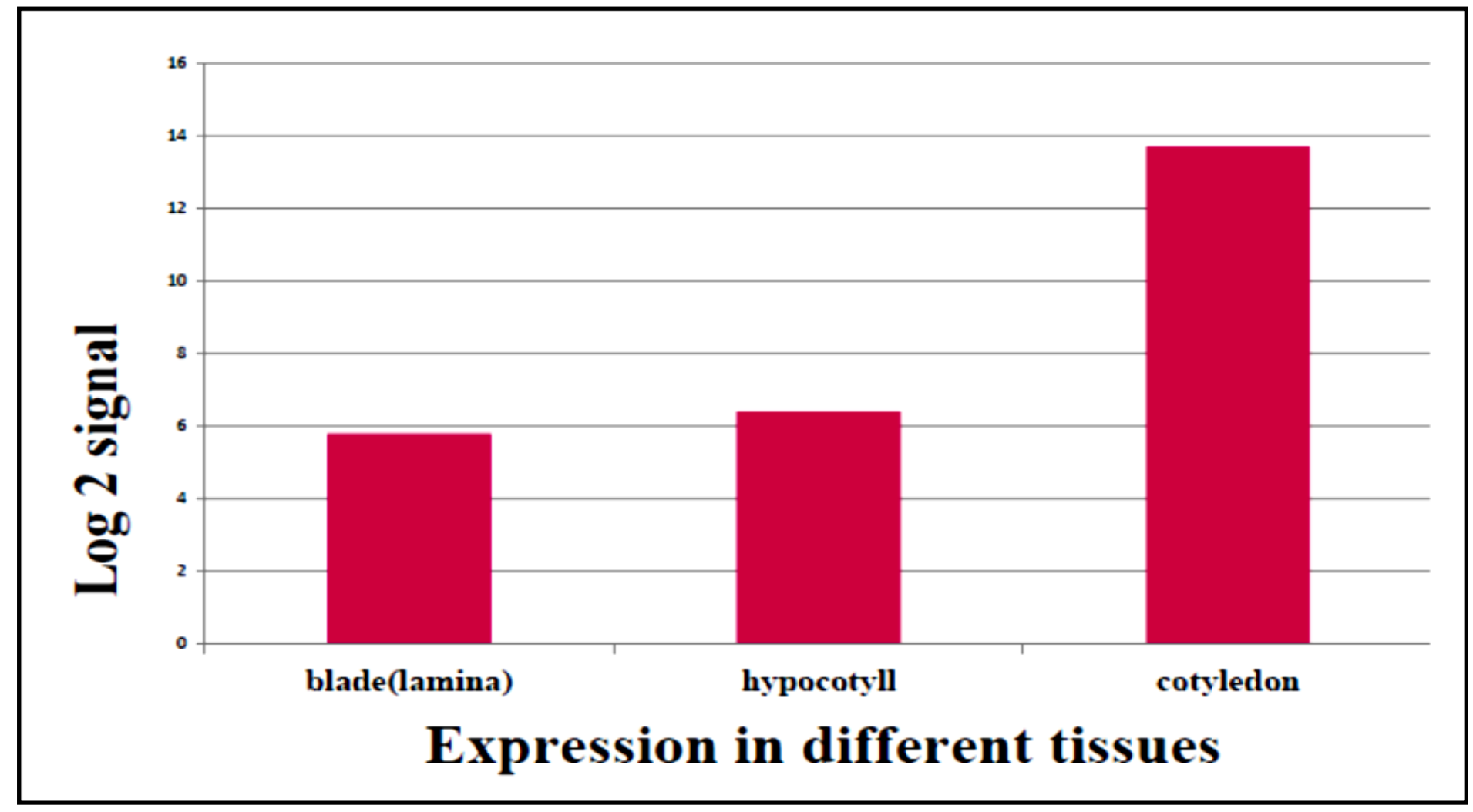

Figure 4: Expression levels of PR1 in different tissues of Solanum lycopersicum. 


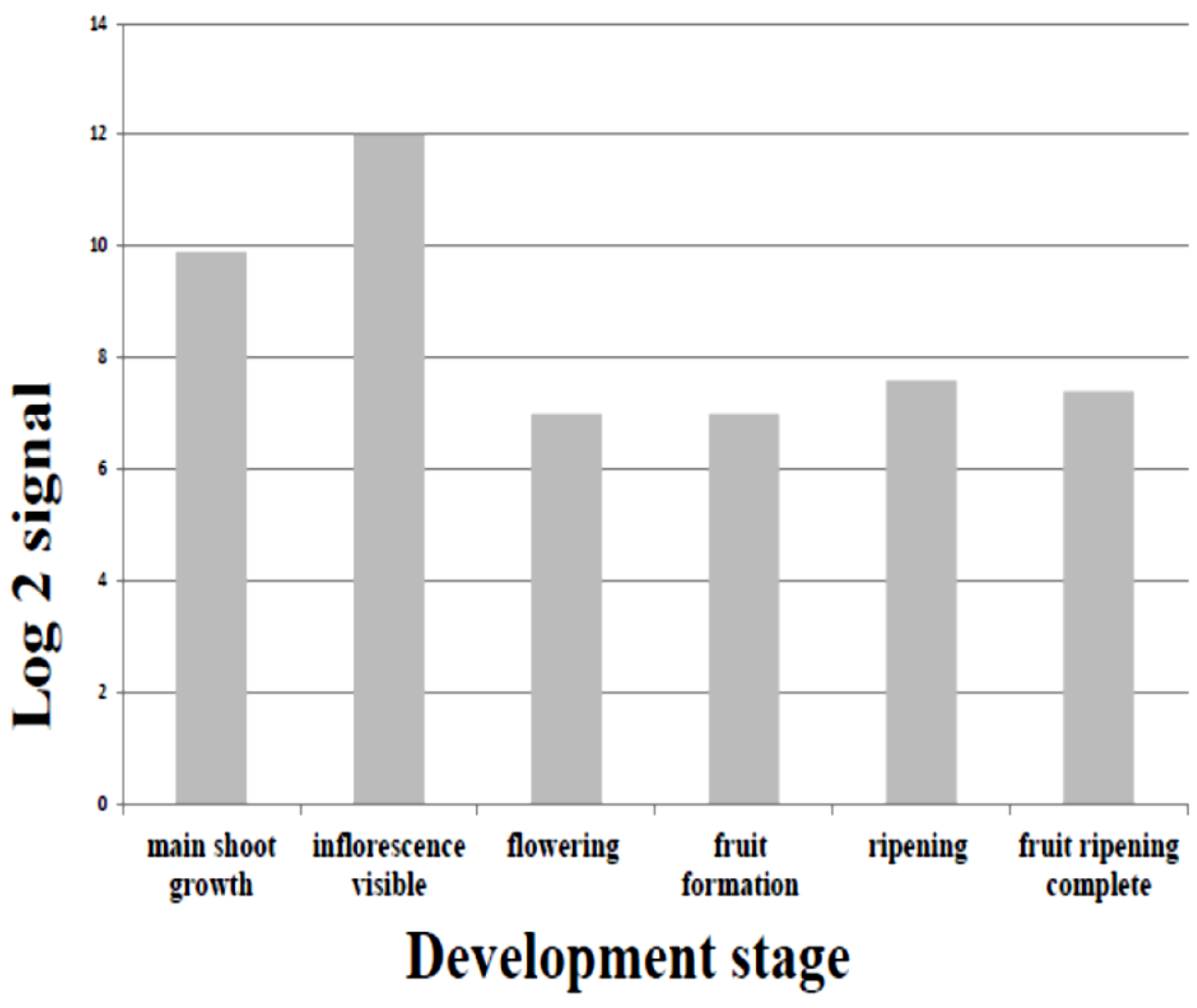

Figure 5: Overall expression of PR1 across different stages of development. 


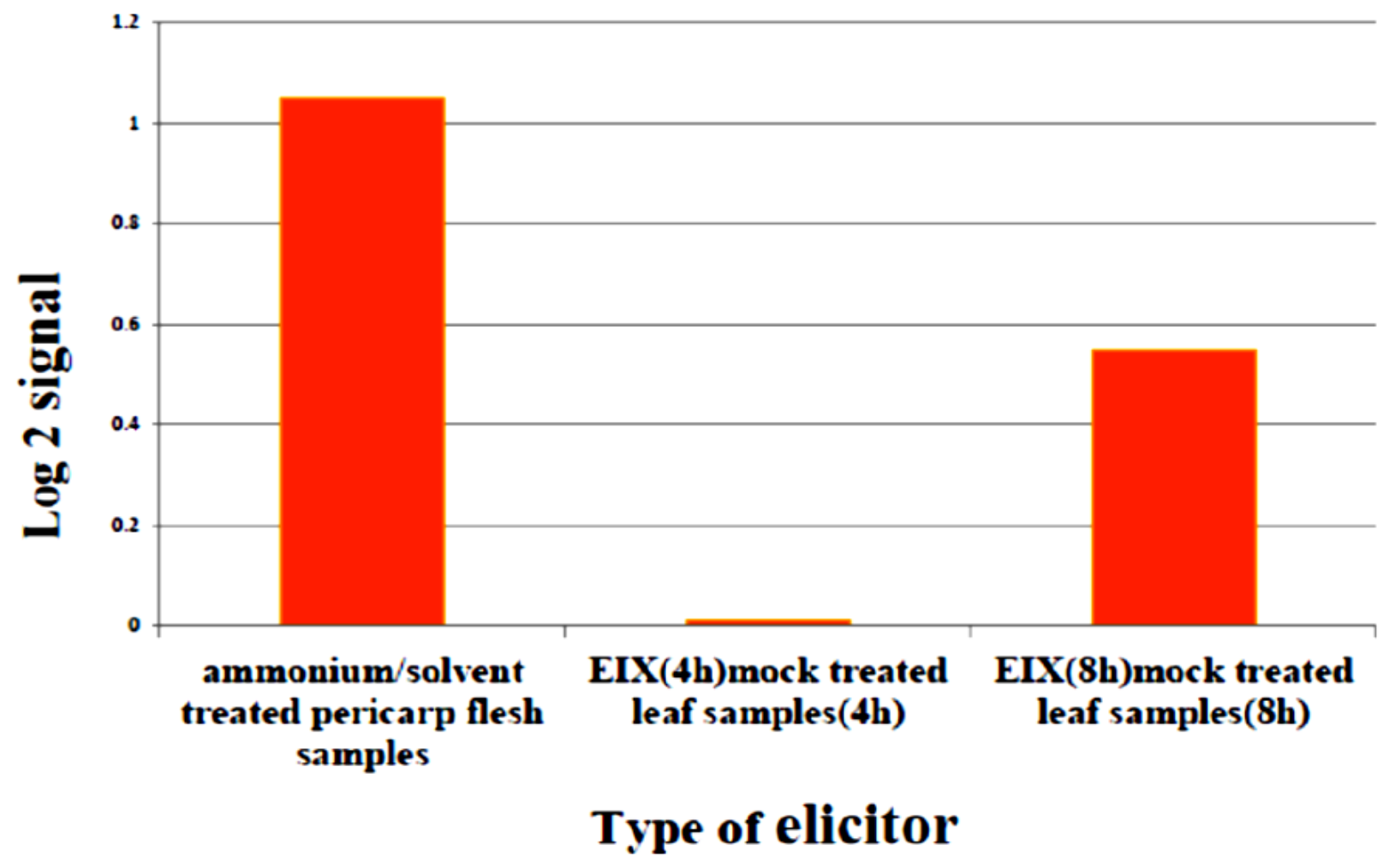

Figure 6: PR1 expression level in Solanum lycopersicum leaves exposed to elicitor EIX. 


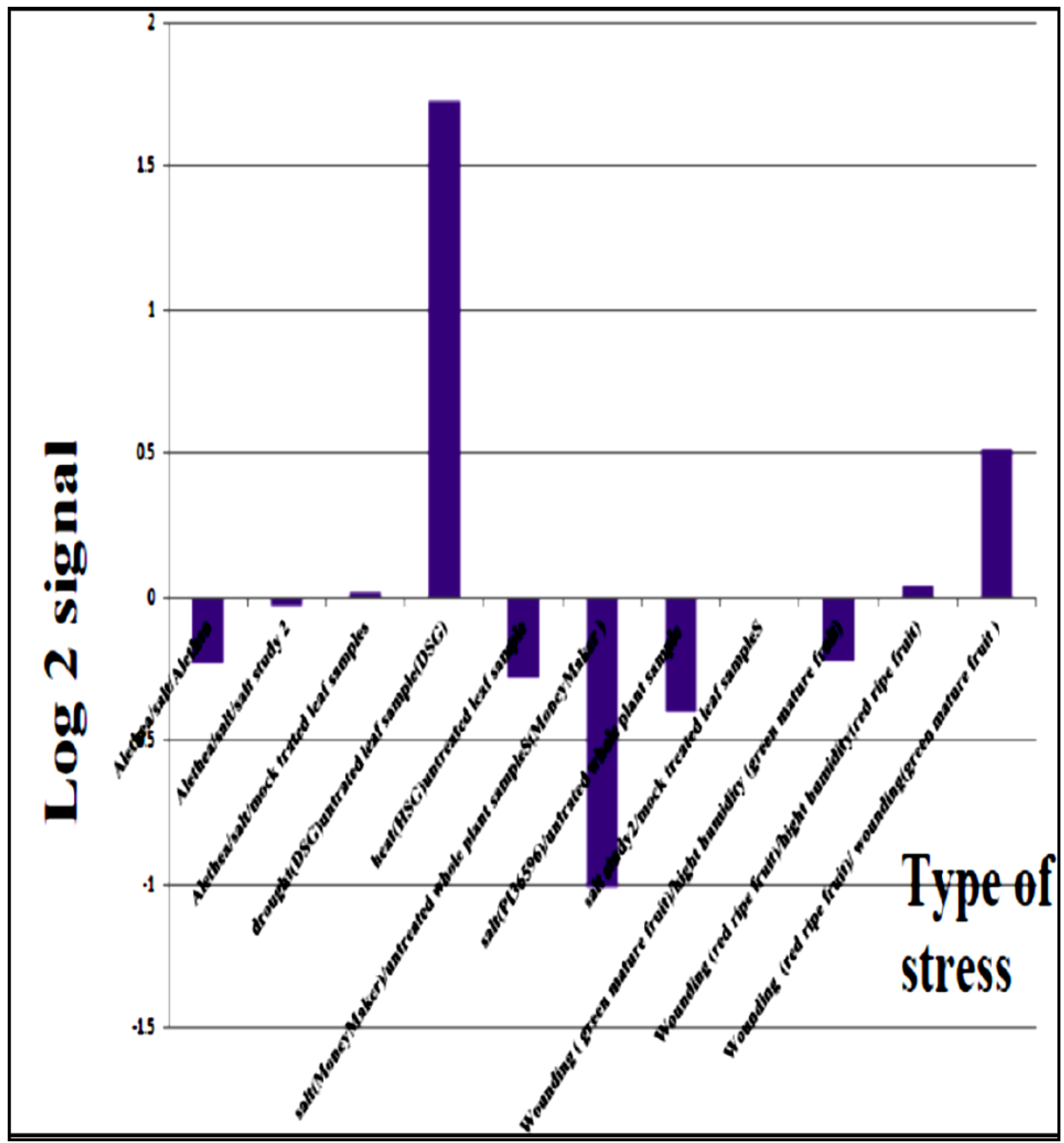

Figure 7: PR1 expression level in Solanum lycopersicum leaves exposed to different stresses. 


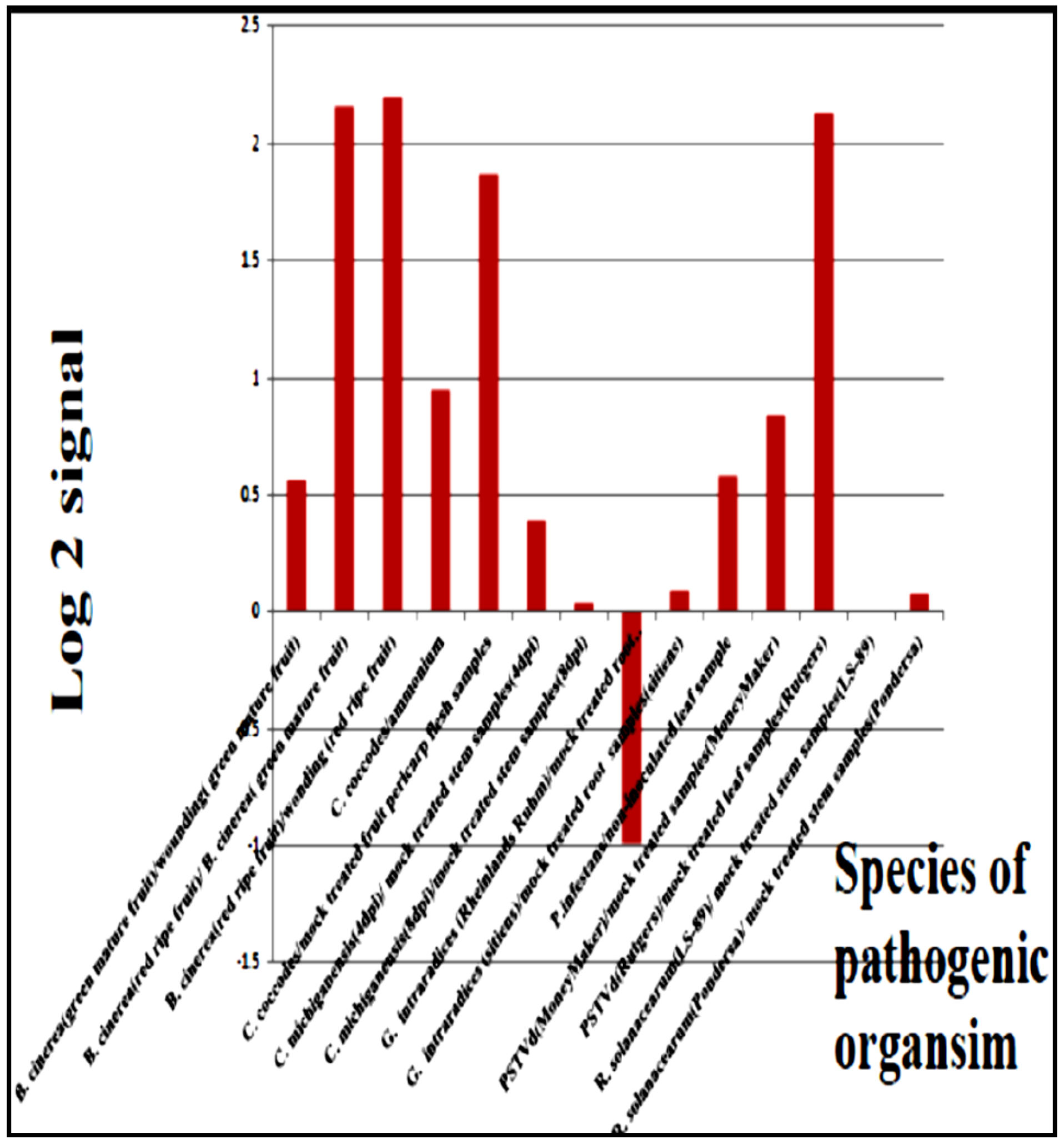

Figure 8: Effect of pathogens on PR1 expression level in Solanum lycopersicum leaves. 


\section{Appendix 5: Analysis of Solanum lycopersicum PDF1.2.}

A

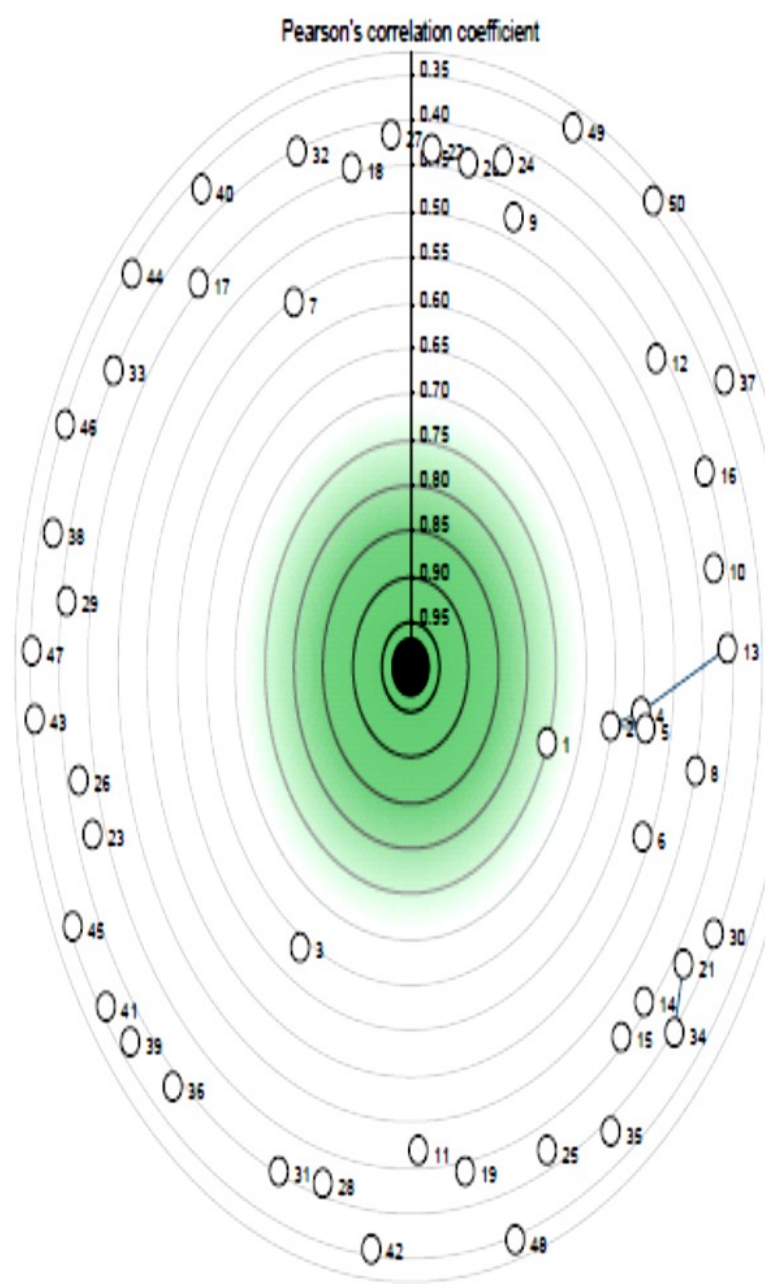

B

Figure 1: A. The co-expression analysis of Solanum lycopersicum PDF1.2 gene; B.

Description of the most correlated genes to PDF1.2 (top 50). 


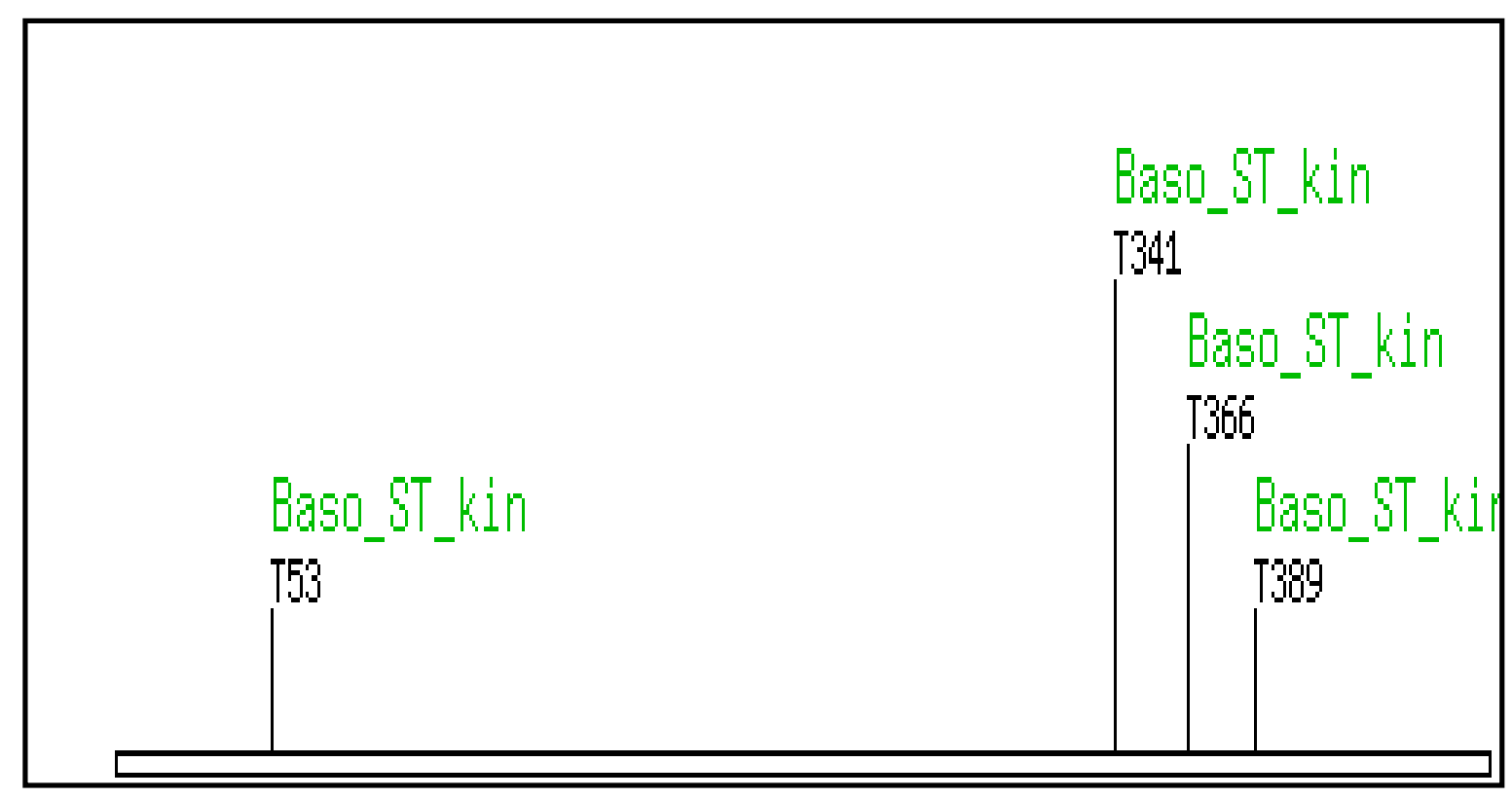

Figure 2: High stringency ScanSite Motif scan output for Solanum lycopersicum PDF1.2 protein sequence indicating multiple protein phosphorylation sites. 


\begin{tabular}{|c|c|c|c|}
\hline \multicolumn{4}{|c|}{ Basophilic serine/threonine kinase group (Baso_ST_kin) } \\
\hline \multicolumn{2}{|r|}{ PKC delta } & \multicolumn{2}{|c|}{ Gene Card PRKCD } \\
\hline$\underline{\text { Site }}$ & Score Percentile & Sequence & $\underline{\text { SA }}$ \\
\hline T341 & $\underline{0.3542} 0.043 \%$ & AAACTAGTCATGGTC & 0.258 \\
\hline \multicolumn{2}{|r|}{ PKC delta } & \multicolumn{2}{|c|}{ Gene Card PRKCD } \\
\hline Site & Score Percentile & Sequence & $\underline{\mathrm{SA}}$ \\
\hline T366 & $\underline{0.3764} 0.085 \%$ & TATGCAATTATGGTG & 0.710 \\
\hline \multicolumn{2}{|r|}{ PKC delta } & \multicolumn{2}{|c|}{ Gene Card PRKCD } \\
\hline$\underline{\text { Site }}$ & $\underline{\text { Score }}$ Percentile & $\underline{\text { Sequence }}$ & $\underline{\mathrm{SA}}$ \\
\hline T53 & $\underline{0.3848} 0.113 \%$ & ATGCTTGTCATGGCT & 0.369 \\
\hline \multicolumn{2}{|r|}{ PKC delta } & \multicolumn{2}{|c|}{ Gene Card PRKCD } \\
\hline Site & Score Percentile & Sequence & $\underline{\mathrm{SA}}$ \\
\hline
\end{tabular}

Figure 3: ScanSite Database Analysis of Solanum lycopersicum PDF1.2 protein. 


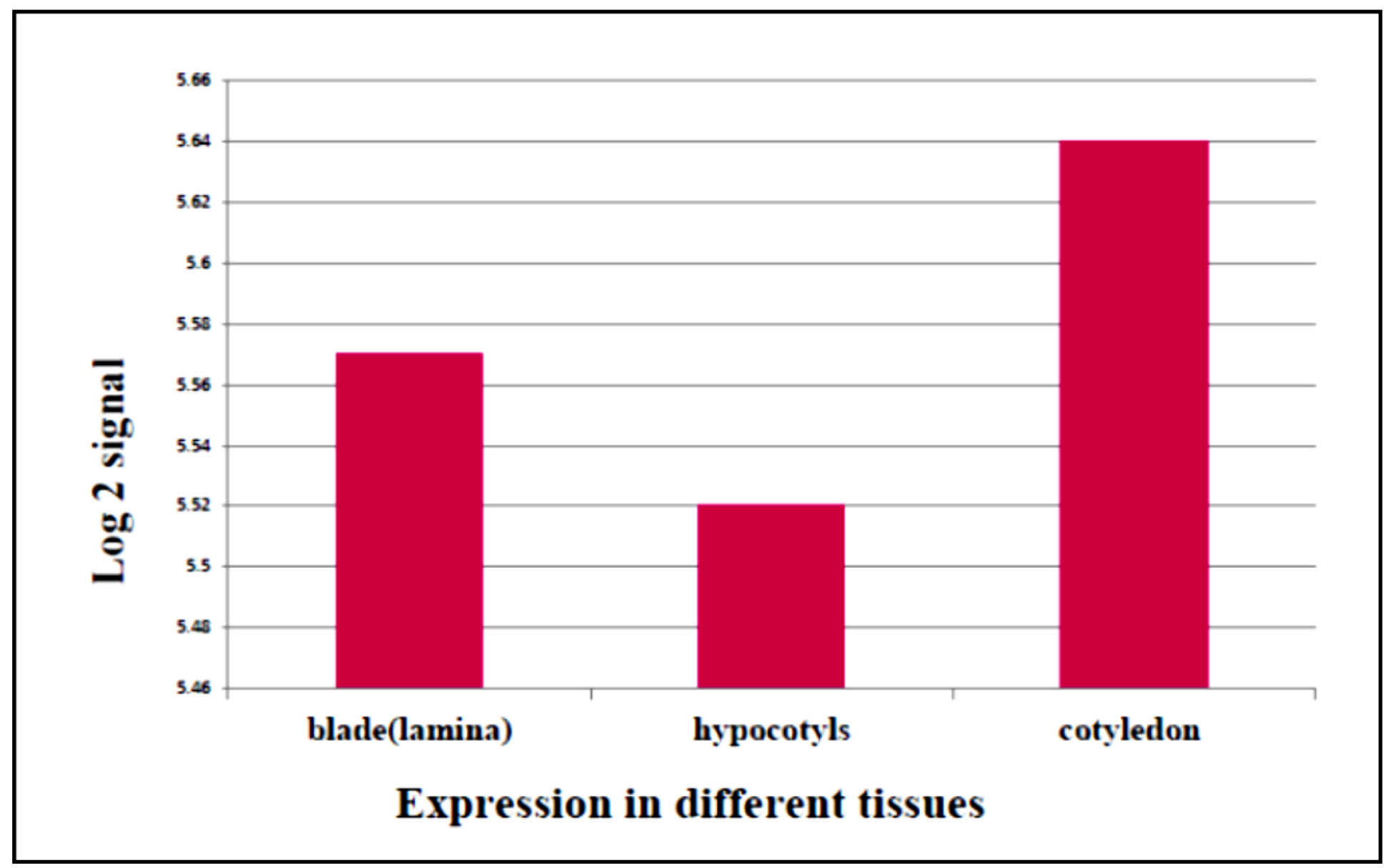

Figure 4: Expression levels of PDF1.2 in different tissues of Solanum lycopersicum. 


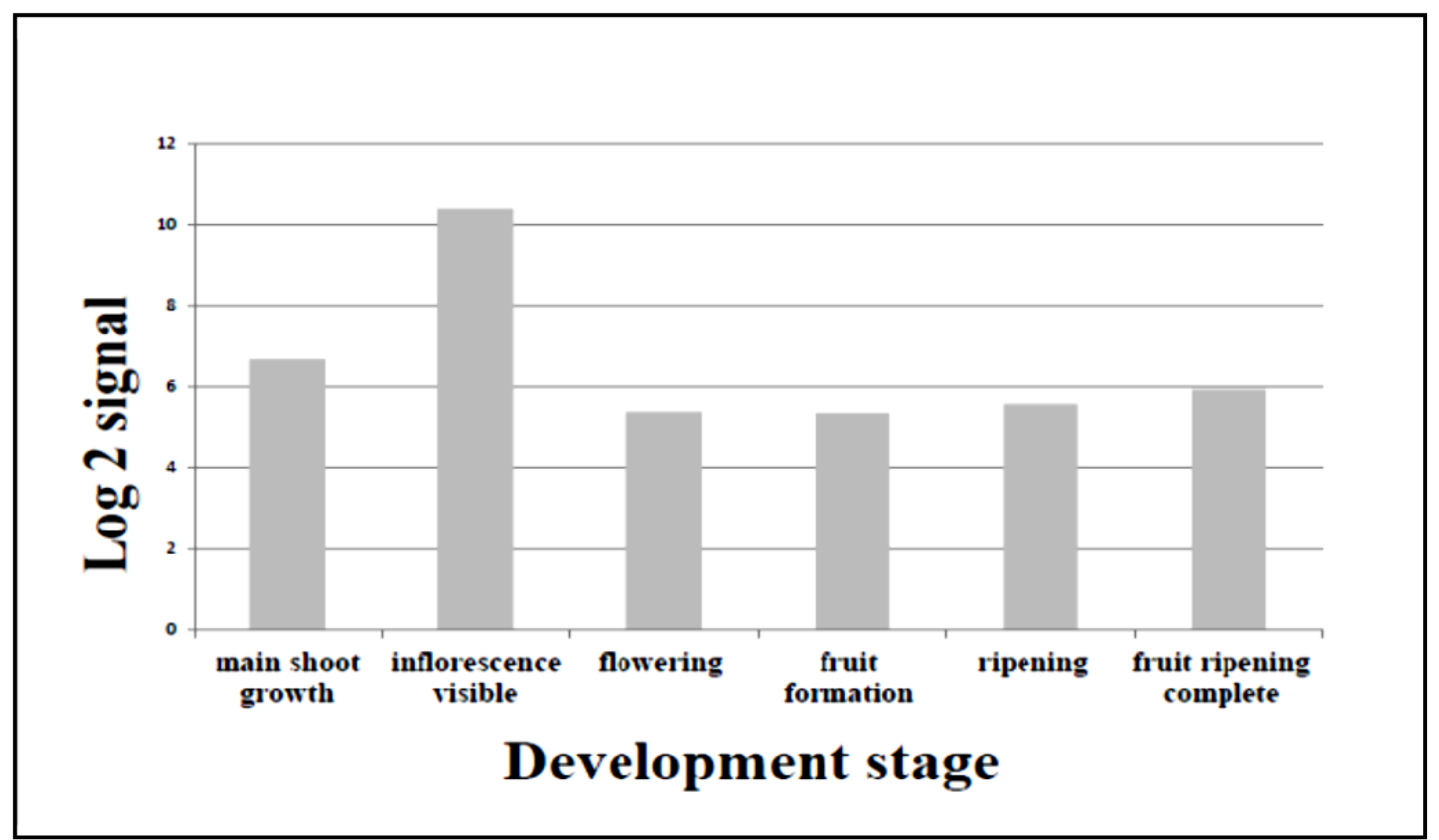

Figure 5: Overall expression of PDF1.2 across different stages of development. 


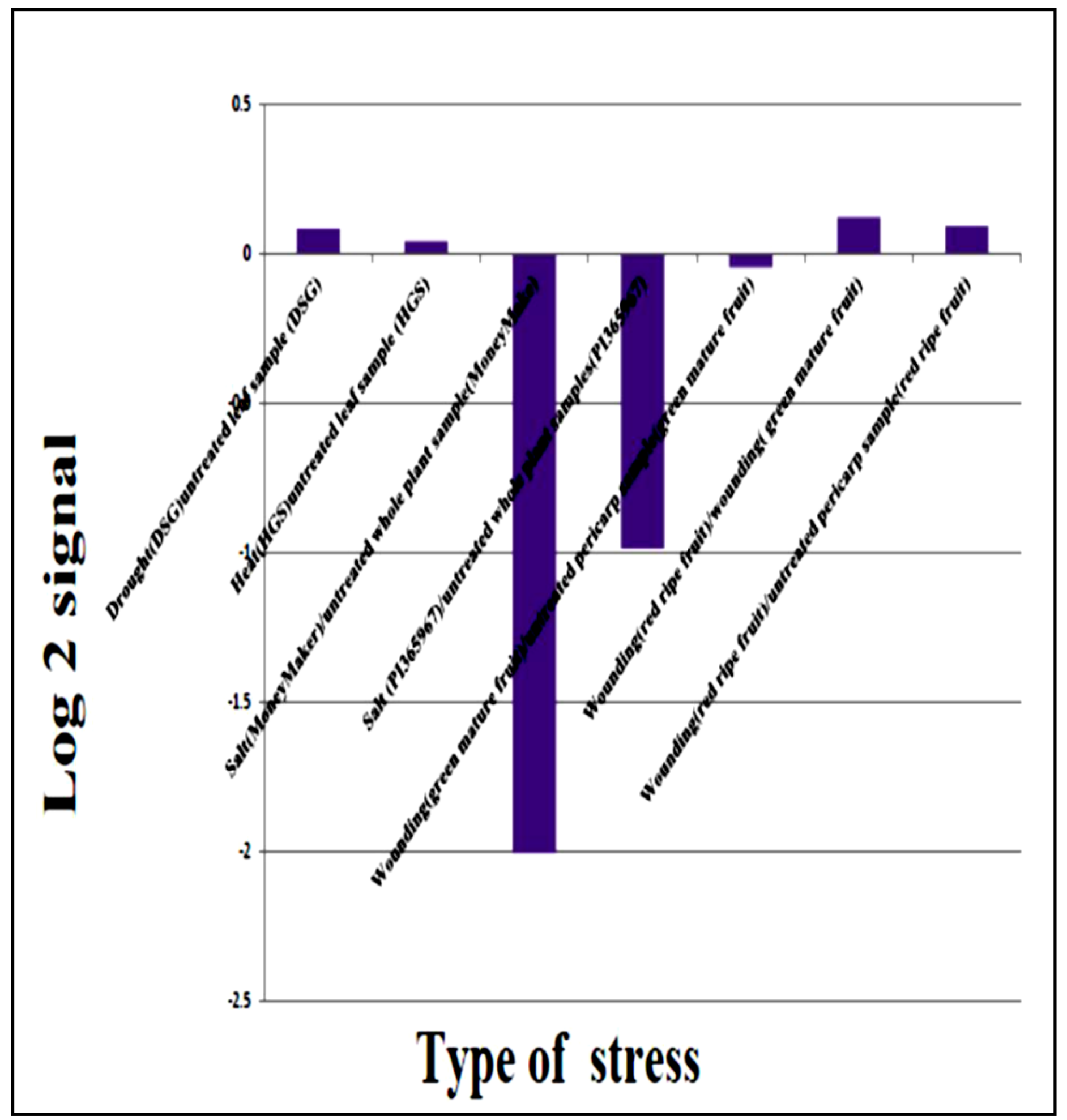

Figure 6: PDF1.2 expression level in Solanum lycopersicum leaves exposed to different types of stress. 


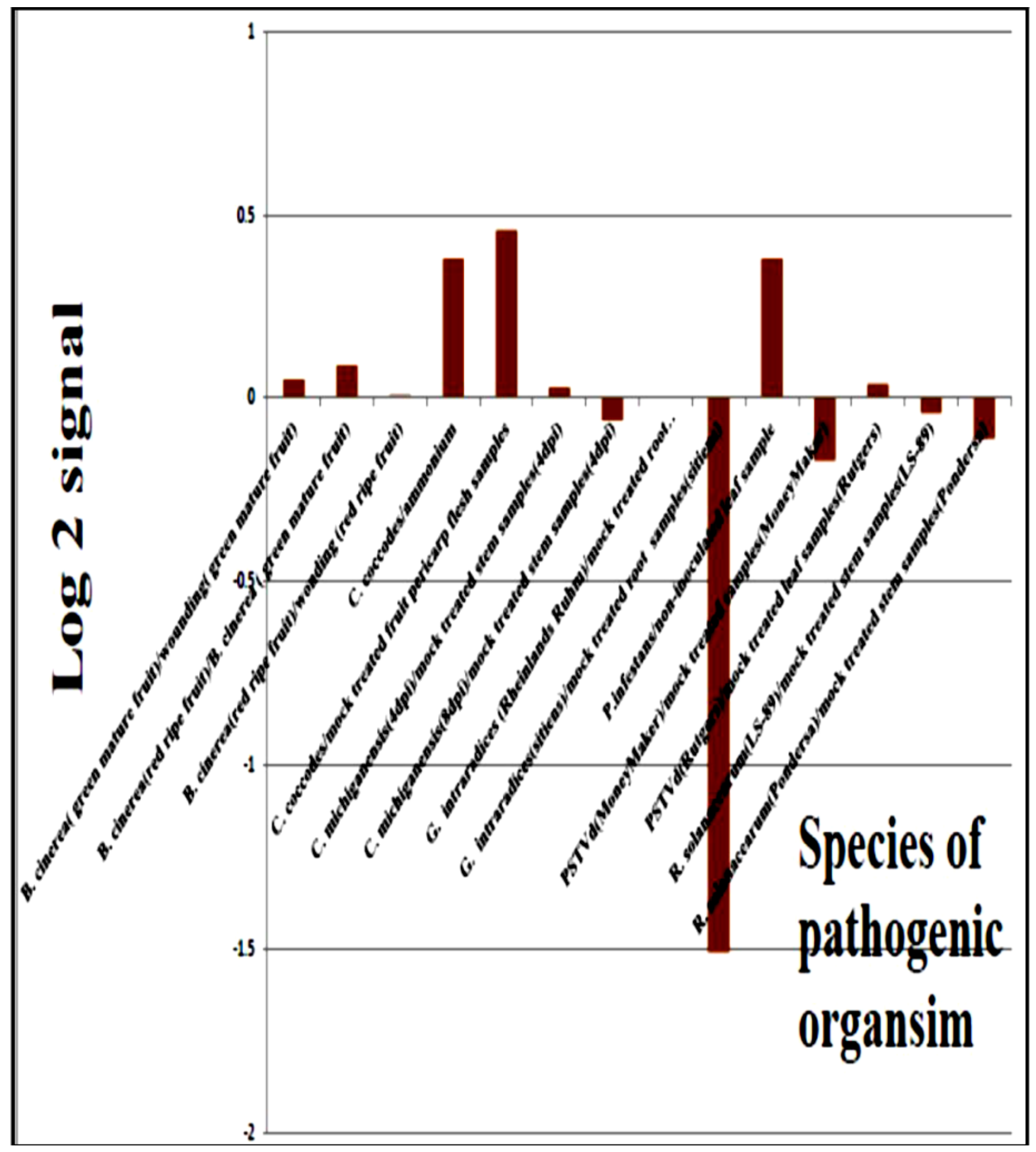

Figure 7: PDF1.2 expression level in Solanum lycopersicum leaves exposed to a variety of pathogenic organisms. 


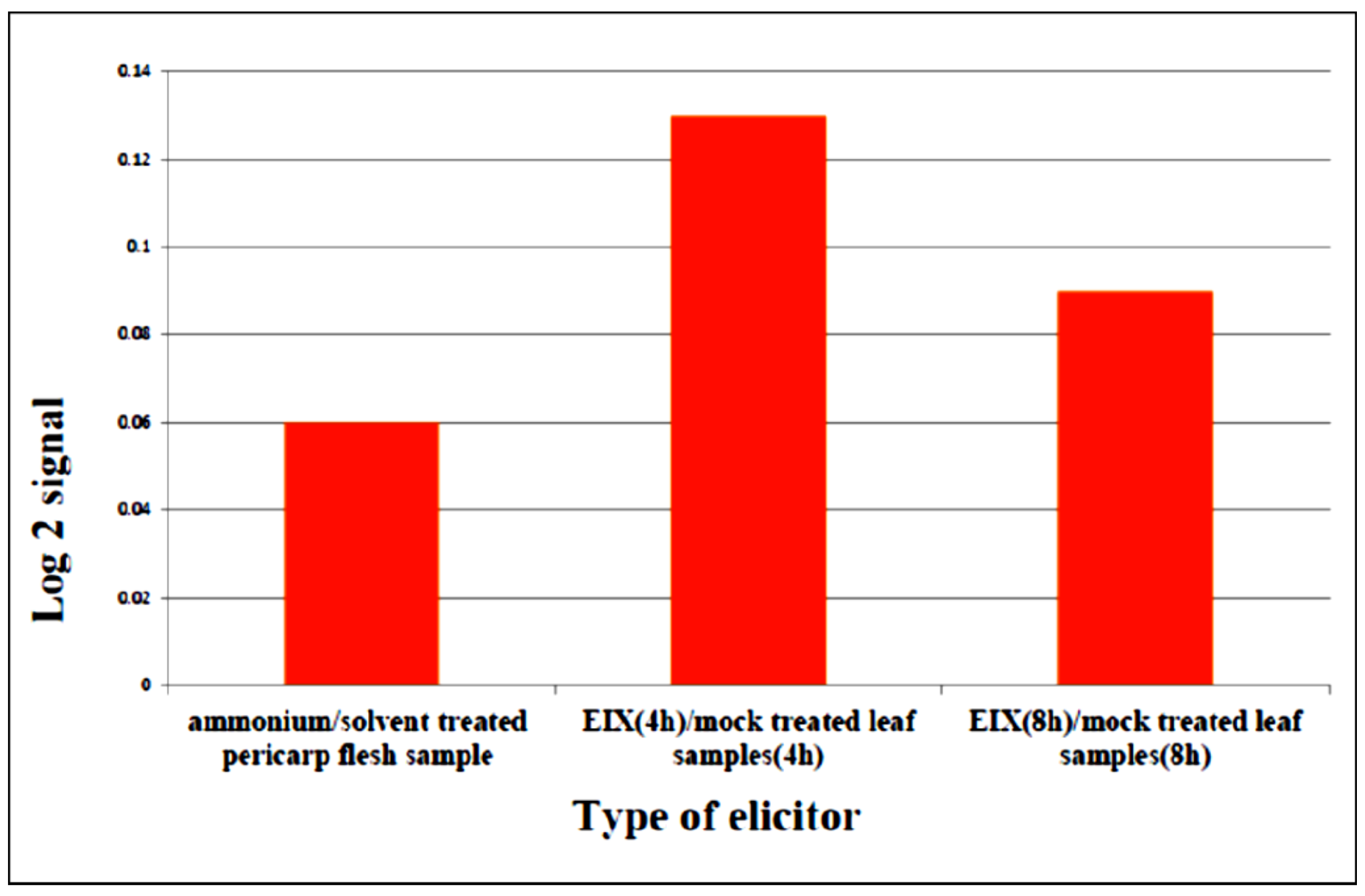

Figure 8: Effect of elicitor EIX on PDF1.2 expression level in Solanum lycopersicum leaves. 